Fanny

Yolanda

Paladines
Alejandro

Álvarez

Nobell
Jenny

Jovita

Yaguache

Comunicación estratégica en las organizaciones

Prólogo: Ángeles Moreno, PhD, Universidad Rey Juan Carlos, España - UEPRERA

Juan Carlos Molleda, PhD, Universidad de Florida, Estados Unidos - IPR

Epílogo: Jenny Yaguache, PhD, Universidad Técnica Particular de Loja, Ecuador

Cuadernos Artesanos de Comunicación / 94

ULL

Universidad de La Laguna

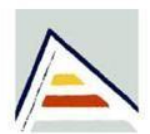

Universitat d'Alacant

Universidad de Alicante
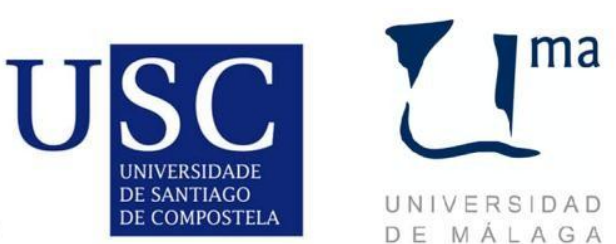

UNIVERSIDAD

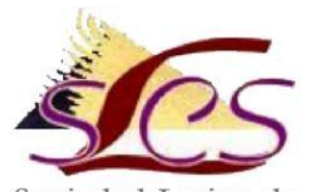

Sociedad Latina de 


\section{Cuadernos Artesanos de Comunicación}

Coordinador editorial: José Manuel de Pablos

Comité Científico

Presidencia: José Luis Piñuel Raigada (UCM)

Secretaría: Concha Mateos (URJC)

- Francisco Campos Freire (Universidad de Santiago de Compostela, USC)

- José Cisneros (Benemérita Universidad Autónoma de Puebla, BUAP)

- Bernardo Díaz Nosty (Universidad de Málaga, UMA)

- Carlos Elías (Universidad Carlos III de Madrid, UC3M)

- Paulina B. Emanuelli (Universidad Nacional de Córdoba, UNC)

- José Luis González Esteban (Universitas Miguel Hernández de Elche, UMH)

- Marisa Humanes (Universidad Rey Juan Carlos, URJC)

- Juan José Igartua (Universidad de Salamanca, USAL)

- Xosé López (Universidad de Santiago de Compostela, USC)

- Maricela López-Ornelas (Universidad Autónoma de Baja California, AUBC)

- Javier Marzal (Universidad Jaume I, UJI)

- José Antonio Meyer (Benemérita Universidad Autónoma de Puebla, BUAP)

- Ramón Reig (Universidad de Sevilla, US)

- Miquel Rodrigo Alsina (Universidad Pompeu Fabra, UPF)

- Xosé Soengas (Universidad de Santiago de Compostela, USC)

- José Luis Terrón (Universidad Autónoma de Barcelona, UAB)

- José Miguel Túñez (Universidad de Santiago, USC)

- Victoria Tur (Universidad de Alicante, UA)

- Miguel Vicente (Universidad de Valladolid, UVA)

- Ramón Zallo (Universidad del País Vasco, UPV-EHU)

- Núria Almiron (Universidad Pompeu Fabra, UPF)

* Queda expresamente autorizada la reproducción total o parcial de los textos publicados en este libro, en cualquier formato o soporte imaginables, salvo por explícita voluntad en contra del autor o autora o en caso de ediciones con ánimo de lucro. Las publicaciones donde se incluyan textos de esta publicación serán ediciones no comerciales y han de estar igualmente acogidas a Creative Commons. Harán constar esta licencia y el carácter no venal de la publicación.

\section{(1) (ब)} incluidas, si no se indica lo contrario, se encuentran bajo una Licencia Creative Commons Atribución-No Comercial-Sin Derivadas 3.0 Unported. Puede ver una copia de esta licencia en http://creativecommons.org/licenses/by-nc-nd/3.0/ Esto significa que Ud. es libre de reproducir y distribuir esta obra, siempre que cite la autoría, que no se use con fines comerciales o lucrativos y que no haga ninguna obra derivada. Si quiere hacer alguna de las cosas que aparecen como no permitidas, contacte con los coordinadores del libro o con el autor del capítulo correspondiente.

* La responsabilidad de cada texto es de su autor o autora. 


\section{Fanny Yolanda \\ Paladines \\ Alejandro Álvarez \\ Jenny Jovita \\ Nobell \\ Yaguache \\ Comunicación estratégica en las organizaciones}

Cuadernos Artesanos de Comunicación/ 94

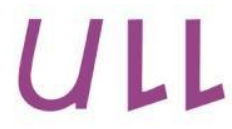

Universidad de La Laguna

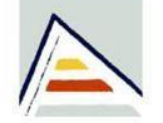

Universitat d'Alacant Universidad de Alicante

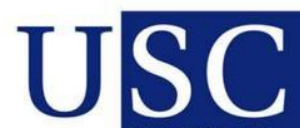

UNIVERSIDADE DE SANTIAGO DE COMPOSTELA

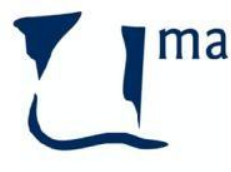

UNIVERSIDAD $D E M A ́ L A G$

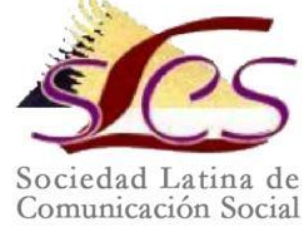


$94^{\circ}$ - Comunicación Estratégica en las organizaciones, Fanny Paladines Galarza, Alejandro Álvarez Nobell y Jenny Yaguache Quichimbo | Precio social: 6,65€-Precio librería: 8,65€.

Editores: Javier Herrero y Alberto Ardèvol Abreu Diseño: F. Drago

Ilustración de portada: Fragmento del cuadro Árboles y viento, de Juan Davó (sin fecha).

Imprime y distribuye: F. Drago. Andocopias S.L. c/ La Hornera, 41. La Laguna. Tenerife. Teléfono: 922250554| fotocopiasdrago@telefonica.net

Edita: Sociedad Latina de Comunicación Social - edición no venal - La Laguna (Tenerife), 2015 - Creative Commons (http://www.revistalatinacs.org/09/Sociedad/estatutos.html)

Catálogo: http://www.cuadernosartesanos.org

Protocolo de envío de manuscritos con destino a CAC: http://www.cuadernosartesanos.org/protocolo.html

Descargar $p d f:$ http://www.cuadernosartesanos.org/94

ISBN-13:978-84-16458-25-7

DL: TF -875-2015

DOI: $10.4185 / \mathrm{CAC} 94$ 
Este libro está dedicado a todos los estudiantes de la Titulación de Relaciones Públicas de la Universidad Técnica Particular de Loja por su dedicación y entrega. Jóvenes llenos de pasión e ilusiones, motor fundamental para el cumplimiento de metas personales y profesionales. Estamos seguros que llegarán muy lejos...

Con cariño, sus amigos de siempre:

Fanny Paladines / Alejandro Álvarez Nobell / Jenny Yaguache 


\title{
Comunicación estratégica en las organizaciones
}

\author{
Fanny Paladines, Alejandro Álvarez Nobell y Jenny Yaguache
}

\begin{abstract}
La comunicación en las organizaciones se vuelve estratégica cuando se integra en los procesos de dirección y se convierte en una herramienta esencial de competitividad empresarial. La Universidad Técnica Particular de Loja crea el primer espacio virtual, el "Observatorio de la Comunicación Estratégica en Ecuador" para estudiar el comportamiento de las organizaciones respecto a la comunicación estratégica en el país.
\end{abstract}

En toda organización se genera información dispersa y variada que necesita ser coordinada y requiere de un profesional, el Dircom o Director de Comunicación, cuyo perfil es de estratega y tiene la tarea de identificar los instrumentos adecuados y transferir el conocimiento. Además, existe la figura del gestor de la comunicación que trabaja con esos instrumentos para diseñar un sistema comunicacional efectivo para la organización.

En su primera fase se recolectó información a través de una encuesta aplicada a 107 gestores a nivel nacional; una entrevista estructurada a 15 Directores de Comunicación de las empresas con mayor aporte tributario en el país y, con el apoyo de la técnica Delphi, a 13 académicos de otros países que permitió el contraste con la realidad de Ecuador. Datos referentes a la posición del Dircom en el organigrama de las empresas públicas y privadas; las áreas de trabajo que se ejecutan en los departamentos de comunicación y la medición y evaluación de la comunicación, así como el estado de la publicidad frente a la Ley Orgánica de Comunicación en el Ecuador.

Como resultado general se obtuvo que las organizaciones seguirán invirtiendo en publicidad y haciendo uso de las agencias. La comunicación digital ya no solo se constituye en un soporte a las estrategias tradicionales sino que además ocupa un espacio importante dentro del área de la comunicación. La LOC ofrece grandes posibilidades a las agencias de publicidad, anunciantes, 
medios de comunicación y productoras; sin embargo, aún está en proceso de adaptación.

Por lo tanto, el presente Cuaderno es la recopilación de todos estos resultados con el objeto de convertirse en un referente nacional e internacional en temas de comunicación estratégica.

\section{Palabras clave}

Ecuador; Dircom; Comunicación estratégica; Comunicación digital.

\section{Forma de citar este libro}

Autor/ra del capítulo (2015): “Título del capítulo" en Comunicación estratégica en las organizaciones (Fanny Paladines Galarza, Alejandro Álvarez Nobell, Jenny Yaguache Quichimbo, Eds). Cuadernos Artesanos de Comunicación, 94, La Laguna (Tenerife): Latina 


\section{Índice}

Palabras de bienvenida, por Fanny Paladines G.

Prólogo, por Ángeles Moreno y Juan Carlos Molleda

Introducción

Antecedentes

Planificación estratégica en comunicación y su evaluación, por

Alejandro Álvarez Nobell

Desarrollo de la investigación.

CAPÍTULO I:

La gestión de la comunicación estratégica en las organizaciones:

enfoque nacional e internacional.

Fanny Paladines, Jenny Yaguache, Carlos Granda y Verónica

Altamirano.

CAPÍTULO II:

El futuro de la gestión del Dircom: habilidades y retos.

Cesibel Valdivieso, Karina Valarezo y Johana Córdova

CAPÍTULO III:

El futuro de la comunicación digital como soporte

a la gestión estratégica de las organizaciones.

Rosario Puertas, Elizabeth Cadme y Alejandro Álvarez Nobell,

Epílogo, por Jenny Yaguache Q.

Autores........................................................ 123 


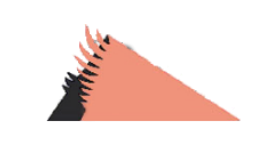

\section{Palabras de bienvenida}

I A comunicación es el eje fundamental para la relación entre las Lersonas y ha evolucionado hasta llegar a ser
agiliza el proceso de intercambio de información.

Organización y comunicación son conceptos interdisciplinarios encaminados al éxito de procesos de gestión y actividades que se realizan. Nace de la necesidad de coordinar de manera integral los recursos de que dispone la organización. Independientemente de su sector, cada vez más las empresas añaden a sus propósitos la importancia de la gestión de la comunicación y saben que para lograrlo se debe invertir en la relación con los públicos internos y externos, pues por experiencias anteriores conocen que si se opta por una comunicación rudimentaria, la organización dejará de trascender.

En consecuencia, la responsabilidad de investigación, planificación gestión y evaluación de la comunicación recae en un equipo, ya sea de dos o más personas dirigido por un líder que unas veces se llamará Director de Comunicación y en otras Dircom.

Pero, ¿cuáles son las líneas que debe seguir para una comunicación efectiva?

Sobre este interrogante, la Universidad Técnica Particular de Loja, desde el año 2010, comienza a realizar investigaciones vinculadas a la comunicación. El presente cuaderno es la recopilación de la 
información obtenida de los Dircom, gestores de la comunicación y académicos nacionales e internacionales. Busca ser un referente informativo, empresarial y académico sobre la realidad de la comunicación estratégica en el Ecuador frente a la de otros países.

La buena gestión así como la medición en base a resultados son indispensables para el cumplimiento de los objetivos comunicacionales propuestos a fin de determinar la efectividad de la comunicación estratégica.

El desafío está presente para Ecuador y otros países Latinoamericanos que comienzan a adentrarse en el mundo de la comunicación estratégica y organizacional, ya que se constituye en la llave de la puerta al mercado global.

Fanny Paladines, Ph. D.

Departamento de Ciencias de la Comunicación Sección Departamental Comunicación Organizacional Coordinadora de la Titulación de Relaciones Públicas Universidad Técnica Particular de Loja Loja-Ecuador 


\section{$\Delta$}

\section{Prólogo}

CN la llegada del nuevo siglo y las poderosas transformaciones que trajo consigo, acompañadas por un auge de la gestión de la comunicación en todos los sectores sociales, en los ámbitos profesional y académico se incrementó el interés por institucionalizar unos principios genéricos de la profesión a nivel internacional. Los investigadores de relaciones públicas internacionales se ocuparon de estos principios genéricos y de las aplicaciones específicas y concreciones en las idiosincrasias nacionales. Así, un conjunto de investigaciones desde la perspectiva contextual comenzaron a describir la evolución y las prácticas de la profesión de gestión de comunicación y relaciones públicas a lo largo de diversas áreas geográficas en el mundo.

Al mismo tiempo, diversas asociaciones internacionales de Relaciones Públicas como la International Public Relations Association (IPRA), la Global Alliance for Public Relations and Communication Management, the European Public Relations Education and Research Association (EUPRERA) o el Institute of Public Relations, hicieron nuevos esfuerzos para promover la investigación internacional y los estudios internacionales comparativos que pudieran descubrir los principios genéricos de relaciones públicas a lo largo de las diversas naciones y regiones en el mundo. En Europa, por ejemplo, se desarrolló en 2002 el Ebook Project que estudiaba la evolución de las relaciones públicas en diversos países del viejo continente a través de una metodología cualitativa.

En esta misma línea se han venido desarrollando diversas investigaciones en la región latinoamericana, algunas de ellas premiadas internacionalmente (Ej. Molleda \& Moreno, 2008), que venían a aportar una nueva aproximación empírica a las aportaciones teóricas que habían sido referencia en el continente. 
La mayoría de estos estudios han proporcionado aproximaciones a la profesión a través de metodologías cualitativas, pero ya en la primera década del nuevo siglo, se ponía de manifiesto la importancia de llevar a cabo estudios macro con métodos cuantitativos que pudiesen proporcionar datos extensivos de grandes países, continentes y subcontinentes y estuviesen en condiciones de ofrecer un marco de análisis comparativo.

En 2005 el Generally Accepted Practices fue la primera encuesta macro que proporcionó gran cantidad de datos sobre la profesión en un país con amplia población de profesionales de relaciones públicas, Estados Unidos (Mitroff, Swerling \& Floto, 2002). Por su parte, el European Communication Monitor fue pionero en 2007 proporcionando datos comparativos entre países (Zerfass et al., 2007). Con nueve ediciones y participación de más de 1700 profesionales de 32 países este proyecto anual se ha consolidado como el mayor estudio sobre la profesión de gestión de comunicación en el mundo, permitiendo un análisis longitudinal de los principales temas principales durante casi una década. En 2014 y 2015 además dos nuevos estudios promovidos por la European Research and Education Association (EUPRERA), y apoyados por instituciones académicas y profesionales en cada región, se han lanzado en Latinoamérica (Latin American Communication Monitor) y en Asia y Pacífico (Asian Pacific Communication Monitor).

Estos avances son una perfecta muestra de la institucionalización que está logrando la investigación en relaciones públicas con la colaboración conjunta de instituciones académicas y asociaciones profesionales. Además suponen la consecución de un viejo reto: la creciente transferencia de conocimiento entre el mundo académico y profesional. Representan un claro avance en el conocimiento sobre la profesión y la práctica de gestión de comunicación y relaciones públicas en diversas regiones del mundo. La metodología basada en macro-encuestas dirigidas a profesionales a través de continentes y subcontinentes permite una colección de datos muy significativa que jamás hasta ahora había estado a disponibilidad de los propios profesionales del sector.

Podemos afirmar, por tanto, que la investigación académica de relaciones públicas a nivel global atraviesan un excelente momento. No sólo porque hay un mayor número de profesores e investigadores 
con una alta formación y producción de calidad en la materia, sino porque además tienen cada vez una mayor proyección internacional y profesional.

El Latin American Communication Monitor (LCM), con una participación de 1.774 profesionales y un análisis final de 803 casos de profesionales de comunicación y relaciones públicas de 18 países ha puesto de manifiesto asimismo una situación avanzada de la profesión en Latinoamérica, pero no exenta de retos. Conectar las estrategias de la organización y de la comunicación sigue siendo un objetivo aún no alcanzado. Los profesionales se enfrentan con nuevas demandas generadas e intensificadas por la era digital y el uso masivo de las nuevas tecnologías. Estas nuevas realidades conllevan importantes efectos para los profesionales de comunicación estratégica como sobrecarga de trabajo, novedosos modelos de relación entre profesionales y una revisión del rol que juegan las comunicadoras en sus organizaciones. El nuevo escenario nos enfrenta asimismo con nuevos equilibrios en el uso de los medios online frente a los medios tradicionales y muy particularmente en la búsqueda por entender y satisfacer las demandas de los stakeholders en los social media. La profesionalización de las relaciones públicas y la gestión de la comunicación en Latinoamérica siguen presentando graves barreras para los jóvenes profesionales, pero existen departamentos de comunicación excelentes, que poseen características singulares en su posicionamiento dentro de las organizaciones y en su desempeño, que pueden servir de agenda en este entorno de cambios.

La situación de cambios y como muchas veces nos han dicho los profesionales latinoamericanos de países en conflicto "el estado de crisis permanente" hacen necesario continuar investigando más profundamente las direcciones que toma la profesión en cada país. Sólo con un conocimiento actualizado, estratégico y ético de las personas que hacen gestión de comunicación, la comunicación seguirá sumando accesos a las mesas de dirección de las organizaciones y poniéndose en valor.

Por eso, solo podemos acoger la iniciativa de los investigadores de la Universidad Técnica de Loja con el "Observatorio de la Comunicación Estratégica" como una respuesta a las necesidades reales del sector, en consonancia con la investigación internacional. 
Compartimos con entusiasmo el deseo de profundizar en el crecimiento exponencial que la gestión de comunicación está teniendo en Ecuador en los últimos años y agrademos a los autores que pongan a disposición de toda la comunidad académica y profesional los resultados de investigación de la primera edición del observatorio a través de este volumen.

\author{
Ángeles Moreno, PhD \\ Directora Latin American Communication Monitor \\ Directora Ejecutiva European Public Relations \\ and Research Association (EUPRERA) \\ Profesora Titular - Universidad Rey Juan Carlos, España \\ Juan Carlos Molleda, PhD \\ Co-Director Latin American Communication Monitor \\ Director de Departamento de Relaciones Públicas \\ Universidad de Florida, \\ Estados Unidos \\ Fundador de la Commission on Global Public \\ Relations Research del Institute \\ for Public Relations (IPR)
}

\title{
Referencias bibliográficas
}

Molleda, J. C., \& Moreno, Á. (2008). Balancing public relations with socioeconomic and political environments in transition: Comparative, contextualized research in Colombia, Mexico, and Venezuela. Journalism \& Communication Monographs, 10(2), 115-174.

Mitroff, I. I., Swerling, J., \& Floto, J. (2000). Public relations generally accepted practices (GAP) study. USC Annenberg Strategic Public Relations Center. 


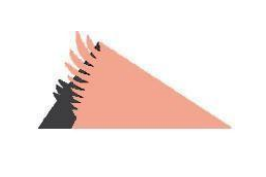

Introducción

\title{
Un escenario en transformación: la comunicación estratégica de las organizaciones
}

\begin{abstract}
T A Universidad Técnica Particular de Loja con la Universidad Nacional de Córdoba, Argentina, a través de su sección de Comunicación Organizacional, han desarrollado, desde el año 2010, un conjunto de investigaciones vinculadas al campo de la comunicación organizacional y estratégica.

Uno de los proyectos más emblemáticos e importantes es la creación en el 2104, del primer "Observatorio de la Comunicación Estratégica en Ecuador" que tiene como finalidad conocer el estado y las tendencias de la comunicación estratégica en campos como la comunicación interna, corporativa, organizacional, institucional, digital, comercial, así como la responsabilidad social corporativa.

La comunicación estratégica es el arte organizar y planificar, utilizando una estructura integral de los canales dentro y fuera de la organización de manera que se comporten en un entorno que favorezca el logro de objetivos planteados tanto por la empresa como por los mismos empleados y generando un sentido de pertenencia que desemboca en una favorable percepción de la imagen de la organización.
\end{abstract}


Actualmente las organizaciones, independientemente de su tamaño, requieren de expertos de la comunicación dentro de su estructura organizacional que les permitan gestionar valores intangibles. En la denominada sociedad del conocimiento, los responsables de comunicación deben ser estrategas y creativos en identificar instrumentos adecuados para transferir el conocimiento. En este contexto surge la figura del Dircom. Villafañe (1999) define al Dircom "como el corporate que es el responsable de la comunicación o la imagen de una organización”.

Es imposible prescindir de un departamento de comunicación; su labor es estratégica a nivel interno y externo; debe involucrarse en todos los niveles institucionales y ser direccionada a cada departamento. La comunicación se constituye en el corazón de la organización.

Por otro lado, hay un notable e insólito crecimiento de los medios alternativos o no tradicionales a través de Internet que ha evolucionado desde simples anuncios en la Web hasta incluir blogs, sitios interactivos y populares como las redes sociales digitales entre las que destacan Facebook, Twitter, YouTube, Google+, Pinterest, entre otros. Así mismo, los dispositivos móviles con acceso a Internet en cualquier espacio y momento han ampliado el panorama de la comunicación y evolucionado a tal grado que es cada vez más sencillo hacer llegar un mensaje gracias a la inmediatez y rapidez de los mismos. Además, los usuarios se convierten en, no solo receptores de la información, si no en productores de contenidos y mensajes transmitidos por la organización. De todo este abanico de oportunidades se sirve el director o gestor de la comunicación para establecer estrategias comunicacionales óptimas que vayan a la par con los hábitos del consumo de medios de las audiencias.

En este contexto, las empresas están al momento reduciendo su inversión en medios tradicionales para dar paso a los alternativos o no tradicionales. "El reto actual es encontrar la forma de llegar a los públicos concretos y potenciales interesados en el quehacer de la empresa; por lo tanto, la comunicación de marketing ya no se centra 
en solo llamar la atención sino en encontrar formas para atraer e interactuar con los consumidores consiguiendo fidelidad a su marca y una correcta reputación" (Clow Baack, 2010: 4-5).

Pero el reto, no solo para los directores o gestores, sino también para agencias de comunicación, es que "el involucrar a los medios digitales requiere adoptar nuevos pensamientos, equipos de trabajo, alianzas e incluso aceptar un nuevo modelo económico por parte de las agencias" (Paladines, 2012: 260-261).

Dentro del "Observatorio de la Comunicación Estratégica en Ecuador: estado actual, tendencias, medición y evaluación" ejecutado por el equipo de docentes investigadores de la Sección de Comunicación Organizacional del Departamento de Ciencias de la Comunicación de la Universidad Técnica Particular de Loja-Ecuador (UTPL) y por docentes de la Universidad Nacional de Córdoba- la finalidad del proyecto consistió en recolectar información sobre la función y el futuro del Dircom en el Ecuador y su relación al contexto internacional. Por otro lado, se debe mencionar que esta investigación es la primera que se realiza a nivel nacional, siendo un gran aporte tanto para los comunicadores como para la sociedad en general.

Queda mucho camino por recorrer: los investigadores somos ahora quienes debemos responder a las nuevas tendencias de la comunicación estratégica dentro de las organizaciones ante la creciente demanda de la investigación en un país donde se publicaba muy poco. 



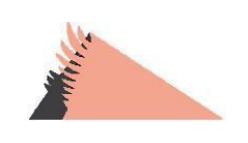

\section{Antecedentes}

T A comunicación es la vía por la cual los seres humanos nos 1 podemos comunicar. Este proceso ha ido evolucionando y hoy se habla de una comunicación 2.0 que se entiende como la Web 2.0.

La comunicación en el ámbito laboral cumple un rol fundamental dentro de las organizaciones, independientemente del sector al que pertenecen. Uno de sus objetivos es vender bienes o servicios, lo que determina su sobrevivencia en el mercado, pero todo debe ir en armonía con la gestión de intangibles. Por lo tanto, se hace indispensable para la empresa establecer canales de comunicación que permitan fortalecer vínculos entre los públicos. Como las organizaciones poseen sus propias particularidades según su naturaleza, estructura, tamaño, objetivos empresariales y sociales, los resultados de su actividad van a depender en mayor o menor medida, de cómo aborden sus prácticas comunicativas.

En este contexto surge la comunicación organizacional y según los postulados del profesor Sotelo, "se le han dado algunas denominaciones: comunicación organizacional, institucional, corporativa y relaciones públicas" (Carlos Sotelo, 2004).

En las últimas décadas múltiples han sido los estudios que a nivel mundial están analizando y determinando el desarrollo de la profesión en Comunicación Estratégica y en Relaciones Públicas. Entre ellos se destacan el European Communication Monitor (ECM) ${ }^{1}$, un conjunto de informes que desde 2007 elaboran anualmente la European Public

${ }^{1}$ [Disponible en http://www.communicationmonitor.eu] Consultada el 10 de octubre de 2010. 
Relations Education and Research Association (EUPRERA) y la European Association of Communication Directors $(\mathrm{E} A C D)^{3}$. Este estudio, el más representativo del sector en Europa ${ }^{4}$, identifica las principales características de los profesionales europeos de relaciones públicas y las organizaciones en las que trabajan, conectando las situaciones contextuales con las disciplinas, los instrumentos de comunicación y los temas estratégicos, así como la influencia de los mismos en las decisiones corporativas y sus roles ejecutivos.

Otro antecedente de relevancia e importancia en la temática es el reciente informe titulado "PR 2020: The Future of Public Relations. Scenario Planning with members of the Chartered Institute of Public Relations" (White, 2011) realizado en el Reino Unido para la Chartered Institute of Public Relations (CIPR) ${ }^{5}$. Los resultados surgen de distintos grupos de discusión celebrados en las distintas filiales de la CIPR quienes, a través de la "planificación de escenarios", determinaron las posibles "prácticas en relaciones públicas en el Reino Unido para el año 2020".

En 2012 se presentaron los resultados del VII Communication and Public Relations Generall y Accepted Practices (GAP) Studies ${ }^{6}$, con datos correspondientes al último trimestre de 2011 sobre las opiniones de 620 profesionales de comunicación y relaciones públicas de varios países del mundo, pero principalmente Estados Unidos. La investigación, desarrollada por el Strategic Communication and Public Relations Center de la Escuela de Comunicación y Periodismo de la USC Annenberg, contó también con el apoyo del IPR (Institute for Public

${ }^{2}$ [Disponible en http://www.euprera.org] Consultada el 10 de octubre de 2010.

${ }^{3}$ [Disponible en http://www.eacd-online.eu] Consultada el 10 de octubre de 2010.

${ }^{4}$ Bajo la autoría de Ángeles Moreno, Prof. Dra., Universidad Rey Juan Carlos (ES); Ansgar Zerfass, Prof. Dr., University of Leipzig (GE) - Lead Researcher; Ralph Tench, Prof. Ph.D., Leeds Metropolitan University (UK); Piet Verhoeven, Ass. Prof. Dr., University of Amsterdam (NL); Dejan Vercic, Prof. Ph. D., University of Ljubljana (SI).

${ }^{5}$ [Disponible en http://www.cipr.co.uk] Consultado el 12 de febrero de 2013.

${ }^{6}$ [Disponible en http://ascjweb.org/gapstudy] Consultado el 20 de marzo de 2013. 
Relations); la LABC (International Association of Business Communicators); The Artbur Page Society y la PRSA (Public Relations Society of America).

Ante estas iniciativas y la falta de investigaciones en este campo, se vio la necesidad de crear el "Observatorio de la Comunicación Estratégica en Ecuador" que se convierte en el primer proyecto formal realizado desde la Academia en el país y bajo el criterio de expertos y académicos internacionales, pretende ser el repositorio donde profesionales, directores, estudiantes y docentes de la comunicación estratégica encuentren resultados que permitan fortalecer sus campos de interés. Además, es financiado por la misma institución con una subvención de $\$ 20.000$ para su ejecución.

Fruto de las investigaciones iniciales, así como de los resultados de la primera fase del proyecto "Observatorio de la Comunicación Estratégica en Ecuador" se han realizado algunas publicaciones que se presentan a continuación, y se espera que el equipo de investigación trabaje a futuro en nuevos proyectos y artículos en función de los resultados que se vayan obteniendo:

$\checkmark$ La marca ecuatoriana y su gestión en redes sociales.

$\checkmark$ La comunicación integral, un factor determinante en la gestión de la empresa ecuatoriana.

$\checkmark$ La marca online como parte de la comunicación integral. Manejo de marcas ecuatorianas en las redes sociales.

$\checkmark$ Anuario de las empresas de comunicación en Ecuador

$\checkmark$ Credibilidad de la prensa: misión y responsabilidad social corporativa socioeconómico - mediático.

$\checkmark$ Las universidades tienen un arduo trabajo de gestión de la comunicación para lograr posicionamiento y prestigio. Algunas claves para desarrollarla.

$\checkmark$ Uso de otras formas de comunicación. Consumo de medios en los estudiantes universitarios. Análisis de Internet y teléfono móvil - Caso UTPL

$\checkmark$ Diagnóstico del estado de las Relaciones Públicas en Ecuador desde el 2000 al 2010.

Dentro de nuestro proyecto "Observatorio" hay una amplia referencia de congresos, eventos, cursos y foros sobre la gestión de la comunicación, cuya página es: http://observatoriocom.utpl.edu.ec 
La comunicación se vuelve estratégica cuando forma parte de los procesos de dirección y se transforma en un vector de competitividad que aporta un valor fundamental a la organización, siempre que se midan y evalúen dichos resultados.

"La función de la comunicación debe aplicar, accionar y evaluar las relaciones con los públicos de forma vinculada a la misión y los objetivos de la organización, observando e interactuando, en todo momento, con los distintos entornos existentes: económico, político, cultural, social y medioambiental" (Álvarez Nobel, 2011) ${ }^{7}$.

Poco a poco las grandes empresas del Ecuador incorporan en su planificación estratégica a la comunicación como una estructura integrada, sobre todo en las ciudades capitales. En las ciudades medianas y pequeñas, aún se observa un manejo empírico de la comunicación que llega a ser hasta cierto punto confuso y disfuncional ya que se opera en forma aislada y sin una clara identificación de roles.

Este monográfico constituirá un referente académico y profesional sobre la comunicación estratégica en el país.

\section{Metodología}

El proyecto "Observatorio de la Comunicación Estratégica en el Ecuador", en su etapa inicial, partió de un universo de 1000 empresas con mayor aporte tributario en el 2013, según información de la Superintendencia de Compañías y el Servicio de Rentas Internas.

A esta base se sumaron 100 registros de instituciones públicas y organizaciones no gubernamentales que actúan en el país. De este universo, se trabajó sobre una muestra de 350 organizaciones a nivel nacional y de este total, a través de llamadas telefónicas, se identificó a 214 instituciones que cuentan con un departamento de comunicación.

\footnotetext{
Álvarez Nobell, A. (2011). Medición y Evaluación en Comunicación. Málaga, España: Instituto de Investigación en Relaciones Públicas (IIRP).
} 
Con la aplicación de la encuesta online se conoció el estado actual de la gestión comunicacional de 107 empresas que revela las áreas que conforman los departamentos de comunicación; líneas de acción que ejecutan; cumplimiento de objetivos; agencias con las que trabajan y medición de resultados, entre otros temas.

La técnica de entrevista estructurada se aplicó a quince Directores de Comunicación que lideran los departamentos o unidades de comunicación de diferentes instituciones públicas y privadas, a fin de conocer: la proyección a tres años de las funciones y retos del Dircom en Ecuador; la revolución tecnológica; la necesidad de contar con agencias de relaciones públicas, publicidad y marketing; sistemas de medición y los beneficios o limitaciones que la Ley Orgánica de Comunicación respecto a la gestión estratégica, entre otros temas.

La técnica de previsión Delphi tuvo como objetivo el resultado de un consenso basado en la discusión entre académicos internacionales y nacionales expertos en comunicación estratégica. Se diseñó en dos tiempos con bancos de preguntas que fueron contestados por los participantes. Es importante señalar que esta técnica se aplicó una vez obtenidos los resultados de las encuestas y entrevistas ya que se buscaba profundizar en ciertos temas que no fueron claramente especificados a través de las dos técnicas señaladas. Entre los principales aspectos que entraron en discusión en la primera fase fueron: las habilidades, conocimientos y posición que tiene el Dircom en el organigrama de las empresas; áreas de trabajo; líneas de actuación; uso de herramientas; métodos de medición y evaluación; el aprovechamiento de la Web 2.0. Del primer interrogante -habilidades y conocimiento del Dircom- se desprendió información para la segunda discusión: rol del director en la toma decisiones; procesos y herramientas para el manejo de medios digitales y crisis; incorporación de responsabilidad social. Del segundo interrogante -líneas de actuación- se indagó sobre las técnicas de comunicación que permitieron que estas líneas sean efectivas. También se buscó profundizar en la descripción de los métodos de medición y evaluación y sobre componentes de comunicación integral.

En la primera fase, de 24 expertos consultados respondieron 13; y en la segunda, de 22 dieron respuesta 7 . Todos corresponden a diferentes países como: España, México, EEUU, Brasil, Colombia, Chile y 
Ecuador, y universidades como: Universidad de Sao Paolo, Universidad de Málaga, Universidad Loyola Andalucía, Universidad Rovira i Virgili, Universidad Pompeu Fabra, Universidad Ramón Llull, Universidad Alicante, Universidad Rey Juan Carlos, Universidad Santiago de Compostela, Universidad San Luis de Potosí, Universidad Florida, Universidad Luterana do Brasil, Universidad de Medellín, Universidad de Sao Paolo, Universidad del Pacífico, Pontificia Universidad Católica de Ecuador - Sede Ibarra.

Como resultado del proyecto "Observatorio de la Comunicación Estratégica en Ecuador: estado actual, tendencias, medición y evaluación", se evidenciaron algunos hallazgos importantes surgidos al momento de interpretar los datos, mencionados a continuación:

$\checkmark$ Las principales áreas que integran el departamento de comunicación.

$\checkmark$ Las líneas de acción que consolidan la labor del Dircom al momento de tomar y ejecutar decisiones en la organización.

$\checkmark$ La buena gestión de los responsables de la comunicación que se mide en base a los resultados. Es así que se hace indispensable comprobar el cumplimiento de los objetivos comunicacionales a fin de determinar la efectividad de la comunicación estratégica.

$\checkmark$ El rol de las agencias de publicidad como indispensable ya que se constituyen en aliadas estratégicas del Dircom. A partir de los objetivos institucionales se canalizan las estrategias y contactos a través de la experiencia de equipos especializados en las áreas competentes de la comunicación.

$\checkmark$ El crecimiento de los sitios Web, la Web 2.0 y la transición hacia la Web 3.0.

$\checkmark$ El aporte progresivo de la LOC en la gestión de la comunicación del Ecuador.

Y sobre todo, de estos primeros resultados surgieron las principales tendencias o líneas de investigación que el equipo debía seguir investigando. 


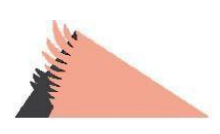

\title{
Planificación estratégica en comunicación y su evaluación
}

\author{
Alejandro Álvarez Nobell, Ph.D, Universidad Nacional de Córdoba \\ (Argentina) - Consejo Nacional de Investigaciones Científicas y Técnicas \\ (CONICET)
}

\section{La comunicación en las organizaciones}

T A función de evaluación en la planificación estratégica supone dos variables claves independientes pero absolutamente relacionadas: organización y comunicación. Por caso, se hablará de un tipo específico de organización, la que, como sistema, orienta su misión (el management) al cumplimiento de objetivos. La gestión de la comunicación forma parte de esas actividades, las cuales se dirigen y gestionan en el marco de procesos de planificación estratégica.

Si bien la denominación de organización (o corporate, en inglés) responde a un tipo de sociedad mercantil, a lo largo de décadas, tanto en Europa, Estados Unidos como Latinoamérica, el encuadre teórico de la comunicación empresarial, dentro de la comunicación institucional u organizacional, es producto de la influencia, origen y evolución transitada en cada una de estas latitudes (Cardoso Castro, 2012).

De todos modos, existe una similitud de identificación entre lo corporativo -entendido de forma funcional, como un todo, un corpus social- y lo empresarial, frente a la institución, con paralelo contenido latino y anglosajón y referido, principalmente, a las instituciones políticas. Pero desde la perspectiva latinoamericana, se 
señalará como organizaciones no sólo a las empresas de carácter lucrativo, sino también a las asociaciones civiles o profesionales, hospitales, grupos religiosos, partidos políticos y, en definitiva, a todo grupo que persigue un objetivo y que para lograrlo tiene que interactuar con otros grupos, personas u organizaciones (Araujo, 2009).

A continuación se zanjarán tales discusiones en el marco de un enfoque que pretende analizar los comportamientos organizativos sistémicos y sus correlatos en la planificación estratégica de la comunicación y que incluye entre sus fases la función de EVALUACIÓN.

\section{1. Las organizaciones como sistemas orientados a objetivos}

Para Araujo, la institución incluye el concepto de organización, de modo tal que define institución (citando a Scott, 1989) como:

Toda organización humana en la que varias personas, a partir de unos principios configuradores y bajo una estructura concreta, coordinan diversas actividades para alcanzar unos determinados fines en el ámbito de una entidad social superior a la que sirven (2009:2).

Pero sobre organización son múltiples las teorías y perspectivas disponibles. Lucas Marín la especifica como "agrupación de personas relacionadas con la realización de funciones básicas de la sociedad. Los fines que se propone la organización están determinados con precisión y definen el tipo de relación dominante entre las personas que la componen" (1997:37).

Para el autor, existen distintos tipos de acuerdo a la naturaleza de los objetivos que persigan. Uno de estos tipos de organización, emblemática de las sociedades modernas, son las empresas ${ }^{8}$, en las que los objetivos de quienes las integran son exclusivamente económicos.

"A partir de aquí se considerarán los términos "organización" y "empresa" indistintamente y en forma sinonímica. 
Desde la sociología fenomenológica, Berger y Luckmann (1994) buscan clarificar los fundamentos del conocimiento de la vida cotidiana indagando sobre la construcción social de la realidad. Superado un primer mecanismo de socialización -delimitados como miembros útiles que emplean el lenguaje, tienen valores, saben operar en la sociedad global, etc.-, los autores dirán (a la luz de Lucas Marín, 1997) que el hombre es capaz de producir una segunda socialización en las organizaciones mediante un proceso dialéctico IndividuoOrganización, que al tiempo que constituye al hombre, define a la propia organización.

Las funciones definidas por Berger y Luckmann (1994) que permiten la objetivación de la realidad son:

- Habituación. Capacidad que tiene el hombre de repetir acciones en el futuro de la misma manera y con idéntica economía de esfuerzos.

- Institucionalización. Supone un paso más en la permanencia de la conducta. De esta manera, aparecen las instituciones como realidad social edificada y construida con una cierta independencia de la relación interindividual que le dio origen.

- Legitimación. Consiste en lograr que las objetivaciones de "primer orden" (ya institucionalizadas) lleguen a ser objetivamente disponibles y subjetivamente plausibles, constituyendo una objetivación de significación de "segundo orden". Así, el sujeto puede utilizar las instituciones y transmitirlas a nuevas generaciones.

La aplicación de estos procesos al mundo de la organización es inmediata, siguiendo las mismas pautas establecidas para la sociedad en general donde el proceso de objetivación social es la construcción de la cultura y la socialización (habituación, institucionalización y legitimación); es la asimilación o interiorización de esa cultura.

Desde la perspectiva sistémica, Wiener (1979) planteó que la organización debía concebirse como "una interdependencia de las distintas partes organizadas, pero una interdependencia que tiene grados. Ciertas interdependencias internas deben ser más importantes que otras, lo cual equivale a decir que la interdependencia interna no es completa"” (citado por Buckley, 1970: 127). 
Por su parte, en la misma línea, Schein (1982: 210) viene a sostener que:

"La organización es un sistema abierto y complejo en interacción dinámica con múltiples medios, que trata de alcanzar y realizar metas a muchos niveles y en grados diversos de complejidad, evolucionando y desarrollándose a medida que la interacción con un medio cambiante determina nuevas adaptaciones internas".

Así, entender la organización como un sistema obliga necesariamente a remontar las fuentes de este concepto central, del cual tanto se habla y emplea en la actualidad. En un sentido amplio, se habla de la Teoría General de Sistemas (TGS) que se presenta como una forma sistemática y científica de aproximación y representación de la realidad y al mismo tiempo, como orientación hacia una práctica estimulante para formas de trabajo transdisciplinarias. La primera formulación en tal sentido es atribuible al biólogo Bertalanffy (1976), quien acuñó la denominación Teoría General de Sistemas.

"Sus objetivos originales fueron: a) impulsar el desarrollo de una terminología general que permita describir las características, funciones y comportamientos sistémicos; b) desarrollar un conjunto de leyes aplicables a todos estos comportamientos y c) promover una formalización (matemática) de estas leyes".

En tanto paradigma científico, la TGS se caracteriza por su perspectiva holística e integradora, en donde lo importante son las relaciones y los conjuntos que a partir de ellas emergen. Aunque, si bien el campo de aplicación de la TGS no reconoce limitaciones, al usarla en fenómenos humanos, sociales y culturales se advierte que sus raíces están en el área de los sistemas naturales (organismos) y en el de los sistemas artificiales (máquinas) (Arnold y Osorio, 1998). 
Sobre estas bases se constituyó en 1954 la Society for General Systems Research ${ }^{9}$. A poco de andar, la TGS despertó un gran interés y pronto se desarrollaron bajo su ala diversas tendencias (muchas de ellas fundantes en el campo de la comunicación) entre las que destacan la Teoría de la Información (Shannon y Weaver, 1949); la antropología ecológico-cultural (Rappaport, 1963); organizaciones y empresas (Katz y Kahn, 1966); la dinámica de sistemas (Forrester, 1969) y la cibernética (Wiener, 1979), entre otras especialidades antropológicas y sociológicas.

Siempre que se habla de sistemas se tiene en vista una totalidad cuyas propiedades no son atribuibles a la simple adición de las propiedades de sus partes o componentes (Arnold y Osorio, 1998). Como resultado de los comportamientos de dichas propiedades, un conjunto de elementos que constituyen un sistema siempre expone alguna característica o puede exhibir cierto comportamiento que ninguno de sus elementos o subgrupos tiene o puede mostrar. Además, la pertenencia al conjunto aumenta o disminuye las capacidades de cada elemento pero no deja de afectarlo. El sistema es algo más que la suma de sus partes; es un todo indivisible. Las propiedades esenciales de un sistema derivan de las interacciones de sus partes y no de sus acciones por separado, por eso un sistema desmembrado pierde sus propiedades esenciales. Por lo tanto, siendo el sistema un todo integrado por elementos que están en una relación recíproca, la disposición de sus respectivos elementos; los atributos particulares de cada uno; su modelo de ordenamiento y las relaciones entre ellos condicionan el tipo de sistema.

En las definiciones más corrientes se identifican los sistemas como conjuntos de elementos que guardan estrechas relaciones entre sí; que mantienen al sistema directo o indirectamente unido de modo más o menos estable y cuyo comportamiento global persigue, normalmente, algún tipo de objetivo (teleología). Así, si existe una alineación de los procesos del sistema hacia determinados objetivos, se habla entonces de sistemas orientados a objetivos. Con lo cual se puede definir las organizaciones como sistemas sociales tendientes a objetivos en donde las

[Disponible en http://isss.org/world/index.php] Consultado el 30 de julio de 2010. 
partes interrelacionadas son personas o grupos que funcionan como organización a partir de los principios sistémicos.

Estas conceptualizaciones que priorizan fuertemente procesos sistémicos internos (relación entre el todo - sistema- y sus partes -elementos-) deben necesariamente ser complementadas con una concepción de sistemas abiertos, en donde queda establecida como condición para la continuidad sistémica, el establecimiento de un flujo de relaciones con el ambiente (sistema/ambiente).

Habrá sistemas abiertos, diferenciando entre el sistema (lo que está adentro) y el contexto (lo que está afuera) siempre que exista interacción entre ellos. Los sistemas de entrada/salida o entrada/proceso/salida son capaces de generar algún resultado (salida u output) siempre que también estén alimentados adecuadamente (entrada o input). El sistema requerirá adaptarse a los cambios del contexto y corregir el proceso (aprendizaje y ajuste) por retroalimentación (feed-back) o prealimentación (feed-forward) si se ajusta antes de que se produzca un resultado indeseado. En este caso, lo central son las corrientes de entradas y de salidas mediante las cuales se establece una relación entre el sistema y su ambiente.

Son igualmente apropiadas y enriquecedoras las definiciones que el propio campo de la comunicación y las relaciones públicas han formulado sobre su entendimiento de las organizaciones.

Bernays (1947, 1990, 1995) -considerado como uno de los padres de las relaciones públicas (Arceo Vacas, 2004; Castillo Esparcia, 2009 y 2010; Ruiz Mora, 2011) por dotar de cierto rigor científico a la disciplina y en consecuencia, a la profesión-, señala que la función de relaciones públicas (del consultor) debería posibilitar a las organizaciones "definir los objetivos socialmente sanos de su cliente o de su proyecto (...); descubrir por medio de la investigación qué ajustes o desajustes hay entre su cliente y los públicos de los que depende" (Bernays 1995: 39).

De allí que uno de los principales pasos que deba realizar toda organización sea favorecer relaciones que mantenga de manera interna y externa para luego poder establecer los mecanismos 
comunicativos necesarios que permitan interactuar con esas instancias (Castillo Esparcia, 2005).

\subsubsection{Las funciones esenciales en la gestión organizacional}

La organización así concebida es un sistema dinámico que acciona para la consecución de objetivos. Esas funciones esenciales se engloban en lo que se conoce como planificación, definida como (Albrecht, 1996: 74):

"El conjunto de acciones orientadas al logro de un resultado claramente definido, siempre y cuando se posea un alto nivel de certidumbre sobre la situación en que éstas van a llevarse a cabo y un elevado control de los factores que permitirán que se alcance el resultado perseguido".

La planificación será así un escenario teórico-descriptivo que relata todo aquello que hay que hacer en la organización y con qué se cuenta para ello. Incluye metas y objetivos, modos o estrategias para conseguir lo que se pretende, tácticas, acciones y herramientas que soporten intenciones y mensajes, etc. Es un escenario que pretende proponer objetivamente un guión y un directorio de pautas a seguir.

Tradicionalmente, en los procesos de management se suelen distinguir estas cuatro funciones esenciales para la organización, cada una de las cuales se corresponde con una serie de actividades y tareas.

1. Planear: supone prever y decidir así como definir objetivos y modos de acción.

2. Organizar: implica definir la estructura que comprende relaciones, responsabilidades (funciones y tareas) y decisiones (autoridad).

3. Dirigir: integra las actividades de selección y capacitación, comunicación, motivación (creación de incentivos), liderazgo y conformación de equipos y también resolución de conflictos.

4. Controlar: verificar el desempeño del plan previamente establecido y qué ocurre a lo largo de su implementación, en busca de posibles ajustes. 
Sin embargo, hoy en día, las funciones de dirección giran también en torno a la motivación, la comunicación, el estilo de liderazgo, la formación de equipos, la toma de decisiones, la observación y la resolución de conflictos.

En este sentido, Hammer (1998) introdujo el concepto de la "organización en cambio" para plantear componentes y funciones centrales, como una manera particular de desarrollar habilidades y roles en su interior. Este concepto implica una organización horizontal que se caracteriza por:

- Estructuración alrededor de procesos (estructuras matriciales y ad hoc).

- Existencia de jerarquías aplanadas (pocos niveles y muchos dependientes de cada jefe).

- Alto nivel de delegación y descentralización.

- Gestión a través de equipos.

- Concepción de los públicos como guía de la organización (trabaja para ellos y no ya para los directivos).

- Reconocimiento del desempeño de los equipos, con incentivos que responden a resultados del conjunto.

- Comunicación fluida con los distintos públicos (se prioriza el proceso más que la jerarquía).

- Información y capacitación de todo el personal.

El aspecto fundamental de este modelo de organización radica en el trabajo con una serie de nociones del management, entre las que priman la planificación y la evaluación.

\subsubsection{Los comportamientos organizativos y la comunicación}

Capriotti (1992) dirá que existen tres motivos por los que las organizaciones ven la necesidad de comunicarse:

a) Por la toma de conciencia social de que la organización integra la sociedad y por ello debe vincularse y relacionarse con los demás actores que conforman el tejido social. Como organismo de 
crecimiento económico y social necesita manifestarlo, comunicarlo, decirlo y transmitirlo

b) Porque la aceleración y masificación del consumo ha provocado alteraciones en las formas en que adquirimos los bienes y servicios; la oferta se estandariza y esto produce un problema para poder ser notorio y diferenciarse ante el público.

c) Con un ecosistema comunicativo absolutamente saturado, con superabundancia de información que obliga a las personas a activar mecanismos de selección de información y acciones que generen relaciones de confianza y credibilidad con determinadas organizaciones, marcas y productos a los que asocia con determinados valores o percepciones que le dan seguridad al momento de elegir, enfocando en este contexto la atención más en el emisor (organización) que en el mensaje mismo (discurso persuasivo).

Ante esta realidad, desde las ciencias sociales se ha despertado hace décadas un creciente interés por los temas comunicativos y su relación con las organizaciones (Bartoli, 1991).

Lucas Marín (1997: 63) sostiene: "la preocupación teórica -estudios universitarios y centros de investigación- acompaña al crecimiento de las prácticas profesionales comunicativas -gabinetes de prensa, relaciones públicas, lobbying o publicidad-.

Por ello, definida ya la variable organización, en nuestro caso como un sistema orientado al cumplimiento de objetivos, se analiza a continuación la relación e influencia de la variable comunicación.

Se encuentran definiciones como la de Kreps (1995: 13), en una clara línea de pensamiento funcionalista, que sostienen que la comunicación organizacional es:

"El proceso por medio del cual los miembros recolectan información pertinente acerca de su organización y los cambios que ocurren dentro de ella (...). La comunicación ayuda a los miembros a lograr las metas individuales y de organización, al permitirles interpretar el cambio de la organización y finalmente coordinar el cumplimiento de sus necesidades personales con el logro de sus responsabilidades evolutivas en la organización”. 
Para este autor no existe posibilidad de cambio, sino únicamente de adaptación funcional a los cambios internos o del entorno organizacional. De esta manera se refiere a la comunicación considerándola como: "un mecanismo de adaptación crucial para los miembros de y para las organizaciones" (Kreps, 1995: 13).

Otra de las concepciones en torno a la comunicación organizacional es la que brinda Costa (1995: 124) desde una perspectiva holística e integradora:

"La comunicación corporativa, ligada a la acción y a la conducta global de la organización, será el vehículo y soporte de la calidad del servicio y ambos el vector de la imagen corporativa. La comunicación corporativa es holística e integradora, es decir que en ella se coordinan, se integran y gestionan las distintas formas de comunicación como un todo orgánico en el sentido corporativo".

Esta definición remarca la importancia de que las acciones de comunicación, llevándose a cabo de manera coordinada, permiten cumplir con los objetivos planteados por la organización, haciendo hincapié en los resultados que se pueden obtener sobre la imagen corporativa. Esta visión, quizás un tanto limitada sobre la función directiva que se ha planteado, define a la comunicación en las organizaciones (Egidos y Páez, 2000).

La gestión de comunicación en las organizaciones ha sido definida también por diversos autores bajo el concepto de comunicación corporativa. Van Riel, al respecto sostiene que (1997: 26):

"Es un instrumento de gestión por medio del cual toda forma de comunicación interna y externa conscientemente utilizada está armonizada tan efectiva y eficazmente como sea posible, para crear una base favorable para las relaciones con los públicos de los que la institución depende". 
Losada Vázquez (1998: 46) se referirá a la comunicación institucional para la gestión del cambio, como:

"El conjunto de interacciones en las que la organización, como ente colectivo - poseedor de una personalidad diferenciada- se constituye en el sujeto reconocible de un proceso de comunicación social que se desarrolla tanto en el ámbito interno como en el entorno social".

Por su parte, al hablar de comunicación en las organizaciones, Masoni sostiene que:

"La comunicación atraviesa transversalmente a las organizaciones, está íntimamente vinculada a la calidad de sus prácticas y a la coherencia de éstas con los objetivos, metas institucionales y voluntades de diálogo y participación de sus miembros. Será necesario entonces detenerse a explorar los canales internos de circulación de la información y los mecanismos previstos para garantizar fluidez de información y transparencia de las acciones encaradas y de mecanismos de participación en la toma de decisiones vinculadas a la vida de la organización (2011: 33)".

Martín Martín (1998) dirá que a quienes gestionan la comunicación empresarial e institucional les compete la:

"Creación, análisis, desarrollo, difusión y control de toda acción de gestión informativa interna y externa que se produce en una empresa o institución, tanto a nivel de actividades, servicios o productos, que afecta a un determinado público o colectivo social y que se transmite a través de los medios de comunicación".

Otros autores españoles (Carrillo, Castillo y Gómez) definen la comunicación empresarial como: 
"El conjunto de decisiones, materializadas en distintas acciones (publicidad, folletos, relaciones con los medios...) para que una organización alcance sus objetivos, entre los que se sitúa el reconocimiento y notoriedad, o el cambio de actitud hacia sus productos o hacia la propia empresa, por parte de sus públicos internos y externos (2005: 20)".

Evidentemente, existen tantas definiciones sobre la gestión en comunicación estratégica como enfoques posibles puedan atribuírsele a la relación de estas dos variables tan complejas de abordar. Quizás una sistematización de las mismas en función del recorrido histórico de la evolución de las teorías de la administración sea un anclaje apropiado para el presente marco teórico.

Así como el desarrollo económico de las sociedades ha hecho necesario generar planteamientos psicológicos y sociológicos para comprender racionalmente la conducta de los individuos en la actividad económica, existen estudios conocidos como "teorías de la organizaciones". Diversos son también los enfoques que la función de comunicación adquiere en las organizaciones, dependiendo de las teorías o Escuelas administrativas desde la cual se parta. En este sentido, Lucas Marín (1997) habla de un nuevo campo de estudio: la "comunicación en las organizaciones", de tal transcendencia e importancia estratégica que Kaufmann afirmó sin sutilezas: "es la comunicación lo que otorga vida a la estructura organizativa" (1993: 158).

Estrictamente hablando desde el punto de vista histórico, puede decirse que el interés por el estudio de la comunicación en las organizaciones tiene origen en necesidades prácticas y teóricas de las mismas y que ingresa en lo académico por una doble vía: "en los intentos de mejorar las habilidades comunicativas de los que intervienen en los procesos económicos y en la evolución vista de las teorías de la organización, cada vez más centradas en la cultura de las organizaciones" (Lucas Marín, 1997: 101). Según el autor, la investigación sobre comunicación en las organizaciones empezó centrándose en cinco áreas que denomina tradicionales:

1) La comunicación como medio (1920). 
2) El estudio de los canales de comunicación.

3) El clima comunicativo.

4) El análisis de las redes de trabajo,

5) El estudio de la comunicación entre superiores

y subordinados.

Pero no será hasta la prevalencia de las teorías sistémicas (1945, con los trabajos de Simon de Administrative Behavior y "los sistemas de comunicación en las organizaciones") que el campo de la comunicación en las organizaciones comience a desarrollarse, sostiene Lucas Marín (1997).

En ese sentido, tanto Lucas Marín (1997) como Kaufmann (1993) proponen planteamientos similares, al considerar tres grandes modelos teóricos generales de referencia, los cuales atienden de diferente manera las cuestiones comunicativas en las organizaciones: la Escuela Clásica (del Management científico, para Kaufmann), la Escuela de Relaciones Humanas y la Escuela Sistémica.

Entre los supuestos básicos que permiten comprender la estructura y el funcionamiento de las organizaciones y el rol que le asignan a la comunicación, los autores señalan que:

- La Escuela Clásica (o del Management Científico) nace frente a la necesidad de interpretar la sociedad industrial de principios del siglo XX y sus representantes más destacados son Taylor (“Teoría de la Organización Científica del Trabajo", 1911); Fayol ("Teoría de la Organización Formal", 1946) y Weber ("Teoría de la Burocracia", 1947). Se consideraba a los trabajadores como una mera extensión de las máquinas que solamente respondían a incentivos económicos, bajo una concepción del hombre puramente racional y orientado al trabajo. En aquella época la comunicación en las organizaciones sólo era concebida como información operativa, unidireccional y formal; de este modo, este paradigma se sostiene en base a los supuestos de "eficiencia" de la comunicación vertical, siguiendo 
los causes y las necesidades reflejadas en la línea de mando que señala el organigrama. A la comunicación en las organizaciones, según esta Escuela Clásica, se le da relativamente poca importancia, ya que la misma tiene como propósito transmitir órdenes e información sobre tareas laborales para lograr obediencia y coordinación en el trabajo. Además, la dirección de los flujos de comunicación es vertical hacia abajo, de la dirección a los trabajadores, para persuadirlos o convencerlos de seguir instrucciones.

- La Escuela de las Relaciones Humanas nace a mediados de la década del '30 como una crítica al excesivo racionalismo de la Escuela Clásica. Se destacan las contribuciones de Barnard (1938); Mayo (1960); Lewin (1935); Maslow (1943) y Likert (1961). Su característica más importante es el componente afectivo y natural de la actividad humana productiva. En ella se intenta superar el reduccionismo economicista y mecanicista de las Teorías Clásicas con la consideración del sujeto productivo como ser social, incluso de persona que busca "realizarse" en las tareas que ejecuta. A diferencia de la anterior, esta corriente enfatizaba la comunicación, particularmente la que se producía entre pares, como una clave del comportamiento organizativo. Redescubre la importancia de los grupos informales dentro de la estructura formal (estudios de Hawthorne, Landsberger, 1955) y ve a la comunicación organizativa como el medio para relacionarse con las clases trabajadoras, pero desde una perspectiva de escucha; dándoles a los obreros un rol fundamental. El modelo presenta flujos ascendentes y descendentes y considera a la comunicación importante y necesaria para el buen funcionamiento de la organización. Sus principales propósitos son satisfacer las necesidades de los trabajadores para conseguir interacción entre iguales y facilitar la participación de éstos en la toma de decisiones.

- Finalmente, la Escuela de los Sistemas, surge también en el año sesenta y sustenta una teoría de totalidad, en la necesidad de entender al hombre que actúa en nuevas organizaciones complejas. La revolución científica creada por el paradigma de los sistemas determinó una reorientación en la investigación acerca de las organizaciones. Se concibe al sistema como un 
conjunto de partes con una cierta estructura, interconectadas e interdependientes con un permanente flujo comunicativo. La organización es considerada como un sistema social formado por partes interrelacionadas en equilibrio, subsistemas, y cuyas características son el dinamismo, la apertura y la importancia de la comunicación, considerada como el elemento que mantiene unidos a los subsistemas. Un sistema abierto se halla permanentemente intercambiando información con su entorno. Katz y Kahn (1964) son investigadores destacados de esta corriente.

Las tres escuelas señaladas se diferencian en su percepción de la comunicación. En tanto la escuela de las Teorías Clásicas enfatizaba la comunicación vertical y descendente, la escuela de las Relaciones Humanas lo hacía en el papel fundamental que jugaba la comunicación entre las partes. La Escuela Sistémica va a considerar a todos los flujos comunicativos como importantes, en especial las relaciones con el entorno y entre los subsistemas de la organización.

\subsubsection{El enfoque sistémico y los modelos de relaciones públicas}

Se ha visto que las conceptualizaciones históricas que contemplan a las organizaciones como sistemas (Escuela de los Sistemas para Kaufmann, 1993 o Teoría Sistémica para Lucas Marín, 1997) atribuyen un papel axial a la comunicación. En ese sentido, el desarrollo del campo teórico de la comunicación en las organizaciones, que también se caracteriza por la diversificación de denominaciones que ha ido recibiendo, postula hacia finales de 1970 con mucho auge (fundamentalmente en Estados Unidos) uno de sus basamentos teórico-científico más fuerte conocido como relaciones públicas.

Las relaciones públicas pueden definirse como parte de un sistema complejo, ocupando una posición límite, ya que son el canal de relación entre una organización y los públicos y actúan interna y externamente (Castillo Esparcia, 2009). Así visto, para Grunig y Hunt (2000, adaptado por Xifra) las funciones de las relaciones públicas son: 
- Dirigen, planifican y ejecutan la comunicación para la organización como un todo.

- Gestionan el discurrir de los mensajes dentro de la organización a través de los diversos métodos de investigación para, a partir de ahí, elaborar las estrategias comunicativas más adecuadas.

- Gestionan la circulación de un mensaje fuera de la organización cuando ayudan a la dirección a decidir la forma de explicar una política o una acción al público y luego intentan acceder a los medios de comunicación para explicar la actividad.

Y su participación y relación con el resto de subsistemas organizativos se concreta con las siguientes aportaciones:

- Funcionan en el límite de la organización, sirviendo de enlace entre la organización y los grupos e individuos externos.

- Tienen un pie en la organización y otro fuera.

- A veces apoyan al subsistema de disposición ayudándole a promocionar productos o servicios.

- Apoyan al subsistema de mantenimiento por medio de la comunicación con los empleados.

- Apoyan al subsistema de adaptación aportando nuevas ideas procedentes del entorno y comunicando las ideas de la organización a grupos externos.

El origen de esta sistematización se remonta a 1976, cuando Grunig inició un programa de investigación para explicar cuál era el comportamiento de las organizaciones en término de relaciones públicas. Los resultados no fueron muy convincentes, con lo cual, como sostiene Xifra (Grunig y Hunt, adaptado, 2000: 30):

Fue necesario ir más allá y analizar el fenómeno desde una perspectiva histórica. En la obra 'Dirección de relaciones públicas', Grunig y Hunt definen cuatro modelos de relaciones públicas basados en la investigación empírica, en la historia de su práctica y su posterior extrapolación a la actualidad, tanto desde la dimensión teórica y metodológica, como desde la pragmática.

Para el investigador catalán, traductor al español de la obra de Grunig y Hunt (2000), estos modelos van a significar una verdadera 
"revolución científica en el campo de la relaciones públicas" (Grunig y Hunt, adaptado Xifra, 2000: 30):

\section{a) Agentes de prensa/Publicity}

En este modelo, las relaciones públicas realizan una función de propagación de la información hacia los públicos y principalmente, hacia los medios de comunicación. Para ello, se recurre a todo tipo de acciones sin importar el componente ético de las mimas -como la desinformación o la manipulación, por ejemplo. La relación con los periodistas es de engaño con el único objetivo de que aquello que aparezca sobre la organización sea siempre positivo y, como elemento esencial, conseguido a cualquier precio, ya sea comprando periodistas, dando información distorsionada o con verdades a medias. Este modelo aparece en el período de 1850 a 1900 y se ha utilizado como ejemplo la figura de Phineas T.-Barnum, promotor circense que creó el Circo Barnum \& Bailey, quien realizaba esfuerzos permanentes para conseguir espacio gratuito en los medios de comunicación para sus clientes, independientemente de las formas de conseguir esas apariciones, como señala Marston (1963) (Grunig y Hunt, 2000: 83).

Barnum no era contrario a comprar espacios; también conocía el interés periodístico de sus atracciones y recogía toda una cosecha de publicity gratuita. Con Barnum y después de él, llegó una hueste de agentes de prensa cuya especialidad era conseguir que se publicaran gratuitamente los nombres de actrices y actores como Lily Langtry o Anna Held y, más tarde, estrellas de la radio y la televisión. Los métodos no eran tan importantes para ellos como los resultados. Se informaba de toda clase de ardides de publicity -robos de joyas falsas, disputas matrimoniales y asuntos amorosos- y se explotaba constantemente una mina de desinformación respecto a matrimonios, divorcios, ropa (o falta de ella), opiniones sobre cualquier tema y viajes. ¡Desgraciadamente, al público, o por lo menos a una gran parte de él, le encantaba!

En consecuencia, el tipo de relación entre organización y públicos es de linealidad directa que va de la organización a los periodistas. Los profesionales que practican este modelo no suelen recurrir a la investigación salvo que recopilen las salidas en los medios de comunicación o realicen un recuento para comprobar cuántas personas han asistido a un acontecimiento. 


\section{b) Información pública}

La intención de la organización es la de difundir información sin ningún atisbo de persuasión, ya que lo único que pretende es realizar una función periodística al suministrar datos sobre ella. Y esa información no es engañosa ni tergiversada sino plenamente informativa. El de la Información Pública es un modelo que aparece alrededor de 1900 y permanece hasta 1920. Su génesis tiene lugar en un contexto en el que los empresarios están más interesados en conseguir beneficios económicos permanentes que en las condiciones socio-laborales de sus trabajadores. Ante esos excesos, surge la reacción de trabajadores que se sindican y de determinados periodistas que comienzan a criticar el comportamiento de los empresarios -denominados por Theodore Roosevelt, en su etapa de comisionado de policía de Nueva York, como muckrakers, que equivaldría a "aquellos que sacan trapos sucios al sol". Para las organizaciones, la respuesta no podía seguir siendo la misma que hasta ese momento (compra de periodistas, engaños, no decir nunca la verdad) y comienza a prender la idea de que es necesario cambiar su comportamiento hasta que sea positivo. El más claro exponente es Lee, que consideró al público lo suficientemente racional como para tomar la decisión correcta si se le proporciona una información completa y fidedigna. Ese postulado fue correctamente resumido por Page, relaciones públicas de AT\&T (Grunig y Hunt, 2000: 94):

En un país democrático, toda actividad empresarial empieza con el permiso del público y existe gracias a la aprobación del mismo. Si eso es cierto, lo que se desprende de ello es que el sector empresarial debería estar alegremente deseoso de explicar al público cuáles son sus políticas, lo que está haciendo y lo que espera y confía hacer. Ese parece ser, prácticamente, un deber.

La investigación que se realiza entonces desde las relaciones públicas es escasa y limitada a un modelo periodístico de preparación de materiales informativos para un público básicamente formado por desconocidos. Así, recurren al análisis de contenido para verificar lo publicado o al test de legibilidad para comprobar si la información tiene el nivel apropiado de dificultad para la audiencia que se pretende alcanzar. 
Ahora bien, este modelo sigue basado en una información unidireccional, que va de la organización a sus públicos y no pretende hacer un seguimiento o una comprobación de la respuesta del receptor.

\section{c) Asimétrico Bidireccional}

En el proceso de desarrollo científico de la disciplina se comienza a estudiar cómo persuadir de la mejor manera posible. Los practicantes de este modelo recurren a la teoría de las ciencias sociales e investigan las pautas de comportamiento, valores y actitudes de los públicos con la pretensión de persuadirlos para que hagan suyos los postulados organizativos y los asuman como propios. Este modelo se desarrolla en los años 20 y es consecuencia del esfuerzo comunicativo realizado en Estados Unidos para conseguir que la población apoyara la participación en la Primera Guerra Mundial. Demostró que la persuasión de masas era una realidad, como lo señalan Grunig y Hunt (2000: 95).

Tobin y Bidwell -en el libro Mobilizing Civilian America- achacan al trabajo de "un grupo de celosos propagandistas amateurs", organizado por el Sr. Creel, "el cambio revolucionario en el sentimiento de la nación". Realizó, dicen, lo que "puede que sea el trabajo más eficaz de propaganda de guerra a gran escala que el mundo hubiera visto nunca". Un bombardeo intelectual y emocional elevó a los norteamericanos a la cima del entusiasmo; llegó a la ciudadanía desde todos los flancos: anuncios, noticias, oradores, voluntarios, carteles, escuelas, teatros: millones de hogares pusieron banderas de servicio. Los objetivos y los ideales de la guerra eran proyectados continuamente a los ojos y oídos del populacho. Estas técnicas de alta presión eran nuevas en aquella época, pero desde entonces se han convertido en habituales.

El genuino representante de este modelo es Bernays (1990), quien tras su paso por el Comité de Información Pública de George Creel, teorizó la necesidad de que el profesional de relaciones públicas debía conocer las actitudes o valores del público para que las organizaciones realizaran acciones acordes a esas características, a lo que se dio en llamar la "ingeniería del consenso" o "cristalizando la opinión pública”. 
Ello conlleva una planificación estudiada de los instrumentos y canales más pertinentes para analizar los impactos conseguidos con éxito. Para realizar esa comprobación es necesario obtener alguna respuesta, por mínima que sea, por lo que no es posible hablar de un modelo unidireccional. Se contempla esa pequeña revisión, ahora bien, no para modificar la conducta organizativa sino más bien al contrario, para cómo conseguir un mejor y mayor grado de éxito. Esto es, la organización no se adapta a lo que recibe debido a que lo que pretende es mejorar la manera y forma de cambiar las actitudes y la conducta del público.

Si se piensa en una representación gráfica de ese modelo, se verá que existe una fuente que emite (organización) y un receptor (públicos), quien a su vez remite una respuesta que ayuda a la fuente a verificar el grado de éxito o de fracaso. Esa bidireccionalidad implica la necesidad de investigar, conocer qué se ha conseguido. Para Grunig y Hunt (2000: 77), en el modelo asimétrico, el profesional de relaciones públicas utiliza la investigación formativa para descubrir qué es lo que el público aceptará y tolerará.

\section{d) Simétrico Bidireccional}

Las relaciones públicas tienen como función servir de mediadores entre las organizaciones y los públicos buscando una comprensión mutua entre ambos. Los profesionales utilizan teorías de la comunicación conjuntamente con teorías y métodos de las ciencias sociales, dejando de lado instrumentos de comunicación persuasiva.

Esta actividad dialógica implica la existencia de influencias recíprocas en las que tanto la organización como los públicos tienen la posibilidad y también la competencia de señalar modificaciones en el comportamiento y en la actitud del otro.

Una de las mayores contribuciones que podemos hacer al proceso de formación de la opinión en un momento o época de crisis es ayudar a los decisores (que suelen ser nuestros clientes) a encontrar nuevas formas de pensar en cómo solucionar problemas con gente que antes no había tenido un papel en los asuntos directivos... El relaciones públicas que sirve bien a su cliente no intentará convencer a todo el mundo de que la dirección tiene razón (lo que de todos modos es probable que no pudiera conseguir) (Grunig y Hunt, 2000: 76). 
En cambio, intentará crear las circunstancias en las que gente responsable con opiniones diferentes (incluyendo a sus clientes) realicen juntos un esfuerzo serio para encontrar una solución que tome en consideración todos los factores relevantes.

En este modelo, tanto el emisor como el receptor no están establecidos apriorísticamente sino que es una función ejercida por la organización y los públicos y en la que la iniciativa puede partir de ambos, al tiempo que ambos son susceptibles de asumir esas indicaciones. Eso conlleva una interacción recíproca en la que tanto uno como otro son al mismo tiempo, emisor y receptor.

Como modelo bidireccional, la investigación es una de sus actividades esenciales, en la modalidad formativa, para conocer la manera en la que el público percibe a la organización y para determinar qué consecuencias tiene ésta para el público. A partir de esos resultados, se planifican y ejecutan las estrategias organizativas que mejor respondan a los requerimientos del público. Asimismo, es pertinente acometer una investigación evaluativa para comprobar el grado de comprensión que tienen los públicos de la organización y el de ésta sobre los públicos. Este modelo comienza a teorizarse en los años 50 cuando las universidades acogen a mayor número de investigadores a tiempo completo que ocupan gran parte de su tiempo en reflexionar sobre el sector profesional. En esa situación, Cutlip et al. (1952), profesor de la Universidad de Wisconsin, y Center, profesional de Motorola Corporation, describen las relaciones públicas como una estrategia comunicativa conducente a crear buenas relaciones con el público y definida como una comunicación simétrica bidireccional (Grunig y Hunt, 2000: 103):

Se basa en la difusión de información y de hechos cuando hay involucradas materias no controvertidas. Pero cuando existe la controversia, las relaciones públicas pueden convertirse en abogado ante el tribunal de la opinión pública, buscando ganarse su apoyo por medio de la interpretación de los hechos y el poder de la persuasión.

Arceo Vacas (2004) sostiene que a esta cuatripartición de modelos debe añadirse la existencia de un quinto modelo de entendimiento, práctica y dirección de los programas de relaciones públicas o comunicación en las organizaciones o similares de todo tipo: 


\section{e) Modelo Bidireccional Simétrico Persuasivo}

Se trata de una mezcla del tercer y cuarto modelos de Grunig y Hunt (2000), de la que resulta uno de actuación bidireccional simétrico, como el cuarto, pero sin renunciar por ello a la persuasión como objetivo último y explícito del tercero. Lo que este quinto modelo hace es destacar ese mutuo entendimiento y con ello el posible cambio en ambas partes, emisor y público receptor, como fase anterior necesaria para lograr una mayor eficacia, esto es, para alcanzar una mayor persuasión. Porque el cuarto modelo es difícil de aplicar desde la mentalidad de la comunicación persuasiva profesionalizada, es decir, desde la comunicación preparada por un emisor que, finalmente, lo que quiere es persuadir a sus públicos (aun corrigiendo eventualmente para ello la postura propia) y no sólo relacionarse bien con ellos. Pero todo esto no queda así de explícito en los escritos de Grunig (2000), quien describe esa mezcla de los modelos tercero y cuarto sin declarar que en realidad de ese mix resulta específicamente otro modelo más que, por añadidura, es el óptimo (Arceo Vacas, 2004:19).

Otero (2002) se referirá al quinto modelo de Grunig (2000) como el Simétrico de Motivación Mixta (Dozier et al., 1995). Está basado en el papel fronterizo del profesional de las relaciones públicas entre la organización y el público y que necesita encontrar un espacio común de entendimiento entre intereses contrapuestos. Incorpora la naturaleza contractual de esta relación; ofrece una dimensión conflictual poco conocida de las relaciones públicas y un horizonte de entendimiento lejos de planteamientos utópicos.

La influencia de estos modelos ha ganado la esfera académica y profesional del campo de las relaciones públicas eclipsando otras propuestas. A pesar de ello, Xifra (2006, 2006b, 2009, 2012), quien ha dedicado gran parte de su producción a la reivindicación de la doctrina europea liderada por el francés Matrat (1975), sostiene que la misma representa (2006: 230):

El primer gran punto de inflexión en la construcción teórica de las relaciones públicas, tanto en el ámbito europeo como internacional, únicamente igualada por las aportaciones del norteamericano James E. Grunig, cuya teoría de las relaciones públicas simétricas bidireccionales tiene su origen en los postulados del francés. 
La teoría de Matrat (1975) encuentra sus fundamentos en la antropología de las relaciones públicas; la dimensión corporativa o empresarial de las mismas y el concepto de confianza como elemento central del modelo de las relaciones públicas (Xifra, 2006).

En este sentido, la función corporativa primordial de las relaciones públicas sigue intacta. Al respecto, Xifra (2006) parafrasea que en la obra cumbre el francés "Relations publiques et management" (1971) queda plasmado con claridad que:

Las relaciones públicas forman parte de las estrategias utilizadas por el management para responder a las expectativas y actuar sobre las motivaciones de los públicos, cuyos comportamientos, juicios y opiniones pueden influenciar la marcha o el desarrollo de la empresa (Xifra, 2006: 235).

Sin embargo, la doctrina europea sobre relaciones públicas que postuló Matrat (1971) sólo es aplicable a las organizaciones que gestionan a través de la dirección participativa por objetivos, "el sistema de dirección más completo" (Xifra, 2006: 235).

\subsubsection{La planificación estratégica en comunicación: el modelo RACE}

Se puede avanzar un peldaño más en la cuestión y abordar la interrelación entre la organización (de tipo sistémica) y la gestión de comunicación (desde la perspectiva relacional) en lo que se conoce como planificación estratégica (Matilla, 2007).

Para ello se adopta como base el modelo que en 1963 Marston estableció para definir el proceso de toma de decisiones estratégicas en el ámbito de la comunicación (lo postula para el ámbito de las relaciones públicas), al cual denominó con el acrónimo $\mathrm{RACE}^{10}$ (en español, IACE) en alusión a cuatro fases: Investigación, Acción, Comunicación y Evaluación.

De las siglas en inglés "Research" (R), “Action" (A), "Communication” (C) y "Evaluation" (E) 
El modelo se basa en el proceso clásico del management diseñado por Drucker (1954) conocido como Management by Objectives (MBO) al que antes se hacía referencia, y que parte de la recopilación de información previa, la cual es analizada en profundidad para poder diseñar un plan de acción y, tras su ejecución, evaluar el cumplimiento de determinados objetivos previamente definidos.

Hay otros autores que han elaborado sus propios modelos teóricos, eludiendo o completando el modelo de Marston (1963). Aun así, el método RACE es uno de los más utilizados en el desarrollo de la gestión profesional de la función de comunicación en las organizaciones y es, asimismo, uno de los más citados en el ámbito académico ya que constituye un punto de referencia esencial.

El modelo marstoniano es también conocido como "Método de la Espiral" puesto que, al ser concebido gráficamente, se dibuja como una línea ascendente que, partiendo en su nacimiento de la investigación, avanza hacia la acción, se desplaza por la comunicación y, finalmente, desemboca y termina en la evaluación. Su aportación se centra en la descripción cíclica de sus cuatro etapas o fases y en su ordenamiento cerrado. Aunque la idea de la espiral no es del todo determinante, lo fundamental en Marston (1963) es que cada etapa conduce indefectiblemente a la siguiente, de modo tal que la última "Evaluation", una vez superada, obligará a recurrir nuevamente a la primera "Investigation" para seguir avanzando (Noguero I Grau, 2000: 80).

Se pueden ver a continuación las características de sus componentes:

\section{a) Investigación}

Es el primer paso que describe Marston (1963) y consiste básicamente en analizar la situación actual de las prácticas en comunicación para poder determinar los problemas que se deben afrontar. La planificación estratégica en comunicación de cualquier compañía se ha de elaborar con información proveniente de estudios anteriores, pieza imprescindible del plan de actuación posterior. Sin esta descripción de campo, siempre se estará a expensas de la casualidad, la intuición y el optimismo subjetivo y desmesurado. 
La investigación "es la recopilación e interpretación sistemática de información para mejorar la comprensión”, sostiene Seitel (2002: 117); es una forma de escuchar. Se presenta como una compilación controlada, objetiva y metódica de información con el objetivo de describir, interpretar y comprender lo que está pasando. Aunque Bernays (citado por Seitel, 2002) sólo hacía referencia a una investigación dirigida en una sola dirección, sí acertaba en la necesidad de conocer para luego planear y actuar de forma eficaz.

Robinson será quien escriba definitivamente la necrológica de la aproximación instintiva, al señalar que quien gestiona la comunicación, como un profesional de las ciencias sociales y del comportamiento, debe utilizar la investigación como ayuda en el proceso de resolución de problemas. "El profesional toma sus decisiones en base al conocimiento obtenido a través de la investigación científica" (Robinson, 1969: 50).

Posteriormente, diversos autores del campo de las relaciones públicas (Cutlip, 2001; Center, 2001; Grunig, 1995; Broom, 2001; Dozier, 1992; Ehling, 1992, entre otros) han referido que tal función, en su forma más avanzada, es una parte del proceso directivo científicamente dirigida a la resolución de problemas y procesos de cambio (Cutlip et al., 2001).

Comprender a los públicos, ahorrar tiempo y dinero, tomar decisiones ajustadas, evitar errores, justificar esfuerzos y conectar con el entorno son algunas de las justificaciones del porqué es esencial, según Xifra (2005), investigar antes de diseñar el nuevo plan en comunicación o relaciones públicas.

El proceso inicia su engranaje con esta primera fase de investigación que se concentra en analizar la política, gestión y planificación estratégica de comunicación de una organización en un momento preciso. A esta primera fase se la conoce como auditoría.

\section{b) Acción}

La segunda etapa del proceso de planificación estratégica para Marston (1963) recibe el nombre de "Acción", llamada "Planificación" por Cutlip y Center (1952). Consistiría en poner en relación las actitudes, opiniones, ideas y reacciones de los públicos 
derivadas de la fase de investigación, con las políticas y los planes o programas de la organización. Ya se ha expuesto con anterioridad que la totalidad del proceso estratégico implica una tendencia hacia la acción que se procurará cristalice en una conducta. Es por medio de la transforma su realidad.

Según Cutlip y Center (1952) esta fase debe responder a los siguientes interrogantes (citado por Fita, 1999: 20):

- ¿Cuáles deben ser los objetivos para influenciar en la opinión pública?

- ¿Cuáles serían las vías alternativas para alcanzarlos?

- ¿Qué riesgos supone cada una de las alternativas anteriores?

- ¿Cuáles son los potenciales beneficios de cada una de las vías o alternativas?

- ¿Qué consecuencias potenciales se anticipan para cada alternativa o vía?

- ¿Qué vía se perfila como óptima?

- ¿Qué estructura conformará la propuesta seleccionada en relación al plan o programa que vaya a desarrollarse?

- ¿Cuál será el formato más ventajoso con el que se elaborará dicha propuesta? ¿A quién?

- ¿Qué límites tendrá el apoyo de la alta dirección si se alcanza el logro de los objetivos?

Todo lo trabajado en la etapa de investigación tendrá por único propósito definir claramente los objetivos que darán origen al diseño de las etapas posteriores. Los objetivos permitirán establecer una estrategia para el conjunto de las acciones de comunicación, es decir, la meta a lograr. A su vez, establecer objetivos realistas es absolutamente vital si el programa que se está planificando pretende ser demostrable en la fase final.

En efecto, la delimitación de los objetivos de comunicación, basados en los objetivos corporativos, permitirá desarrollar los dos procesos comunicativos claves: una Política de Comunicación (objetivos) y un Plan Estratégico de Comunicación (método-forma). 


\section{c) Comunicación}

Cutlip y Center (1952), a la tercera etapa del método RACE, la denominan igualmente "comunicación" (citado por Fita, 1999: 21) y responde plenamente a la fase del diseño de elaboración de la estrategia propiamente dicha, entendida como:

El conjunto de decisiones y acciones relativas a la elección de los medios y a la articulación de los recursos con miras a lograr un objetivo. También puede entenderse como un proceso organizado, ya que respeta un determinado proyecto y recurre a ciertos métodos que permiten sintetizar los procedimientos utilizados en cada etapa. La estrategia deberá adaptarse a un método, es decir, tanto su diseño como su aplicación deberán seguir unos pasos rigurosamente establecidos, como la planificación de la estrategia y su posterior programación. A esta fase la considero de suma importancia ya que, de una buena programación de las acciones que cumplan los objetivos de la investigación realizada anteriormente dependerá en gran medida que la estrategia pueda realizarse en los plazos previstos. Posteriormente, deberá controlarse la adaptación de las propuestas estratégicas a su ejecución y evaluarse los resultados a corto y largo plazo (1999: 33).

Las políticas de comunicación integran la totalidad de las diversas actividades contingentes emprendidas en el seno de una organización y en tanto que son el resultado de la decisión de su máximo órgano de gobierno, son de obligado cumplimiento. Las políticas configuran las respuestas a situaciones previamente diagnosticadas, bajo el formato de planes de acción. El hecho de que deba darse un diagnóstico previo obliga a un análisis exhaustivo de la realidad comunicacional y permite, posteriormente, diseñar las grandes líneas orientadoras de la acción futura y de sus prioridades (García Jiménez, 1998: 119).

Wilcox et al. (2001: 9) definen una serie de elementos claves en comunicación que sirven como base orientativa del conjunto de acciones de comunicación que pueden llevarse adelante:

- Asesoría en las comunicaciones del presidente/directores/ consejo de administración.

- Relaciones con los medios de comunicación/publicity. 
- Relaciones con los trabajadores/miembros.

- Relaciones con la comunidad.

- Asuntos públicos.

- Asuntos gubernamentales/lobbying.

- Resolución y gestión de conflictos potenciales/Issues management.

- Relaciones financieras con inversores/accionistas.

- Relaciones industriales.

- Desarrollo y obtención de fondos.

- Relaciones multiculturales/diversidad del lugar del trabajo.

- Acontecimientos especiales/eventos.

- Comunicaciones de marketing/comerciales.

También corresponde a esta fase cuantificar los costos derivados de las acciones bajo la forma de un presupuesto que no es más que el resultado cuantitativo o coste económico al que se llega después de realizar determinadas acciones (plan estratégico de comunicación) para cumplir los objetivos (política comunicativa) establecidos a priori (Martin Martin, 1998: 87).

Además, deberá confeccionarse el calendario del plan de acción (táctico) el cual no debe confundirse con el plan de comunicación (estratégico). El plan de acción no es más que el mero plan de ejecución del plan de comunicación y puede elaborarse bajo dos formatos: el plan anual (normalmente a un año vista, ligado a las asignaciones presupuestarias de carácter anual) o el plan temático, ligado a herramientas concretas (eventos, patrocinios, relaciones con los medios de comunicación, etc.).

\section{d) Evaluación}

Es la etapa final que señala el método RACE formulada por Marston en 1963 y nuestro objeto de estudio en particular. Como ya se ha mencionado, esta función del proceso de planificación estratégica de la comunicación ha sido la menos desarrollada, lo cual justifica nuestro esfuerzo investigador. A continuación se abordará la misma en profundidad. 


\subsection{La función de evaluación en la planificación estratégica}

Weiss (1972) concluiría sus investigaciones con un asunto de severa gravedad metodológica:

Los profesionales de las relaciones públicas intentaban evaluar sus programas sin tan siquiera especificar cuál era sus objetivos. Y ello se producía muy habitualmente hasta tal punto que, si se les facilitaba una declaración de propósitos, con frecuencia 'se manifestaba en términos de actividades del programa, en lugar de en resultados del mismo' (citado por Pavlik, 1999: 84).

Sin embargo, por aquellos años, Robinson (1969) había aventurado que en un futuro próximo los profesionales de las relaciones públicas dejarían de guiarse por procedimientos intuitivos y subjetivos para evaluar la eficacia de sus planes estratégicos y que, para ello, adoptarían métodos de investigación más sistemáticos, de carácter científico.

Y aunque ha pasado casi medio siglo -y está claro que al adquirir la comunicación una función directiva en las organizaciones, las acciones de planificación estratégica se vuelven fundamentales- Xifra (2005) sostiene que si bien la investigación y su posterior evaluación constituyen las etapas más esenciales de todo el proceso de planificación estratégica, sorprendentemente, en el campo de la comunicación y las relaciones públicas son las más menospreciadas.

Según Matilla (2007: 329) "el origen de esta carencia parecería centrarse en dos interrogantes no bien resueltos: el primero sería la definición concreta de qué es lo que se pretende medir y la segunda, con qué metodología hacer la medición".

Con respecto a este dilema, Pavlik (1999) citará a Reeves (1983: 27) quien, con respecto a la primera pregunta -la definición del ámbito de medición- afirmó en su momento:

"Una documentación completa de los efectos de los medios (de una campaña de relaciones públicas) exige datos procedentes de cuatro fuentes: contenido del mensaje; atención de la audiencia al mensaje; efectos (resultados de la atención) y procesos 
condicionales/situaciones en que los efectos pueden producirse o no" (Pavlik, 1999: 84).

Dozier (1984) no daba crédito a un programa de comunicación basado en la dirección por objetivos sostenido a largo plazo, sin que sea imprescindible marcar objetivos realistas cuyo alcance deba ser medido para determinar el éxito de los programas implementados.

Por ello, Dozier se planteó comprobar si la predicción de Robinson se había cumplido y realizó una investigación al respecto, que produjo unos resultados que evidenciaron tres grandes estilos de evaluación (1984: 113):

- La evaluación científica del impacto. Evaluación del impacto del programa por medio de recogida de datos cuantitativos y de ciencia social.

- La evaluación instintiva. Constituía el sistema tradicional que históricamente se venía practicando en el sector profesional, tipificado por una evaluación subjetiva y personal que estimaba la eficacia de un programa o plan mediante la observación casual y anecdótica, sumado al juicio profesional basado en la experiencia acumulada.

- La evaluación científica de la difusión. Constituía otro método de uso tradicional, basado en la emisión del mensaje y en su publicación en los mass media. En general consistía en un análisis del press clipping, de tipo numérico (registro de los centímetros de las columnas recortadas en prensa escrita o tiempo en antena; la audiencia de los medios y soportes que han publicado el tema) y de un análisis de contenido de los recortes.

- Por aquellos años, otras clasificaciones intentarían echar luz señalando las diferencias entre la evaluación sumativa y la formativa (Pavlik, 1999: 84-85):

- Sumativa: se dirige a verificar las consecuencias de la implementación de un programa, las cuales suelen manifestarse de formas tan ambiguas e imprecisas que, en ocasiones, parece que no permiten su medición. Describe si un programa o plan posee unos objetivos concretos, articulados y mensurables antes de que éste sea implementado, por lo 
que resulta de gran ayuda en el proceso de toma de decisiones relativas a si continuar o no con el desarrollo del plan (Scriven, 1967: 39-83).

- Formativa: Es aquella que sirve para determinar la forma en que se alcanzan los objetivos, proporcionando información de diagnóstico acerca de la mejor estrategia a implementar en el plan o programa. Este tipo de evaluación requiere de una investigación previa, de modo que se disponga de un elemento en relación al cual comparar los posibles logros alcanzados en la evaluación posterior.

En los años 80, Pavlik (1999) se muestra pesimista al describir cuál era la situación de la investigación basada en ciencias sociales para la evaluación de la eficacia. Coincidían en esta apreciación otros investigadores norteamericanos: Hiebert y Devine (1985); Lindenmann (1980) y Grunig (1983).

En efecto, aunque el modelo de Marston (1963) especifica claramente las cuatro etapas básicas del proceso de planificación estratégico, es evidente que esta última fase, la de evaluación, no encuentra ni un consenso ni un claro desarrollo. Se puede avanzar entonces en el análisis de la función que la evaluación de la comunicación ha tenido en los diversos modelos de planificación estratégica de la comunicación.

\section{Referencias bibliográficas}

Albrecht, K. (1996). La misión de la empresa: Definir el espiritu, establecer los propósitos, fijar el rumbo. Barcelona: Paidós.

Álvarez Nobell, A. (2011). Medición y evaluación en Comunicación. Málaga: Instituto de Investigación en Relaciones Públicas (IIRP).

Araujo, J. (2009). "Comunicación empresarial e institucional: una perspectiva comparada". Recuperado de: http: L/www.iiis.org/CDs2008/CD2009CSC/CCC2009/PapersP df/D612JC.pdf 
Arceo Vacas, J. (1999). Estrategias de Relaciones Públicas. Metodologías. Madrid: ICIE.

Arceo Vacas, J. (2004). "El gran período de usual falta de psicología e investigación en relaciones públicas”. En Arceo, J. L. (coord.) Las Relaciones Públicas en España (115-119). Madrid: McGrawHill.

Arnold, M. y Osorio, F. (1998). "Introducción a los conceptos básicos de la Teoría General de Sistemas". Revista de Epistemología de Ciencias Sociales, $\mathrm{n}^{\circ}$ 3. Departamento de Antropología. Universidad de Chile.

Bartoli, A. (1991). Comunicación organizativa. La organización comunicante y la comunicación organizada. México: Paidós.

Berger, P. y Luckmann T. (1994). La construcción social de la realidad. Buenos Aires: Amorrortu editores.

Bernays, E. L. (1947). "The engineering of consent". Annals of the American Academy of Political and Social Science, 250, 113-120.

Bernays, E.L. (1990). Los años últimos: radiografía de las relaciones públicas 1956-1986. Barcelona: Promociones y Publicaciones Universitarias.

Bernays, E. L. (1995). Cristalizando la Opinión Pública. Barcelona: Gestión 2000.

Bertalanffy Von, L. (1976). Teoría General de los sistemas. México: Editorial Fondo de Cultura Económica.

Broom, G. M. \& Dozier, D. M. (1990). Using research in public relations: Applications to program management. Englewood Cliffs (NJ): Prentice-Hall.

Buckley, W. (1970). La Sociología y la Teoría Moderna de los Sistemas. Buenos Aires: Editorial Amorrortu.

Capriotti, P. (1992). La imagen de empresa. Estrategia para una comunicación integrada. Barcelona: Editorial Consejo Superior de Relaciones Públicas de España. 
Cardoso Castro, J. (2012). “Aspectos epistemológicos y metodológicos de la comunicación empresarial e institucional". Revista Icono14. Revista científica de Comunicación y Tecnologías emergentes, 8(2), 340-370.

Carrillo, M. V., Castillo, A. y Gómez, L. (2005). Imagen y comunicación en las PYMES. Madrid: Ed. Fragua.

Castillo Esparcia, A. (2005). Comunicación organizacional. Málaga: Clave Aynadamar.

Castillo Esparcia, A. (2009). Relaciones Públicas. Teoría e historia. Barcelona: Editorial UOC.

Costa, J. (1995). Comunicación Corporativa y Revolución de los Servicios. Madrid: Ediciones Ciencias Sociales.

Cutlip, S.; Center, A. H., (1952) Effective Public Relations, Englewood Cliffs: Prentice Hall.

Cutlip, S. M., Center, A. H. y Broom, G. M. (2001). Relaciones públicas eficaces. Barcelona: Gestión 2000.

Dozier, D. M. (1984). "Program evaluation and the roles of practitioners". Public Relations Review, 10(2), 13-21.

Dozier, D. M., Ehling, W.P. (1992) "Evaluation of Public Relations Programs: What the Literature tell Us about their Effects", en J.E. GRUNIG (ed.). Excellence in Public Relations and Communication Management (159-184). Hillsdale, New (NJ): Lawrence Erlbaum.

Dozier, D. M., Grunig, L. A., \& Grunig, J. E. (1995). Manager's guide to excellence in public relations and communication management. Mahwah, New Jersey: Lawrence Erlbaum.

Egidos, D. y Páez, L. (2000). “Comunicación en instituciones y organizaciones: una aproximación teórico-analítica a su diversidad conceptual". Revista Latina de Comunicación Social, $\mathrm{n}^{\circ} 35$.

Fita, J. (1999). Comunicación en programas de crisis. Barcelona: Gestión 2000. 
Forrester, J. W. (1969): Principles of Systems. Wright. Estados Unidos: Allen Press.

García Jiménez, F. (1998). La comunicación interna. Madrid: Díaz de Santos.

Grunig, J. E. (1983). "Basic research provides knowledge that makes evaluation possible”. Public Relations Quarterly, 28 (3), 28-32.

Grunig, J. y HUNT, T. (2000). Dirección de relaciones públicas. Edición adaptada por Jordi Xifra. Madrid: Gestión 2000.

Hammer, C. (1998). Estrategias del Kaizen. España: Mc. Graw Hill.

Hiebert, R. E., Devine, C. M. (1985). "Government Research and Evaluation Gap". Public Relations Review, no 11, vol. 3.

Kahn, R.D; Louis, R. y Katz, D. (1966): The social psychology of organizations. Wiley.

Kaufmann, A. (1993). Elpoder de las organizaciones. Alcalá de Henares: ESIC.

Kreps, G. L. (1995). La comunicación en las organizaciones. Buenos Aires: Addison-Wesley Iberoamericana.

Lindenmann, W.K. (1980). "Use of Community Case Studies in Opinion Research”. Public Relations Review, 6 (1).

Losada Vázquez, A. (1998). La comunicación institucional en la gestión del cambio: el modelo universitario. Salamanca: Universidad Pontificia de Salamanca.

Lucas Marin, A. (1997). La comunicación en la empresa y en las organizaciones. Barcelona: Bosch.

Marston, J. (1963). The Nature of Public Relations, New York: McGraw Hill,

Martin Martin, F. (1995): Comunicación en empresas e instituciones. De la consultora a la dirección de comunicación. Salamanca: Universidad de Salamanca 
Martin Martin, F. (1998): Comunicación empresarial e institucional, Madrid: Universitas.

Matilla, K. (2007). Aportaciones para un modelo global de Planificación Estratégica en Relaciones públicas y Comunicación Integral. Análisis de un caso: el uso de los modelos de Planificación Estratégica en algunas agencias y consultoras de Relaciones públicas y Comunicación. Tesis Doctoral no publicada. Barcelona: Facultad de Comunicación Blanquerna, Universidad Ramón Llull, Recuperada de http://www.tdx.cat/TDX-1001107-131810

Matrat, L. (1971): Relations publiques et management. Bruselas: CERP.

Matrat, L. (1975): "Doctrine européenne des relations publiques, condition du dialogue et de la participation". Estudios de Comunicación Socialy Relaciones Públicas, 1, 29-33.

Noguero I. Grau, A. (2000). La función social de las Relaciones Públicas: historia, teoría y marco legal. Barcelona: FUERP.

Pavlik, J.V. (1999). La investigación en Relaciones Públicas. Barcelona: Gestión 2000.

Rappaport, A. M. (1963). "Acinar units and the pathophysiology of the liver". The liver, 1, 265-328.

Robinson, E.J. (1969). Public relations and survey research: achieving organizational goals in a communication contex. New York: Appleton-Century-Crofts.

Ruiz Mora, I. M. (2011). "Cristalizando la opinión pública, de Edward L. Bernays". Razón y palabra, (75), 30.

Schein, N. E. (1982). Psicología de la organización, Madrid: Dossat.

Seitel, F.P. (2002). Teoría y práctica de las relaciones públicas. Madrid: Prentice Hall.

Sotelo, C. (2004). Historia de la gestión de la comunicación en las organizaciones en Gestión de la comunicación en las organizaciones. (J. Losada, Ed.). Barcelona, España: Ariel, S.A.

Van Riel, C. (1997). Comunicación corporativa. España: Prentice Hall. 
Villafañe, J. (1999). La gestión profesional de la imagen corporativa. Madrid: Pirámide.

Wilcox, D.L. et al. (2000). Public Relations Strategies and Tactics. $2^{\circ}$ ed. New York: Harper and Row Pub. Inc.

Xifra, J. (2005). Planificación Estratégica de las Relaciones Públicas. Barcelona: Paidós.

Xifra, J. (2006): “Lucien Matrat y la consolidación de las relaciones públicas en Europa". Historia y comunicación social, 11, ISSN, vol. 1137, 0734.

Xifra, J. (2006b). "Pioneros y olvidados: la Escuela de París y la doctrina europea de las Relaciones Públicas". Ambitos: Revista internacional de comunicación, (15), 449-460.

Xifra, J. (2009). "Recent Mediterranean literature on public relations: France, Italy, and Spain". Journal of Communication Management, 13(2).

Xifra, J. (2012). "Public relations anthropologies: French theory, anthropology of morality and ethnographic practices". Public Relations Review. 


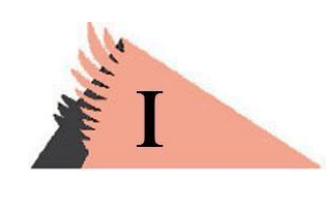

\section{Desarrollo de la investigación}

\section{La gestión de la comunicación estratégica en las organizaciones: enfoque nacional e internacional}

Fanny Paladines. Universidad Técnica Particular de Loja, Ecuador Jenny Yaguache. Universidad Técnica Particular de Loja, Ecuador Carlos Granda. Universidad Técnica Particular de Loja, Ecuador Verónica Altamirano. Universidad Técnica Particular de Loja, Ecuador

La comunicación estratégica es efectiva por el alto cumplimiento de los objetivos comunicacionales

— $\mathrm{N}$ los últimos años, la gestión de la comunicación organizacional ha experimentado un amplio desarrollo en el mundo. La comunicación como eje estratégico es el sostén, la guía y el centro en torno al cual gira la dinámica organizacional. Por tal motivo, para la organización es indispensable sincronizar procesos administrativos, productivos, comerciales, etc., así como a sus diferentes públicos (colaboradores, proveedores, consumidores, 
gobierno, profesionales del sector, competencia, agremiaciones, entre otros) en una permanente interacción estructurada e integral que permita de manera productiva y competitiva alcanzar sus objetivos corporativos comunicacionales (Sandra Fuentes, (s/f)).

Cada modelo de Management requiere procedimientos organizacionales de control, de gestión, de herramientas y dispositivos, por lo tanto, cuando de comunicación se trata, como cualquier otra área de la empresa, se requiere de procesos de evaluación. Estos indicadores de resultados, las herramientas y los dispositivos sirven para evaluar la gestión en relación con los objetivos propuestos. Pero esta gestión debe estar en manos de profesionales con un excelente dominio técnico que vaya mucho más allá de la simple función de difusión de mensajes informativos.

\section{Figura No 1. Cumplimiento de objetivos comunicacionales}

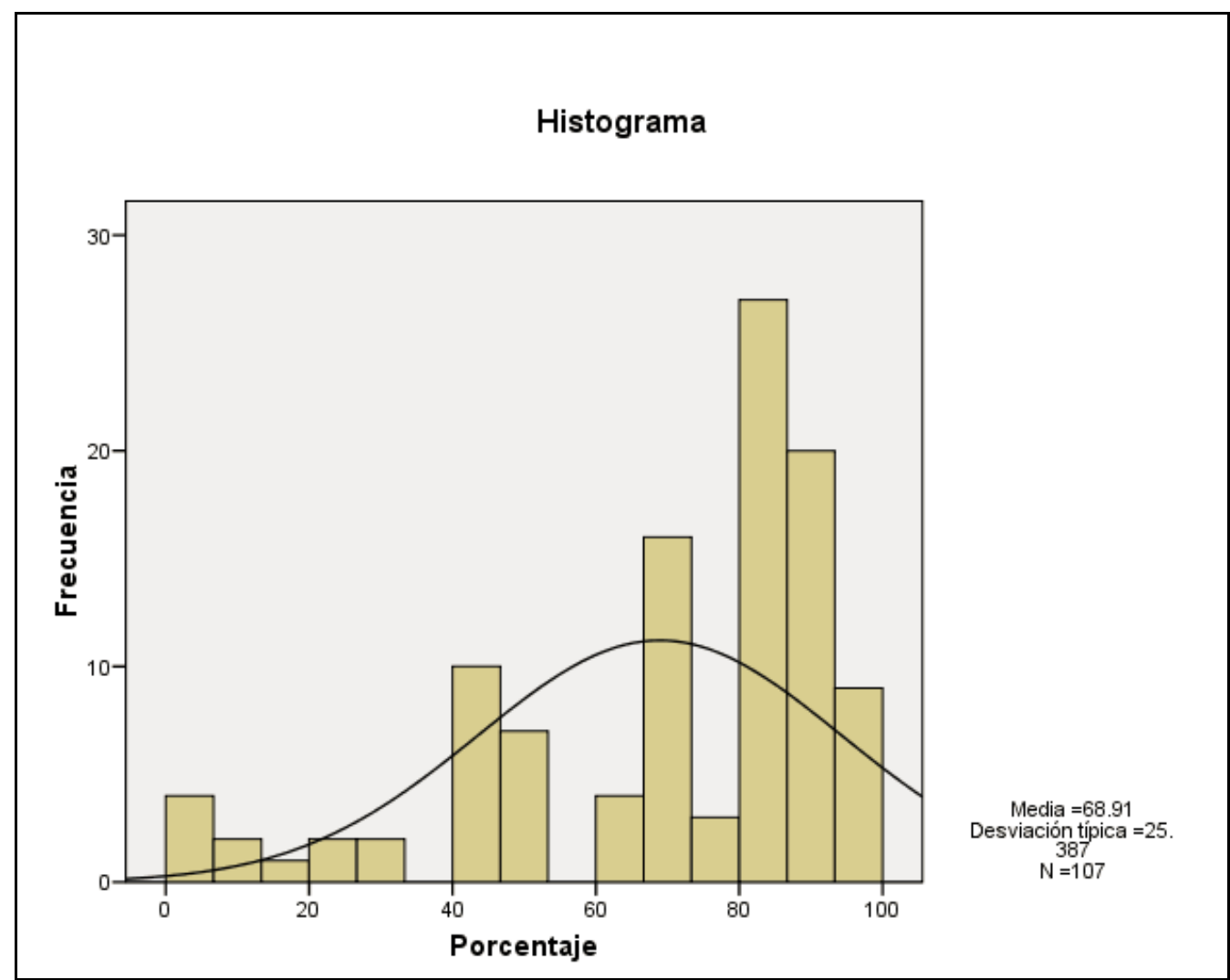

Fuente: Encuesta. Investigación realizada por el Observatorio de la Comunicación Estratégica en Ecuador

Ante lo expuesto y en concordancia con lo señalado por los gestores de la comunicación, se planteó la pregunta: “¿En qué porcentaje su 
organización consiguió sus objetivos comunicacionales el año anterior?”.

Los resultados de la encuesta revelan la efectividad de la comunicación estratégica. De la muestra de 107 empresas estudiadas, entre el $70 \%$ y $90 \%$ cumplieron con sus objetivos comunicacionales, lo que resulta un porcentaje considerable, más aún si se trata de las empresas con mayor aporte tributario. Estos objetivos pueden ser interpretados mediante el cumplimiento de planes estratégicos; ventas o utilidades, métricas de impacto en el sitio Web y redes sociales; métricas de audiencias en Web, etc.

Por lo tanto, para medir cualquier estrategia de comunicación, ésta debe estar en afinidad con los objetivos de la organización.

"Es importante que los objetivos de comunicación deban ser vistos de forma que siempre ayuden a la consecución de los objetivos generales de la organización. De esta manera, serán reconocidos como algo fundamental para el logro de la misión general dentro de la organización” (Rafael Moreno, 2014:(s/f)).

La mayoría de los planes de la organización se cubren durante un período de unos cinco años; la visión y estrategia debería trabajar en el mismo escenario. Un gran número de empresas señalan la importancia de integrar la comunicación en sus planes corporativos; por eso, ya no es extraño encontrar áreas en las organizaciones dedicadas a armonizar la comunicación con sus diferentes públicos. Aunque la responsabilidad de comunicar no recae sólo en un sector sino que es una labor de todo el equipo de trabajo de la organización, éste es un buen indicador para este desarrollo (Sandra Fuentes, (s/f)).

Hoy es necesario, dentro de las organizaciones, requerir de la ayuda del departamento de comunicación interna en la creación de estrategias para la empresa y éste se encarga de cubrir las necesidades comunicativas tanto a nivel interno como externo con el fin de transmitir una imagen positiva e influir en la opinión pública. La comunicación corporativa, para poder cumplir con sus objetivos se sirve de algunas áreas:

- Publicidad. 
- Imagen.

- Relaciones públicas.

- Patrocinio y mecenazgo.

- Marketing social corporativo.

- Diseño gráfico.

- Promoción.

- Merchandising.

- Comunicación digital.

- Comunicación organizacional.

- Marketing directo.

Son algunas de las áreas de gestión de la comunicación, por lo tanto, en la entrevista surgió la necesidad de consultar sobre la forma de asignación de montos en tres años, a través de la siguiente pregunta: "¿A qué área se le asignará mayor presupuesto?".

Los resultados sobre las diferentes percepciones que tienen los distintos gestores de la comunicación se observan en la siguiente figura.

Figura No 2. Áreas a las que se asignará mayor presupuesto

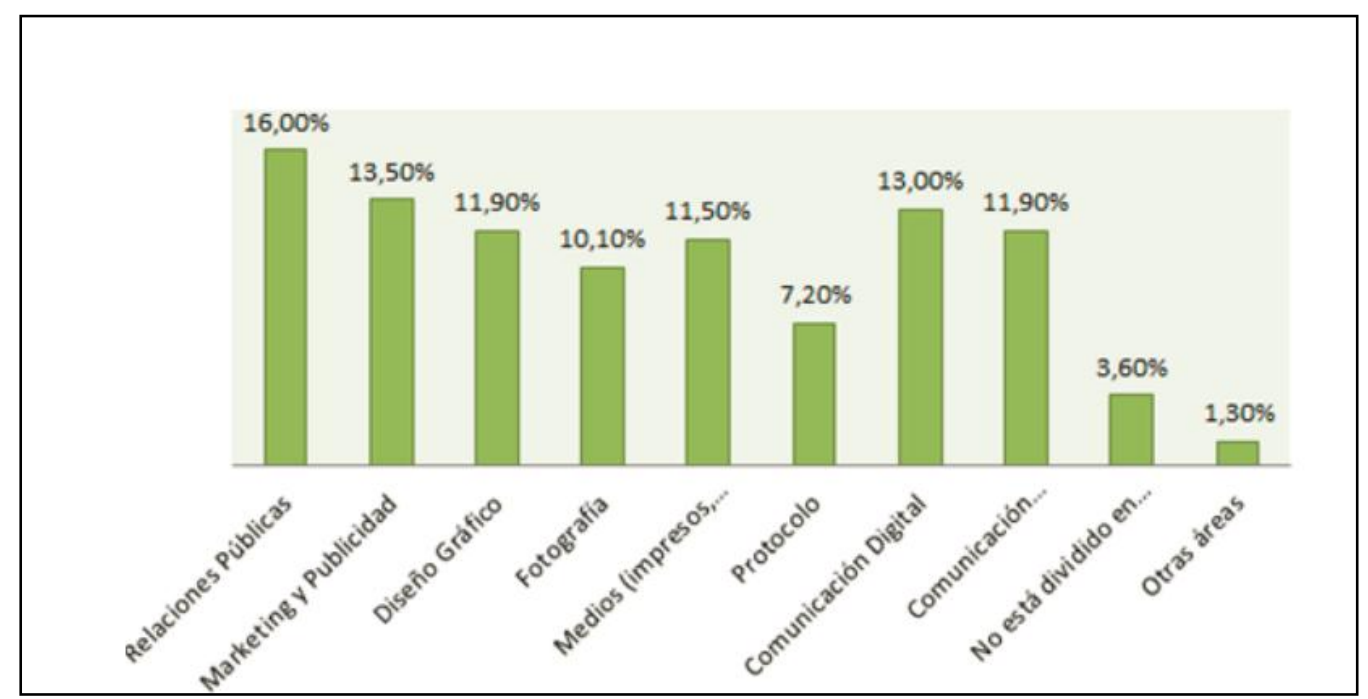

Fuente: Entrevista. Investigación realizada por el Observatorio de la Comunicación Estratégica en Ecuador

Se evidencia que la tendencia dentro del departamento de comunicación es asignar mayor presupuesto al área de Relaciones 
Públicas, seguido por las áreas de Marketing y Publicidad, Comunicación Digital y Comunicación Organizacional entre otros.

Además, dentro de las organizaciones, el papel de las Relaciones Públicas se encamina a la comunicación estratégica cuyo principal objetivo radica en fortalecer los vínculos con los distintos públicos o stakeholders, favoreciendo el cumplimiento de los objetivos institucionales marcados por la organización.

\section{Las agencias se constituyen en aliadas estratégicas para el Director de Comunicación}

Para conocer el uso de agencias en general se planteó a los gestores de la comunicación, a través de la encuesta, la siguiente pregunta: “ ¿La empresa en donde usted trabaja, gestiona algunas actividades de comunicación con una Agencia de: Publicidad, RR.PP, Comunicación, Investigación de Mercados, Marketing u otras?”.

Se destaca que las Agencias de Publicidad se han convertido en aliadas estratégicas del director de comunicación, ya que desde allí se canalizan las estrategias creativas en función de la experiencia de equipos especializados en diferentes áreas de la comunicación comercial, que en muchos casos no es posible tener dentro de una misma organización.

Según Santesmases (2012), la actividad propia de una Agencia de Publicidad se conoce como «above the line» en alusión a la comisión que una agencia recibe por la inserción en los medios convencionales o tradicionales: televisión, diarios, dominicales, revistas, radio, exterior, cine e Internet. Todo lo que no puede comisionar la agencia se denomina «below the line»: serían las técnicas alternativas o no convencionales. A todas estas actividades, los ejecutivos de las agencias les llaman acciones ATL «above the line» y BTL «below the line» y bajo estos acrónimos diferencian a los medios en el diseño de sus planes (Paladines, Valarezo y Yaguache, 2013: 110 -128). 
Figura No 3. Gestión de la comunicación con agencias

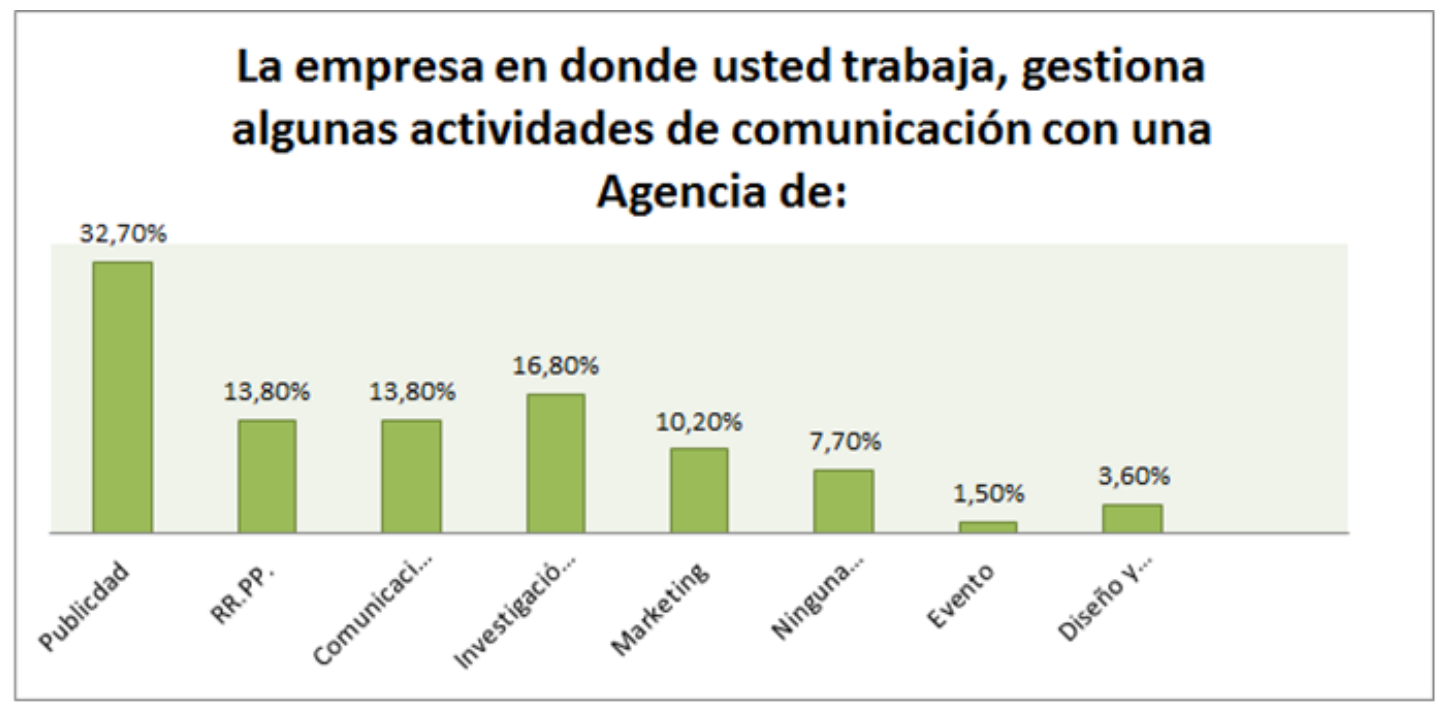

Fuente: Encuesta. Investigación realizada por el Observatorio de la Comunicación Estratégica en Ecuador

Sin duda alguna, las agencias han cambiado su patrón de trabajo; no sólo tienen que crear anuncios e ingresar pauta en medios: su función actual es atraer, motivar y comprometer a una audiencia específica sobre una marca y sobre ello deben lograr el mayor impacto, medir lo obtenido, aumentar las ventas y conseguir el ROI (retorno de la inversión).

"Siempre será indispensable monitorear el mercado para estar atento a sus tendencias para responder efectiva y oportunamente a sus necesidades. La publicidad es una herramienta sin la cual es imposible vender y sobre todo, mantener un adecuado manejo de relaciones públicas. Es fundamental para consolidar la sostenibilidad del negocio". Así lo sugiere Andrés Pérez Espinosa, Director de Relaciones Interinstitucionales de Pronaca.

Una realidad latente es que las empresas están al momento reduciendo su inversión en medios tradicionales para dar paso a los alternativos o no tradicionales. El reto ahora es encontrar la forma de llegar a los jóvenes que cada vez más se ingenian para bloquear los 
mensajes publicitarios tradicionales. Por lo tanto, la comunicación de marketing ya no se centra en llamar la atención sino en encontrar formas para atraer e interactuar con los consumidores (Baack, 2010: 4-5). Ante esta realidad, otro reto para las agencias es que "el involucrar a los medios digitales requiere adoptar nuevos pensamientos, equipos de trabajo, alianzas e incluso requiere aceptar un nuevo modelo económico por parte de las agencias" (Paladines, 2012: 260-261).

Otra de las agencias con mayor demanda es la de Investigación de Mercados por la valiosa información que proporciona a la empresa para la toma oportuna de decisiones. Por lo general, las acciones de relaciones públicas y de comunicación hasta el momento se las lleva desde la organización por el tipo de información que se maneja y por las relaciones que se mantiene con los públicos.

Era necesario conocer la opinión de los Dircom sobre lo que se espera en adelante; por lo tanto se consultó a través de la entrevista: "¿Seguirá siendo indispensable para las empresas trabajar con agencias de publicidad, RR.PP, marketing, investigación de mercados, etc.?”.

Figura No 4. Seguirá siendo indispensable trabajar con agencias.

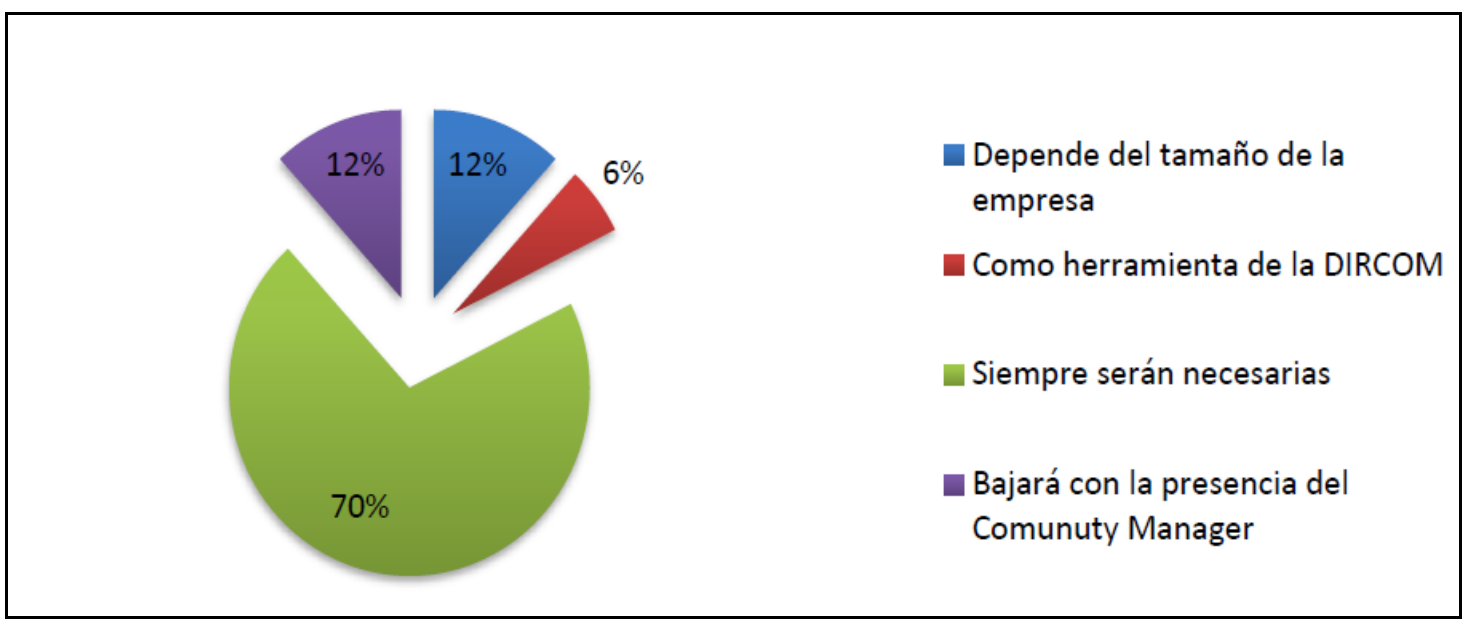

Fuente: Entrevista. Investigación realizada por el Observatorio de la Comunicación Estratégica en Ecuador

Las empresas, dependiendo de su tamaño, siempre van a requerir los servicios de las agencias -sobre todo las de publicidad- para promover sus productos, servicios, eventos y causas. Su objetivo es 
crear campañas memorables que produzcan el máximo de ventas y visibilidad.

Llama la atención que un $12 \%$ de los Dircom señalan que el requerimiento de los servicios de una agencia disminuirá con la presencia del Community Manager, lo que se puede interpretar como una alerta por la creciente tendencia a la comunicación digital. Sobre todo por las agencias de relaciones públicas y comunicación.

\section{Los gestores de comunicación tienden a medir los resultados de sus estrategias de comunicación en sitios Web, redes sociales, etc.}

La "revolución digital" constituye un conjunto de tecnologías cuyas aplicaciones abren un amplio abanico de posibilidades a la comunicación humana.

"En los países más desarrollados, está demostrado que la intensidad en la aplicación de nuevas tecnologías y la incorporación de un Sitio Web está correlacionado de manera positiva con el incremento de las ventas, la productividad y el valor de mercado de las empresas. No importa el tamaño de la empresa; es de suma importancia el poder alcanzar a sus clientes de una manera masiva y sencilla para ellos. Nada mejor para eso que la propia Internet. Si bien es cierto que existen muchas redes sociales en las que te puedes anunciar de forma gratuita $\mathrm{O}$ pagada, el tener un Sitio Web eleva el prestigio propio de la empresa y permite a tus clientes incrementar el nivel de confianza hacia tu producto o servicio. Las redes sociales muestran resultados aleatorios que no siempre van de la mano con el comportamiento del consumidor final, por lo tanto no se puede medir el impacto real del estudio" (García, García \& Sevilla, 2015).

Esta era tecnológica no sólo ha favorecido la calidad de los servicios, sino en un aumento espectacular de los mismos. Así, la implementación de estas nuevas tecnologías se está manifestando 
sobre lo que se ha llamado sociedad industrial, dando lugar a lo que actualmente conocemos como sociedad de la información o del conocimiento (Franco, 2005).

En la aplicación de estrategias digitales, los sistemas de medición se multiplican. Dependiendo de los propósitos de cada organización, se definen y determinan las herramientas adecuadas que permitan obtener la métrica necesaria para cada una. Por lo tanto, se consultó a los gestores de la comunicación: “¿Cómo mide usted los resultados en la aplicación de estrategias de comunicación?”.

\section{Figura No 5. Medición de resultados}

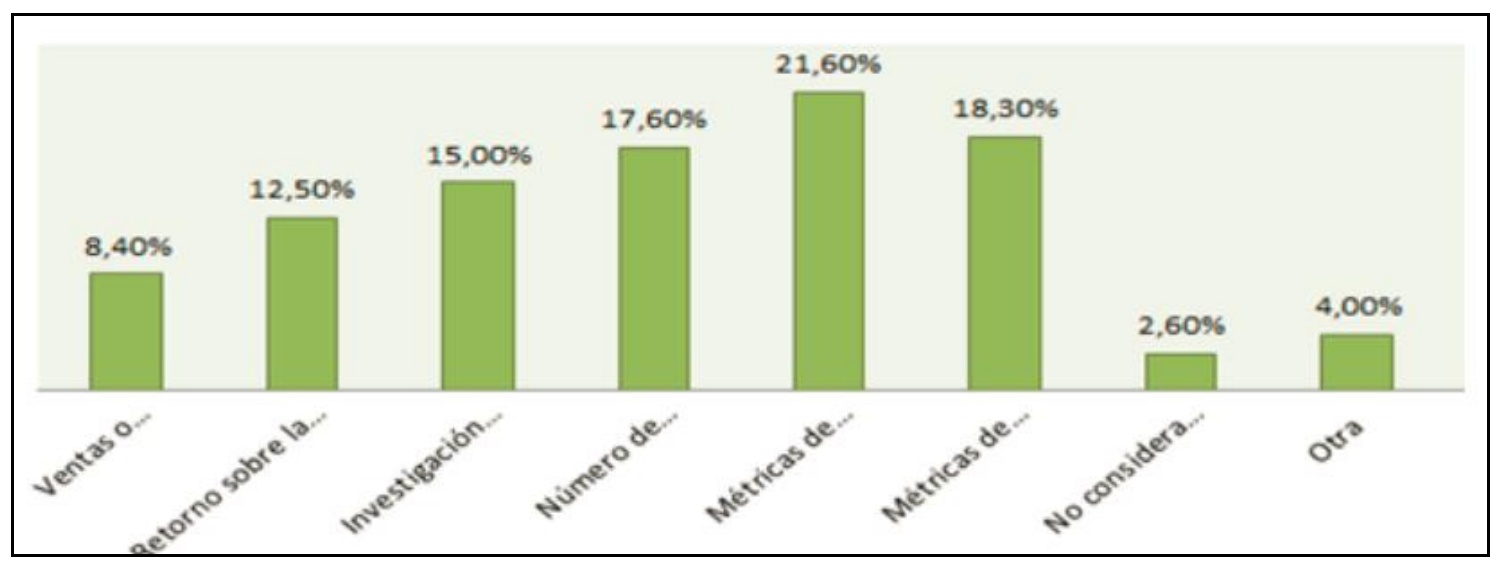

Fuente: Encuesta. Investigación realizada por el Observatorio de la Comunicación Estratégica en Ecuador

Es importante señalar que la pregunta fue planteada en forma general para conocer los sistemas de medición de la comunicación offline y online. Sin embargo, las respuestas se enmarcan en lo digital; el 22\% utiliza las métricas de impacto en el sitio Web y redes sociales (followers, fans, me gusta); el 18\% menciona a las métricas de audiencia en Web (número de visitas, tiempo de permanencia en el sitio Web) y, así mismo, un 18\%, por número de impactos -que también se utiliza para medir medios tradicionales. Estos resultados llevan a suponer que los gestores priorizan las métricas de medición en la comunicación digital, posiblemente porque resulta más sencillo, ya que sólo un 15\% hace referencia a la aplicación sobre impacto publicitario, seguido por un 13\% que hace hincapié en el retorno sobre la inversión (relación costo/beneficio), que son formas de medir en la comunicación offline. 
El monitoreo proporciona la información necesaria para evaluar la marcha del programa permitiendo realizar ajustes durante la ejecución del mismo. Es así que, tanto el monitoreo como la evaluación en base a los resultados son funciones de gestión indispensables que ayudan a fortalecer la planificación de los programas y mejorar la efectividad de las acciones e inversiones.

Una vez que se conocieron las formas de medición que al momento se estaban aplicando en las estrategias de comunicación, se planteó otro interrogante a los Dircom sobre los sistemas de medición que serán aplicados a tres años: “QQué sistemas de medición cree que se impondrán para valorar las acciones e inversiones de la comunicación estratégica?".

Todos los directores enfatizaron la importancia de la medición y ya que los recursos actualmente son limitados, es necesaria su optimización.

A continuación se exponen algunos criterios de los Dircom:

\section{Figura No 6. Sistemas de medición}

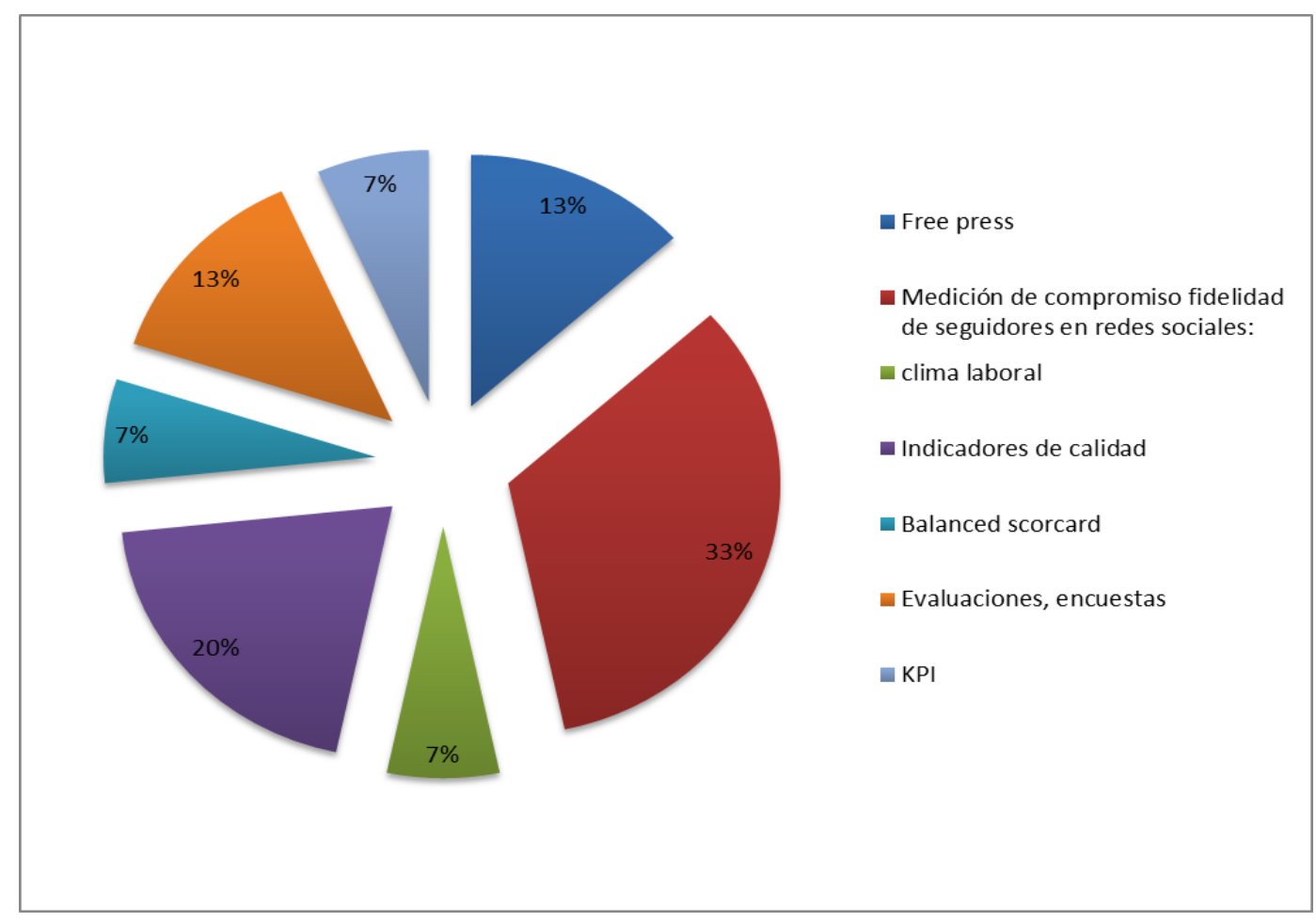

Fuente: Entrevista. Investigación realizada por el Observatorio de la Comunicación Estratégica en Ecuador 
Los resultados denotan mayor preponderancia de la fidelidad de seguidores en redes sociales que coincide con lo señalado por los gestores. Un 20\% para indicadores de calidad e iguales porcentajes para evaluaciones/encuestas (13\%) y free press (13\%). El uso de los KPI, Balanced Scorecard y Free Press son sistemas de medición de gran relevancia para este grupo de entrevistados.

Antes de la medición de resultados se tienen que considerar y conocer en detalle los objetivos propuestos por el Dircom, así como las actividades que conduzcan a la consecución de los mismos. Además, quien ejerce la función de la comunicación debe aplicar, accionar y evaluar las relaciones con los públicos de forma vinculada a la misión y a los objetivos de la organización, observando e interactuando en todo momento con los distintos entornos existentes: económico, político, cultural, social y medioambiental (Álvarez Nobel, 2011).

"Para empezar, creo que toda acción de comunicación debe de ser evaluada y medida. Hay que ir más allá de un Free Press, la parte cualitativa y el análisis de las acciones que se implemente, el verdadero reto es la medición de nuestra actividad en función al valor que le otorga a nuestra organización. Esto es una gestión tanto interna como externa, como lo indica Sylvia Banda, Gerente de Asuntos Corporativos del Grupo DIFARE”.

Al tener cada organización objetivos distintos, sus criterios de medición serán personalizados y a la medida de lo que se busca. Para unas, la prioridad será el número de impactos mientras que para otras podría ser el incremento de su comunidad de followers o seguidores.

Para poder validar la información de Ecuador se necesitó reforzar este tema y a la vez tener un conocimiento sobre los métodos de medición utilizados al momento en otros países, por lo que fue indispensable aplicar la técnica Delphi a académicos en una primera fase.

Tras aplicar la técnica mencionada los resultados se detallan en el siguiente punto: 
Según los expertos académicos, el uso de sistemas de medición es similar al que utilizan los responsables de la comunicación en Ecuador. Las respuestas se centran en el impacto en las redes sociales y por la audiencia Web. Luego señalan impacto en medios de comunicación y retorno de la inversión -que sería la medición en medios offline-.

En una segunda ronda de consulta a los académicos, se plantearon preguntas, abiertas en su mayoría, sobre todo en los temas que requerían mayor profundización.

Tabla No 1: Medición de estrategias.

\begin{tabular}{|l|l|l|}
\hline \multicolumn{2}{|l|}{ MÉTODOS UTILIZADOS } \\
\hline Ventas o utilidades & 4 & $31 \%$ \\
\hline Retorno sobre la inversión (relación costo/beneficio) & 5 & $38 \%$ \\
\hline Impacto publicitario & 1 & $8 \%$ \\
\hline Impactos en medios de comunicación & 5 & $38 \%$ \\
\hline Impacto en redes sociales (followers, fans, me gusta, usuarios) & 7 & $54 \%$ \\
\hline $\begin{array}{l}\text { Audiencia en web } \\
\text { (número de visitas, tiempo de permanencia en sitio web) }\end{array}$ & 7 & $54 \%$ \\
\hline No considera importante medir y evaluar & 0 & $0 \%$ \\
\hline Otro & 4 & $31 \%$ \\
\hline
\end{tabular}

Fuente: Delphi (primera fase). Investigación realizada por el Observatorio de la Comunicación Estratégica en Ecuador

Algunos de los expertos internacionales hacen referencia al uso de métodos cualitativos y cuantitativos con técnicas tales como: entrevistas de profundidad, seguimiento de medios convencionales y no convencionales, social media, foros de discusión, focus group, cuestionarios abiertos, auditorías de comunicación, encuestas, entre los principales. También surgen ideas más avanzadas de otros especialistas que consideran la implementación de técnicas diseñadas según la organización.

"Los principios, políticas, objetivos y estrategias definidas por la organización definen los métodos de medición. Se pueden aplicar o adaptar técnicas como "La estrella de lux", "La 
telaraña", "método soccipo" o procesos y técnicas diseñadas en la organización según el contexto en el que está inmersa. En este sentido, pueden utilizarse los instrumentos de investigación cualitativa y cuantitativa diseñados para evaluar la gestión en comunicación y de relacionamiento: encuestas, grupos de discusión, entrevistas individuales, sondeos, laboratorios comunicacionales". Lo afirma Ana María Suárez, docente de la Universidad de Medellín (Colombia).

A modo de conclusión se puede afirmar que pese a la fuerte inversión por parte de grandes marcas, agencias de publicidad, marketing, investigación de mercados o relaciones públicas, aún no se ha logrado establecer una unidad de medición estándar y efectiva tanto para lo offline como para lo online.

\section{La Ley Orgánica de Comunicación (LOC) da paso a la producción nacional y al talento creativo}

En el mes de junio del año 2013, después de más de cuatro años de debates, fue aprobada por la Asamblea Nacional del Ecuador la Ley Orgánica de Comunicación. En lo referente a la actividad publicitaria, la nueva Ley establece que la interrelación comercial entre los anunciantes, agencias de publicidad, medios de comunicación social y demás actores de la gestión publicitaria se regulará según lo indica el Art.- $92^{11}$.

11

"La interrelación comercial entre los anunciantes, agencias de publicidad, medios de comunicación social y demás actores de la gestión publicitaria se regulará a través de esta ley, que establece parámetros de equidad, respeto y responsabilidad social, así como evitar formas de control monopólico u oligopólico del mercado publicitario”. Disponible en:

http://www.ecuavisa.com/articulo/noticias/actualidad/51519-publicistaanaliza-impacto-comerciales-reglamento-ley [consultado 9/04/2015]. 
Entre las principales normas establecidas, se señalan:

- La creatividad publicitaria será reconocida y protegida por los derechos de autor previstos en la Ley de Propiedad Intelectual.

- Los actores de la gestión publicitaria serán los responsables de la creación, realización y difusión de los productos publicitarios.

- La extensión de la publicidad, "tiempo" en los medios de comunicación, se determinará reglamentariamente por el Consejo de Regulación y Desarrollo de la Información y Comunicación.

- La publicidad y propaganda respetarán los derechos garantizados por la Constitución y los tratados internacionales, donde se prohíbe la publicidad engañosa así como todo tipo de publicidad o propaganda de pornografía infantil, bebidas alcohólicas, cigarrillos y sustancias estupefacientes y psicotrópicas.

- Los medios de comunicación no podrán publicitar productos cuyo uso regular o recurrente produzca afectaciones a la salud de las personas; por lo tanto, la publicidad destinada a productos de alimentación y salud deberá tener la autorización previa del Ministerio de Salud.

- La publicidad que se curse en los programas infantiles será debidamente calificada por el Consejo de Regulación y Desarrollo de la Información y Comunicación a través del respectivo reglamento.

- El Superintendente de la Información y Comunicación dispondrá la suspensión de la publicidad que circule a través de los medios de comunicación cuando ésta viole las prohibiciones establecidas en este artículo o induzca a la violencia, discriminación, racismo, toxicomanía, sexismo, intolerancia religiosa o política y toda aquella que atente contra los derechos reconocidos en la Constitución. Esta medida puede ser revocada por el mismo Superintendente o por juez competente, en las condiciones que determina la ley.

- En cuanto a la inversión pública en publicidad y propaganda. Las entidades públicas que contraten estos servicios en los medios de comunicación social se guiarán según criterios de igualdad; de oportunidades con atención al objeto de la comunicación; el público objetivo; a la jurisdicción territorial de 
la entidad y a los niveles de audiencia y sintonía. Anualmente se elaborará un informe de distribución del gasto de la publicidad contratado por cada medio de comunicación. Este informe debe ir colocado en la página web de cada institución. El incumplimiento de esta obligación por parte del titular de cada institución pública será sancionado por la Superintendencia de la Información y la Comunicación, equivalente al 35\% del total de la remuneración mensual de este funcionario. Dicho informe será publicado en el plazo de treinta días y de no ser así, será causal de destitución del titular de la institución.

- En cuanto a la inversión en publicidad privada.

Al menos el 10\% del presupuesto anual destinado por los anunciantes privados para publicidad de productos, servicios o bienes que se oferten a nivel nacional en los medios de comunicación se invertirá en medios de comunicación de cobertura local o regional. Lo cual garantizará que los medios de menor cobertura o tiraje participen de la publicidad. Este 10\% de los anunciantes será distribuido en forma equitativa por el Consejo de Regulación y Desarrollo de la Información y Comunicación.

- Dentro de la producción de publicidad nacional, la ley obliga también a las agencias de publicidad y productoras a generar piezas de alta calidad; por ejemplo, producción en HD, ya que entran a competir y a remplazar a productoras y clientes internacionales y por lo tanto, hay un incremento de cuentas $y / o$ contratos.

Para conocer si se está cumpliendo con el reglamento establecido, se preguntó a los Dircom: "¿La Ley Orgánica de Comunicación de Ecuador contribuye o afecta a la gestión de la comunicación en aspectos como producción, contratación del personal, etc.?”.

Se destacan algunas de las ideas extraídas de sus respuestas:

"La Ley Orgánica de Comunicación ha establecido un marco adecuado dentro del cual todas las empresas relacionadas a temas comunicacionales deben desenvolverse, lo cual ha creado buenas oportunidades para establecer sinergias y desarrollar la creatividad para alcanzar con nuestros mensajes de manera efectiva a nuestros públicos objetivos". Así lo menciona Hugo Orellana Páez, Director 
de Desarrollo Sostenible \& Comunicaciones Externas de Cervecería Nacional.

La LOC busca regular los contenidos dentro de los espacios radiales y audiovisuales e incrementar la producción nacional para que tenga el mismo espacio que la producción internacional. Dentro de la LOC, en el apartado que hace referencia a la publicidad, menciona que la nómina de personas para su realización y producción debe constituirla al menos un $80 \%$ de personas con nacionalidad ecuatoriana o extranjeros radicados en el país.

Sin embargo, la Ley también ha generado diferentes criterios:

Dentro de las regulaciones y obligaciones: "La Ley Orgánica de Comunicaciones tiene los dos aspectos involucrados: una contribución en términos de regulación dentro de las actividades de comunicación y una afectación negativa en cuanto a obligaciones que riñen con los objetivos de creatividad e independencia”. Lo señala Juan Cárdenas, Gerente de Ventas y Mercadeo de la Cadena Hotelera Sheraton.

Para el responsable de comunicación del Banco Pichincha, la mayor institución financiera de la Nación: "Esta ley ayuda a que los productos creativos marquen una identidad ecuatoriana", en referencia a que las campañas de empresas multinacionales deben hacer una adaptación de sus piezas publicitarias para el país, y este trabajo se hace con personal -modelos, guionistas, voces, editoresecuatoriano. "Los mismos anuncios que una empresa hacía para varios países, hoy tiene que hacerlo con equipo nacional", indica finalmente.

Esta ley obliga también a las agencias de publicidad y productoras a generar piezas de alta calidad - por ejemplo producción en HD- ya que entran a competir y a reemplazar a productoras y clientes internacionales y por lo tanto, hay un incremento de cuentas y/o contratos. "Se prohíbe la importación de piezas publicitarias producidas fuera del país por empresas extranjeras" (Ley de Comunicación, Art. 98).

"Para empresas regionales y/o nacionales es un modelo nuevo e interesante que obliga a todos los que estamos en el medio a 
aprender y profesionalizarnos en el tema para ser más competitivos, pero donde no contribuye es en el costo de las piezas ya que al ser producidas para un solo país, resultan demasiado costosas". Así lo afirma Rodolfo Perez Andrade, Director de Comunicaciones de Yanbal Ecuador.

Así como para la publicidad, la ley tiene también implicaciones para otras áreas de la comunicación corporativa como las relaciones públicas, pues se requiere de un trabajo especial para ubicar estratégicamente la noticia corporativa en medios de comunicación, de tal manera que no caiga en la denominada "censura previa". Para la Dircom de la Universidad Técnica Particular de Loja, "La ley en el ejercicio de la comunicación organizacional no es explícita como en el campo de medios de comunicación".

\section{La LOC ha influido en el cambio de estrategias internas de las agencias de publicidad}

Para la gerente de Asuntos Corporativos del Grupo DIFARE, una de las tres mayores importadoras y distribuidoras de productos farmacéuticos, la ley "contribuye en algunos campos. Está bien que se realice más producción nacional y que se hagan en Ecuador en lugar de otros países de la región. Sin embargo, si eso no contribuye a elevar el nivel de creatividad y producción, no habrá tenido sentido".

Por lo tanto, el cambio de estrategias internas de las agencias está enfocado también a la capacitación del personal en temas de marketing, creatividad, nuevos modelos de negocio, etc., que con seguridad aportarán a la eficiencia y efectividad de la comunicación estratégica.

En Ecuador los creativos publicitarios se encuentran frente a marcas importantes. La cultura publicitaria empieza a tomar forma y busca estar a la par con los grandes. Los creativos ecuatorianos consideran que para que haya un crecimiento de la industria publicitaria hay que ser más arriesgados.

"Creo que se ha avanzado bastante en pocos años pero no estamos al nivel de otros países; somos partícipes de tantos 
cambios culturales y tecnológicos pero los anunciantes no se arriesgan; llegan a ser muy pocos los atrevidos y es necesario el cambio de paradigmas en las agencias y en sus clientes". Andrés Landívar, Director de Arte de Maruri Grey (Citado por Edgar Salas, 2014).

Existen muchas iniciativas de los creativos reconocidas a nivel mundial. "Un claro ejemplo de ello es la Agencia Maruri Grey que en el 2014 se llevó a casa nueve leones en el Festival de Cannes Lion, confirmando su liderazgo como la mejor agencia de publicidad en el país" (Salas, 2014).

Dentro de las agencias de publicidad: ¿Qué herramientas son claves para que una agencia tenga éxito en la actualidad? "Lo fundamental es la parte digital. Pero ahora también se deben tener en cuenta otros puntos como el 'Shopper Marketing', que estudia el proceso de compra de un producto en una tienda o supermercado. Otro aspecto es el 'Big Data', que nos da información sobre el cliente" (Sebastián Angulo, 2013).

\section{Referencias bibliográficas}

Álvarez, N. (2011). Medición y Evaluación en Comunicación. Málaga, España: Instituto de Investigación en Relaciones Públicas (IIRP).

Angulo, S. (2013). Marcos Golfari: "La Ley de Comunicación tiene dos caras para la publicidad". Lideres. Disponible en: http://www.revistalideres.ec/lideres/marcos-golfari-leycomunicacion-caras.html. [Consultado 7/04/2015].

Baack, C. (2010). Publicidad, promoción y comunicación integral en marketing. (4 ed.). México: Pearson Educación.

Cultura (2014,06, 17). "La Ley Orgánica de Comunicación dinamiza el trabajo de las productoras locales (Infografía y Documento)". El Telégrafo. Recuperado de: http://www.telegrafo.com.ec/cultura/medios/item/la-leyorganica-de-comunicacion-dinamiza-el-trabajo-de-las- 
productoras-locales-infografia-y-documento.html. [Consultado 7/04/2015].

Ecuavisa (2014). "Publicista analiza impacto a comerciales con reglamento a Ley de Comunicación. Ecuavisa". Disponible en: http://www.ecuavisa.com/articulo/noticias/actualidad/51519publicista-analiza-impacto-comerciales-reglamento-ley [Consultado 9/04/2015].

Fuentes, S. (s/f). "Asociación Latinoamericana de Investigación de la Comunicación. La comunicación, eje estratégico de las organizaciones". Disponible en:

http://www.eca.usp.br/associa/alaic/boletin11/congreso com unicacion organizacional.htm [consultado 20/04/2015].

García, García \& Sevilla. (2015). "Smack Blog Mantente siempre informado. ¿Por qué es tan importante tener un sitio Web hoy en día?" Disponible en:

http://smackwagonnicaragua.com/porque-es-tan-importantetener-una-pagina-web-hoy-en-dia/htm [consultado 26/05/2015].

Jensen, K. y Jankowski, N. (1993): Metodologías cualitativas de investigación en comunicación de masas. Barcelona: Bosch.

Moreno, R. (2014). "Marketing Digital, People Analytics, Algo de Psicología + Neuromarketing y curiosidad por un tubo. Cómo desarrollar una estrategia de comunicación en 8 pasos".

Disponible en: http://www.benitezrafa.es/como-desarrollaruna-estrategia-de-comunicacion-en-8-pasos $/ \mathrm{htm}$ [consultado 20/04/2015].

Paladines, F. (2012). Tesis. Gestión de la comunicación de la marca en las redes sociales: Estudio de tres casos de campañas con Facebook en Ecuador. Santiago de Compostela, España. Universidad Santiago de Compostela, Facultad de Ciencias de la Comunicación.

Paladines, F., Valarezo, K. \& Yaguache, J. (2013). "La comunicación integral, un factor determinante en la gestión de la empresa ecuatoriana”. Signo y Pensamiento, 32 (63), 110-128. 
Santesmases, M. (2012). Marketing, conceptos y estrategias. (6 $\left.6^{a} \mathrm{ed}.\right)$. Madrid: Pirámide (Grupo Anaya. S.A.). 


\title{
YII \\ El futuro de la gestión del Dircom: habilidades y retos
}

Cesibel Valdiviezo. Universidad Técnica Particular de Loja, Ecuador Karina Valarezo. Universidad Técnica Particular de Loja, Ecuador, y Johanna Córdova. Universidad Técnica Particular de Loja, Ecuador

\section{La posición del Dircom en la empresa deberá ser a nivel directivo y gerencial, con total potestad para la toma de decisiones}

\begin{abstract}
A CTUALMENTE las organizaciones, independientemente de su 1 tamaño, requieren de expertos de la comunicación dentro de su estructura organizacional que les permitan gestionar valores intangibles. Es imposible prescindir de un departamento de comunicación porque es estratégico a nivel interno y externo y debe involucrarse en todos los niveles. La comunicación se constituye en el corazón de la organización.

La ubicación del área de comunicación en una institución también es estratégica junto al máximo ejecutivo o representante de la organización. Casado Molina, Méndiz Noguero y Peláez Sánchez (Molina, Noguero y Sánchez, 2013: 54), afirman que "las grandes corporaciones ponen departamentos de comunicación al nivel
\end{abstract}


gerencial más alto para evitar la dispersión y permitir la coordinación de los mensajes corporativos".

Mora afirma que la localización del departamento de comunicación en el organigrama refleja en cierto modo la importancia que la empresa concede a la comunicación pero por otra parte, no solo depende de la estructura sino de diversas circunstancias como el flujo de la información, la red de relaciones significativas, los procesos reales que conducen a las decisiones (Mora, 2009: 72).

Considerando su ubicación estratégica dentro de la organización, el Dircom cuenta con potestad para influir en la toma de decisiones organizacionales ya que es quien tiene las habilidades para llegar a los públicos a los que se debe la organización. Es quien dirige los procesos de visibilización de la organización y maneja las estrategias comunicacionales para entablar vínculos sociales y productivos. La gestión comunicacional bien planificada permite prevenir crisis y atender situaciones emergentes de manera clara, oportuna y responsable con sus públicos.

$\mathrm{Al}$ consultar a los diferentes académicos nacionales e internacionales en temas de comunicación estratégica, a través de la técnica Delphi, sobre "¿Qué posición deben ocupar los responsables de Comunicación dentro de la estructura de las organizaciones?", señalan en un $92 \%$ que se encuentra junto a la alta dirección de la empresa (con el Gerente, Director, Rector, Presidente...) y el 8\% restante cree que el Director de Comunicación debe formar parte de una Dirección de nivel medio.

La respuesta de los Dircom ecuatorianos a través de la entrevista, revelan datos similares: el 93\% considera que el responsable de la comunicación debe depender directamente de la alta dirección.

“Al ser el Dircom el máximo responsable del diseño y de la gestión del plan estratégico de la Comunicación en la organización, su posición debe estar considerada dentro del esquema de alta dirección, con reporte directo al CEO”. Así lo señala Sylvia Banda, de DIFARE. 
Estos datos permiten afirmar que la posición de los directores de comunicación en las estructuras de las organizaciones debe ubicarse a nivel directivo y gerencial, permitiéndoles así tomar el papel de asesores directos de la alta dirección.

En la segunda fase de la aplicación de la técnica Delphi, se consultó al grupo de académicos: “¿Cómo considera usted que debería el Dircom contribuir en la toma de decisiones organizacionales?" Ana Almansa, académica de la Universidad de Málaga (España) asevera: "Debe formar parte del equipo directivo de la organización”. En esta posición se encuentra el 100\% de los académicos consultados.

Ana María Suárez, académica de la Universidad de Medellín (Colombia), afirma que el Dircom debe estar "orientando al cuerpo directivo sobre las relaciones equilibradas con sus públicos como una decisión estratégica para lograr reputación favorable y consolidada; bajo este principio, definir con el cuerpo directivo políticas de actuación en comunicación e interacción que sean la base de ese relacionamiento; establecer la gestión comunicacional y relacional planificada para prevenir crisis y atender situaciones emergentes de manera clara, oportuna y responsable con sus públicos y definir mecanismos de seguimiento, evaluación y corrección de lo planificado".

\section{Para el Dircom, la comunicación interna será la principal línea y campo de acción}

De la entrevista aplicada a 15 directores de Comunicación de diferentes empresas y organizaciones de Ecuador, en la que se les consultó: “¿Cuáles considera usted que serían las principales líneas y campos de acción que consolidarán el trabajo del Dircom?", se destaca como principal la gestión de la comunicación interna en un $66,7 \%$ y la comunicación externa con el 53,3\%. El $40 \%$ le corresponde al Marketing, que se considera un factor fundamental en el proceso de comunicación.

En la siguiente gráfica se pueden conocer otros elementos que se constituyen en fundamentales a la hora de gestionar la comunicación. 
Figura No 7. Líneas y campos de acción que consolidarán el trabajo del Dircom

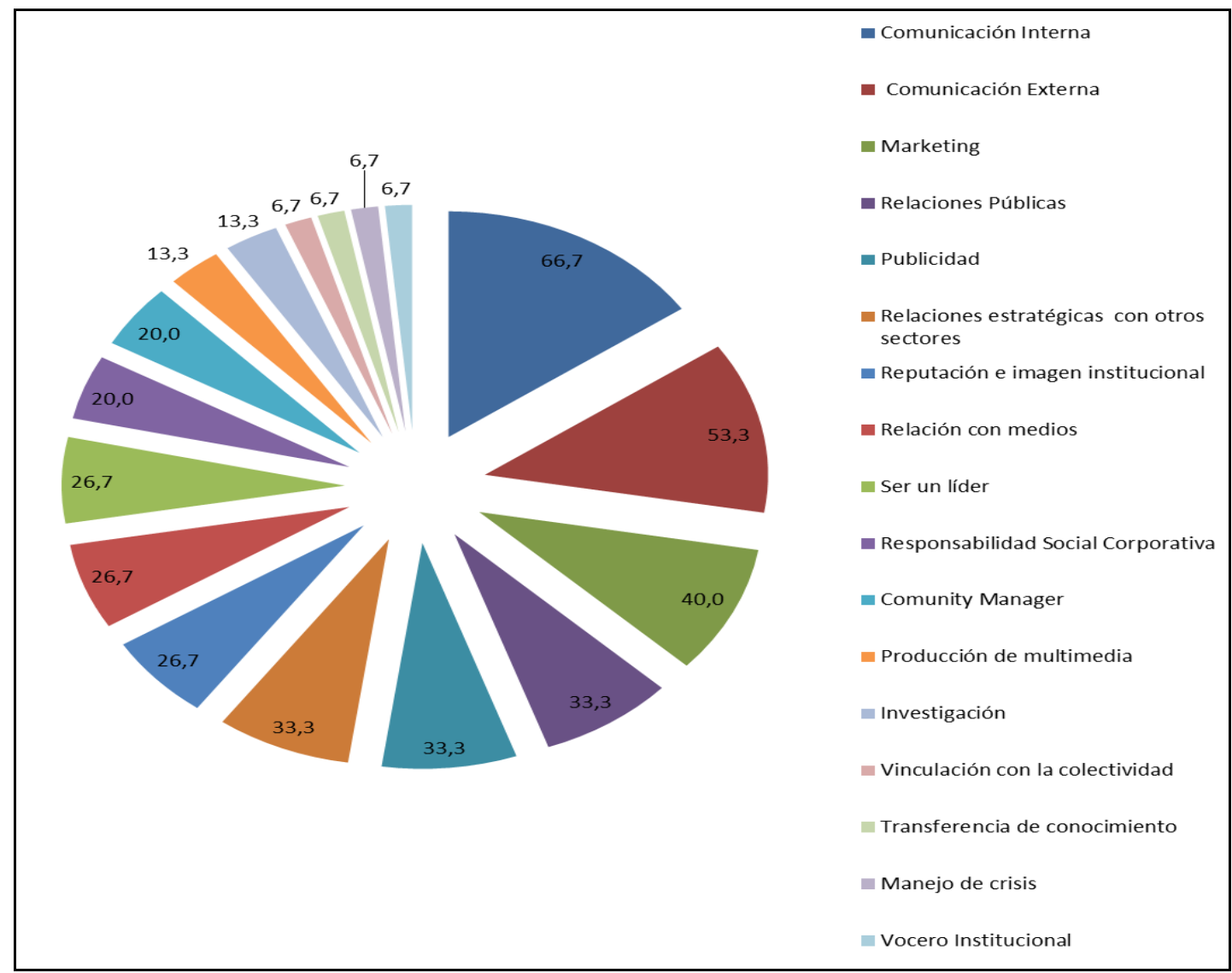

Fuente: Entrevista. Investigación realizada por el Observatorio de la Comunicación Estratégica en Ecuador

\section{E1 Dircom deberá tener habilidad en el liderazgo; aumentar su función estratégica en la toma de decisiones y tener destrezas comunicacionales en todas sus derivaciones}

Las habilidades que debe poseer el responsable de comunicación no sólo se enmarcan es aspectos profesionales, pues existen habilidades claves como el ser empático; tener una visión crítica y estratégica; ser accesible; mostrarse como una persona creíble; ser un buen negociador $y$, especialmente, ser líder en los procesos comunicacionales. Estos y otros elementos son primordiales al momento de ejercer la profesión en las organizaciones. 
El Dircom debe poseer una visión integral que aborde publicidad, relaciones públicas, marketing, mass media, manejo de formatos y herramientas online, branding e imagen corporativa y conocer el entorno económico, político y social entre otros.

En la primera fase del Delphi, cuando se les preguntó a los académicos nacionales e internacionales: "¿Qué habilidades y conocimientos debería tener el Dircom para su desempeño profesional?”, se registró un 46\% como máximo valor, a favor de tener destreza para aumentar su función estratégica como apoyo en la toma de decisiones. Luego, con el 23\%, cuatro ítems: habilidad para controlar los medios digitales; gestionar las crisis online; incorporar al modelo de gestión la responsabilidad social y el desarrollo sostenible y fortalecer las redes de profesionales. Manejar la micro comunicación sobre la comunicación de masas; concertar la velocidad y el volumen del flujo de información y conciliar la necesidad de abordar más audiencias y canales con recursos llegaron cada una al 15\%.

Tabla No 2. Medición de estrategias

\begin{tabular}{|lll|}
\hline Aumentar su función estratégica como apoyo en la toma de decisiones & $\mathbf{6}$ & $46 \%$ \\
Controlar los medios digitales & $\mathbf{3}$ & $23 \%$ \\
Gestionar las crisis online & $\mathbf{3}$ & $23 \%$ \\
Manejar la microcomunicación sobre la comunicación de masas & $\mathbf{2}$ & $15 \%$ \\
Concertar la velocidad y el volumen del flujo de información & $\mathbf{2}$ & $15 \%$ \\
Conciliar la necesidad de abordar más audiencias y canales con recursos & $\mathbf{2}$ & $15 \%$ \\
Incorporar al modelo de gestión la responsabilidad social y el desarrollo sostenible & $\mathbf{3}$ & $23 \%$ \\
Fortalecer redes profesionales & $\mathbf{3}$ & $23 \%$ \\
Otro & $\mathbf{2}$ & $15 \%$ \\
& & \\
\hline
\end{tabular}

Fuente: Delphi (primera fase). Investigación realizada por el Observatorio de la Comunicación Estratégica en Ecuador

$\mathrm{Al}$ establecer una comparación, se podría decir que los académicos enfatizan más en lo digital, mientras que los Directores de Comunicación del Ecuador les suman otras habilidades como creatividad, manejo de relaciones interpersonales, entre otras. 
Figura No 8. Habilidades y conocimientos que debería tener un Dircom

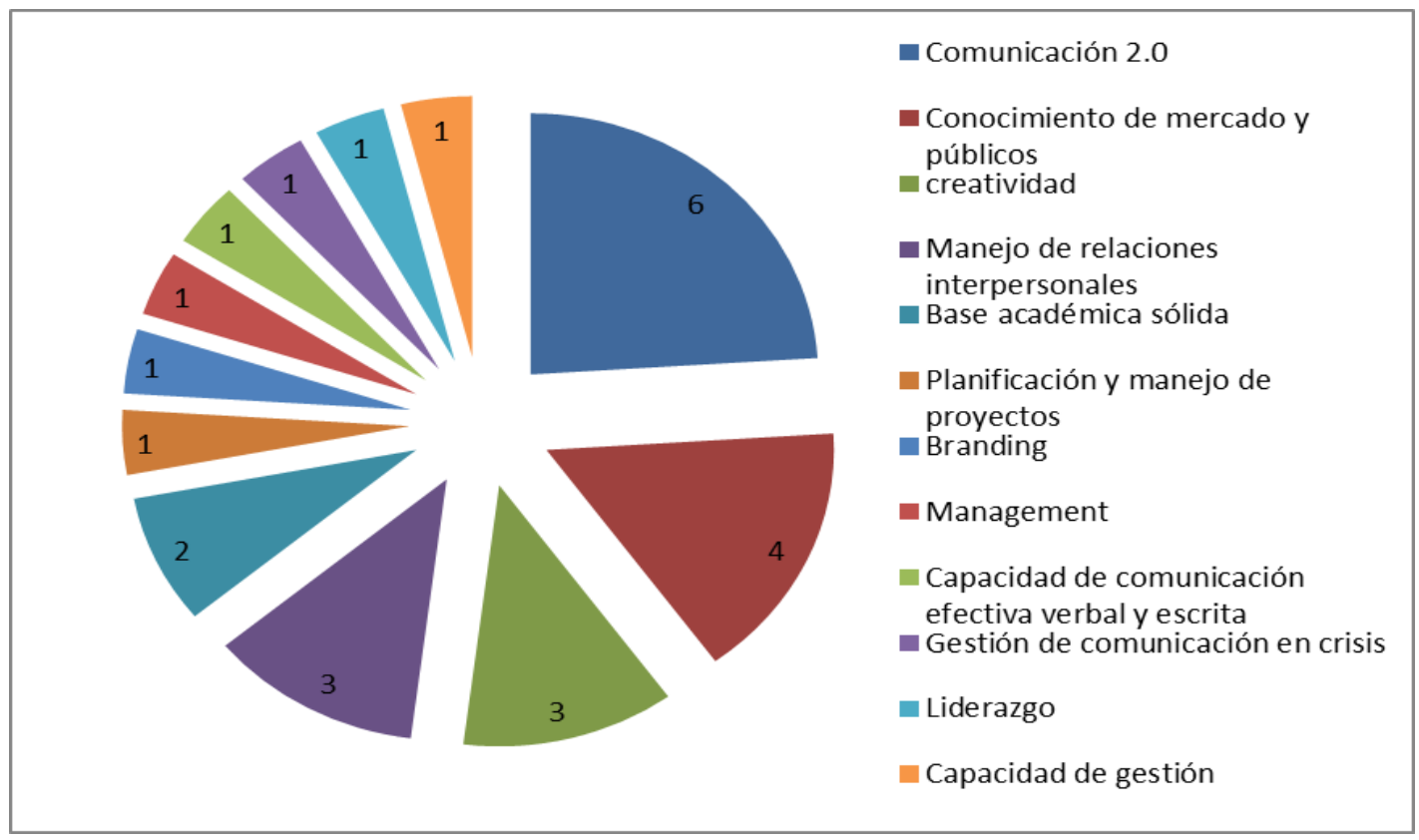

Fuente: Entrevista. Investigación realizada por el Observatorio de la Comunicación Estratégica en Ecuador

\section{4. ¿Un fuerte reto que tendrá el Dircom es coordinar todas las iniciativas de comunicación, incluidas las de marketing y publicidad en la organización?}

Para dar respuesta a este interrogante se aplicó a través de la entrevista la pregunta: "¿A qué nuevos retos y problemas deberá enfrentarse el Dircom (cómo será su relación con el departamento de Marketing/Publicidad y cómo se definirán las funciones de la comunicación interna respecto a su dependencia de RR.HH)?”

A ello que respondieron 15 responsables de comunicación, es decir, el total de participantes. Los Directores de Comunicación entrevistados creen que desde la Dirección de Comunicación se debe coordinar e integrar todas las acciones e iniciativas de comunicación. Además, expresaron que Marketing y Publicidad se deben integrar a la dinámica de la Dirección de Comunicación porque desde esta área se trabaja directamente en la imagen y reputación de la institución. 


\section{La estructura de una Dirección de Comunicación debe estar conformada principalmente por áreas de: RR.PP, Comunicación Organizacional, Marketing y Publicidad, Comunicación Digital, etc.}

Junto a la Dirección de Comunicación existe un equipo de personas que trabajan desde diferentes frentes para gestionar la comunicación a nivel interno y externo. En el Delphi aplicado a académicos nacionales e internacionales con la consulta: "¿Qué áreas de trabajo debería tener una Dirección de Comunicación?”, se destaca que dichas áreas son: Relaciones Públicas: 77\%; Comunicación digital: 62\%; Marketing y Publicidad: 54\%; Fotografía: 54\%; Protocolo: 54\%; Medios (impresos, radio, televisión): 31\%, Diseño Gráfico: 31\% y Comunicación Organizacional: 15\%. Como un dato adicional, un $23 \%$ de académicos consultados cree que dentro de la Dirección de Comunicación no debería haber división de áreas y que la comunicación se debería trabajar de manera integral.

En ambos casos, con división por áreas o no, la gestión de la comunicación debe estar enfocada principalmente a conseguir los objetivos institucionales y aportar a la construcción de intangibles.

Contrastando los datos del Delphi con los obtenidos en la encuesta aplicada a responsables o gestores de comunicación se obtienen datos casi similares. A continuación, dos figuras que lo detallan.

Figura No 9. Áreas que componen una Dirección de Comunicación

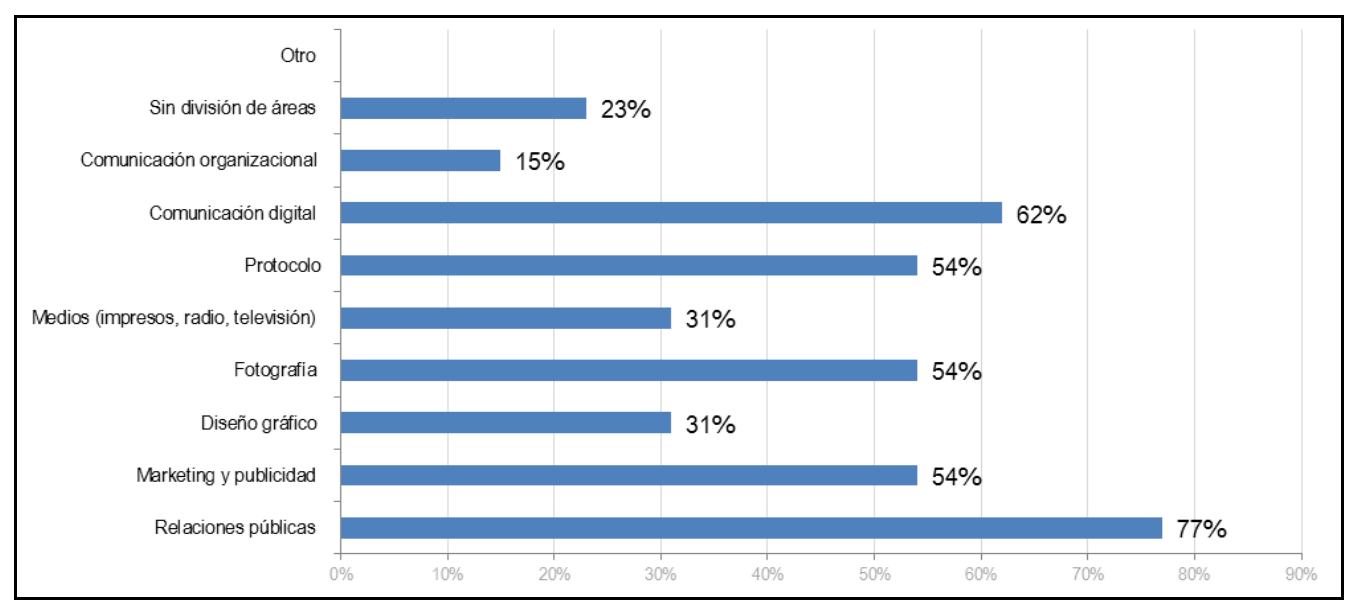

Fuente: DELPHI (primera fase) Investigación realizada por el Observatorio de la Comunicación Estratégica en Ecuador 
Los gestores de la comunicación del país, aunque en diferente orden, establecen una división similar a la de los académicos internacionales y nacionales.

Figura No 10. Áreas que conforman su departamento de comunicación

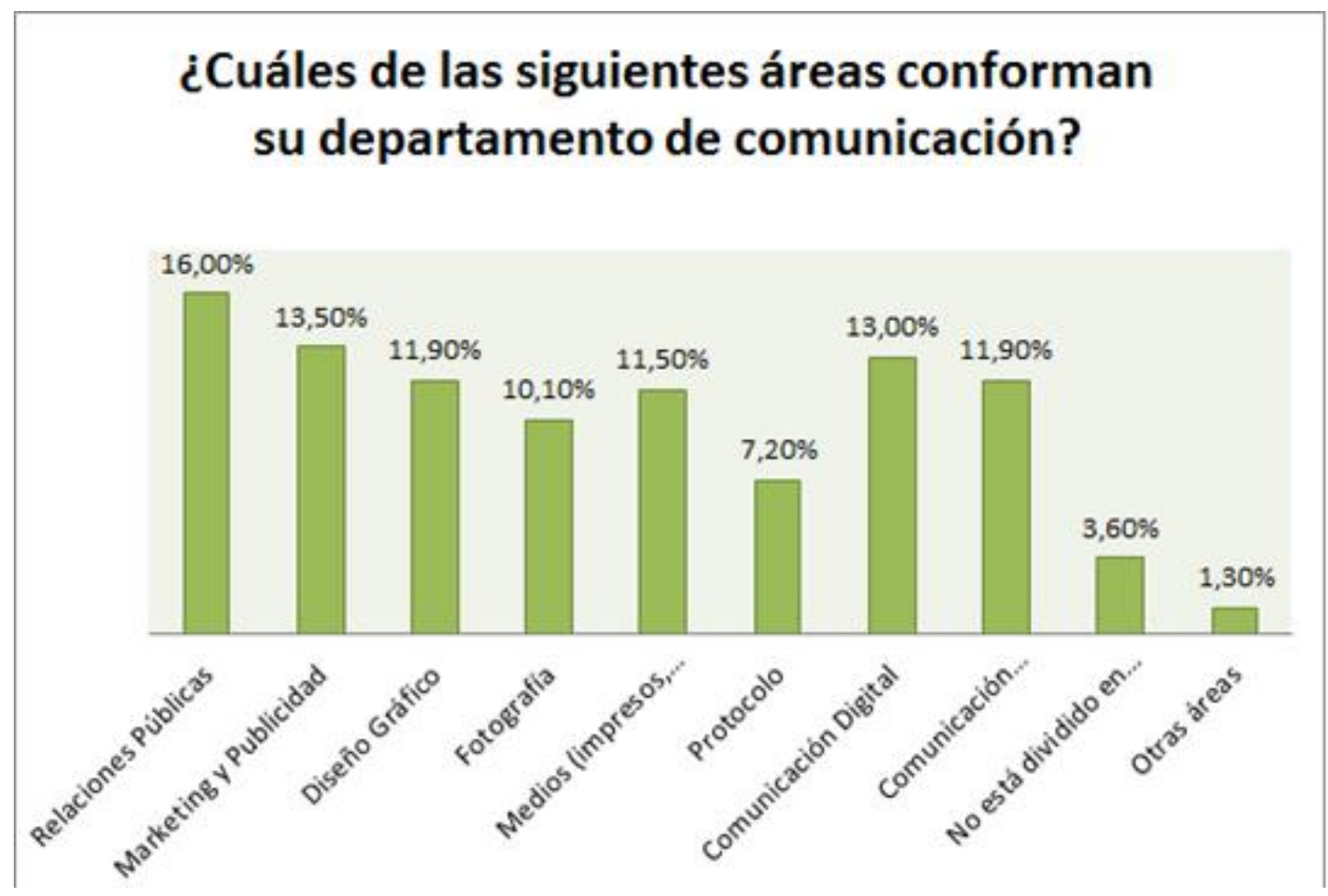

Fuente: Encuesta. Investigación realizada por el Observatorio de la Comunicación Estratégica en Ecuador

\section{Las funciones de comunicación interna serán dirigidas por el departamento de comunicación}

Los trece académicos nacionales e internacionales (en su mayoría) que participaron en el Delphi expresan en un $77 \%$ que la comunicación interna de la institución debe estar coordinada por el responsable de comunicación y la diferencia (23\%) opina que el trabajo debe ser coordinado entre el equipo de Comunicación y Recursos Humanos. 
Figura No 11. Gestión de la comunicación al interior de las organizaciones

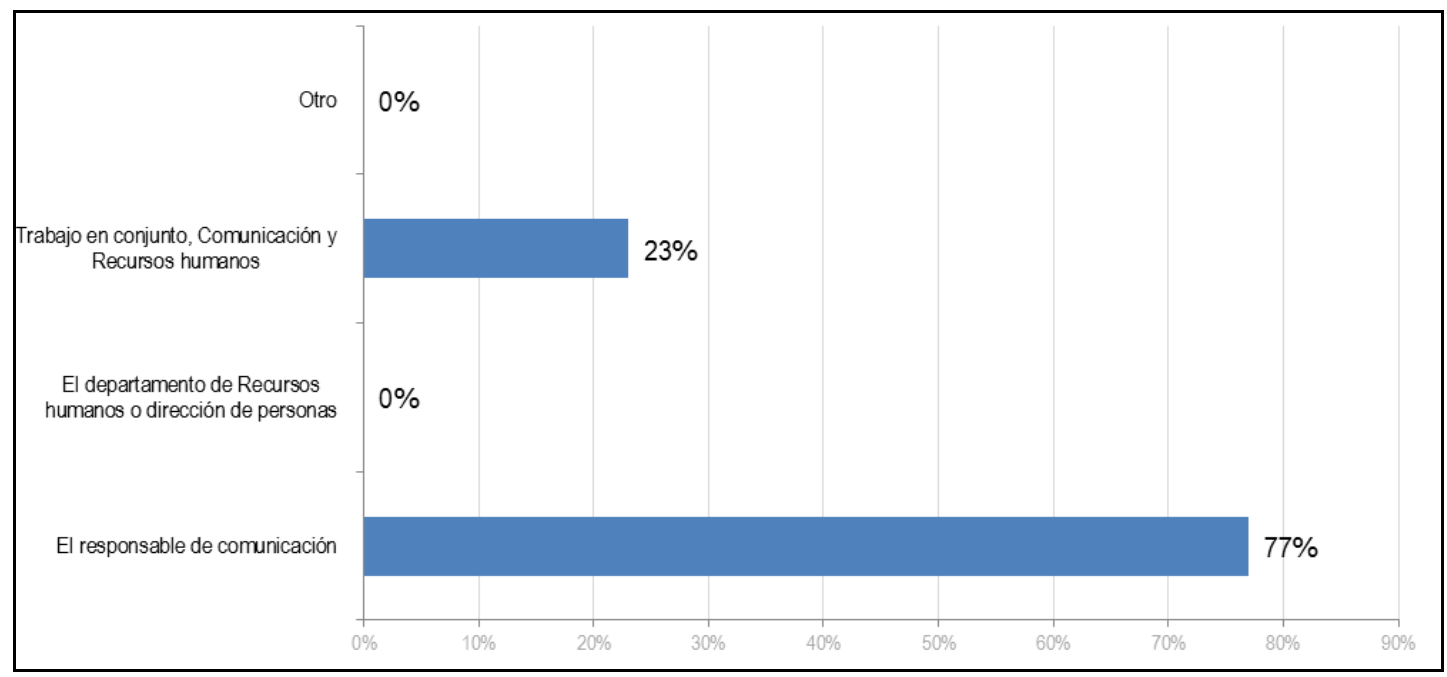

Fuente: Delphi (primera fase). Investigación realizada por el Observatorio de la Comunicación Estratégica en Ecuador

Al consultar a los Dircom a través de las entrevistas sobre cómo se definirán a tres años las funciones de la comunicación interna respecto a su dependencia de RR.HH, se destacan algunas opiniones interesantes:

Katya Torres, jefe de Comunicación Organizacional del Banco de Pichincha, lo resume de la siguiente manera:

"Una de las misiones más importantes de la Comunicación en la empresa es dirigir la Cultura Corporativa, aspecto que estará siempre ligado a la gestión de RRHH, pero cuya administración debe manejarse bajo el mismo paraguas de acción del Dircom, pues se encarga de asegurar coherencia con la estrategia y la filosofía de la empresa".

Por lo tanto, Recursos Humanos es un área fundamental para ejecutar acciones de comunicación interna que debe trabajar de la mano del Dircom.

"Con respecto a la definición de funciones con RRHH se podría decir que, al no estar en contacto con áreas comerciales de forma directa, Comunicaciones es su puente para estar alineados en toda la estrategia de la empresa y mantener 
informado y motivado al personal interno". Así lo vaticina Rodolfo Pérez, director de Comunicación de Yanbal Ecuador.

Es así que el 93\% de los entrevistados consideran que debe haber una alineación de las acciones de Recursos Humanos con la estrategia planteada por el Dircom.

De igual manera, un criterio integrador tienen los gestores de la comunicación del país a quienes se les consultó con la encuesta.

Figura No 12. Responsables de la ejecución de las estrategias de comunicación interna

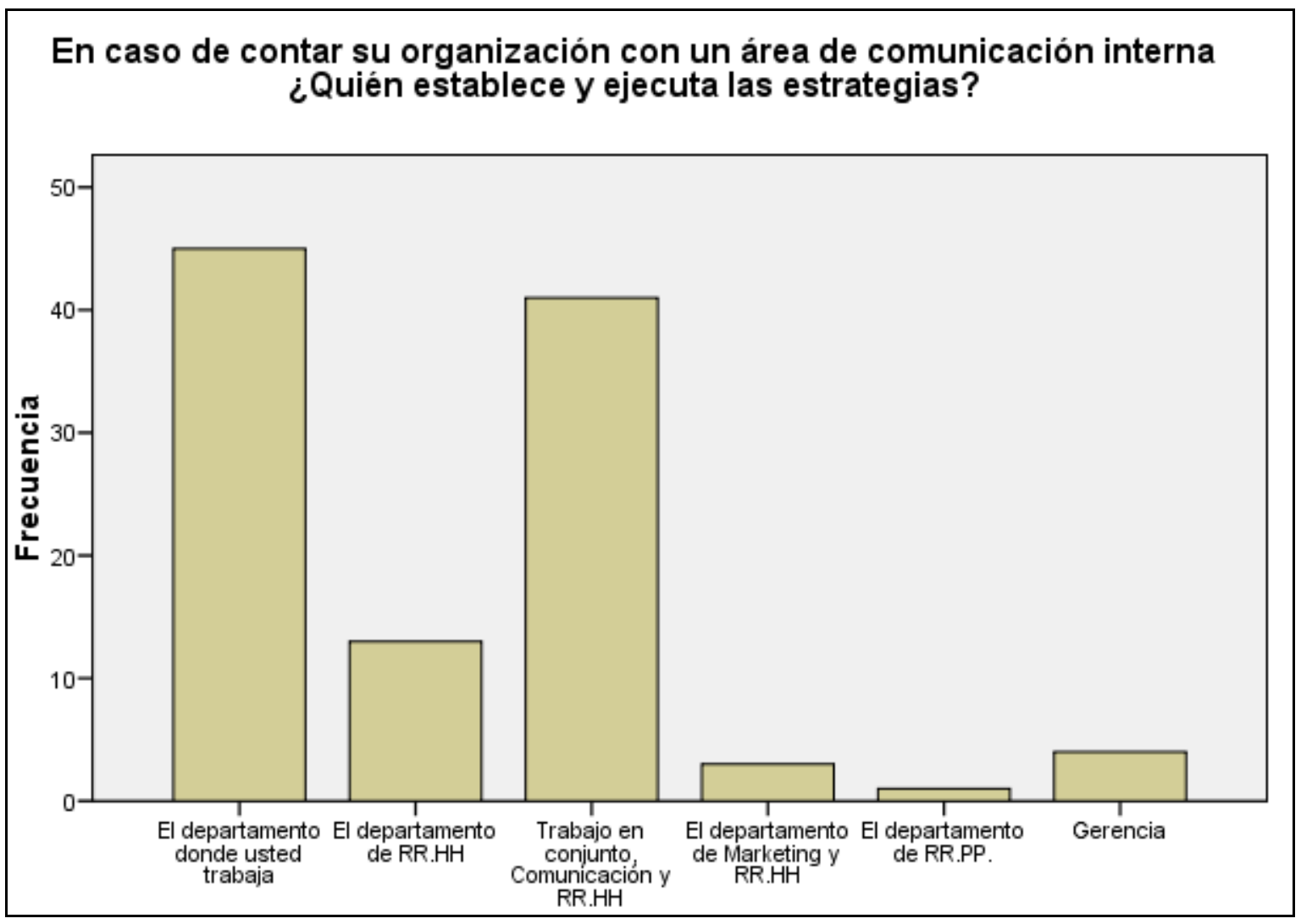

Fuente: Encuesta. Investigación realizada por el Observatorio de la Comunicación Estratégica en Ecuador

Sobre estos resultados, al parecer lo estratégico está en establecer una hoja de ruta de la estrategia de comunicación donde se integren varios actores en el proceso de comunicación de la organización. Al hacerlo de manera coordinada todos ganan y se evita duplicar acciones y se fortalecen la imagen y la reputación institucionales. El riesgo de trabajar la comunicación de manera aislada entre departamentos de la 
misma institución es transmitir mensajes poco alineados a la institución y generar una mala imagen a nivel interno y externo. Entonces, el reto de un Director de Comunicación está en lograr integrar las acciones de todos los actores que trabajen en comunicación dentro de la organización e involucrar al área de Recursos Humanos.

\section{Factores que consolidarán la posición del Dircom}

La función del Dircom está "ligada a la gestión de la reputación; involucrándose cada vez más en la estrategia de la empresa y superando las funciones tradicionales casi únicamente ligadas a la relación con los medios de comunicación..." es la posición de Chief Communication Officer (CCO); "cercano o siendo parte de los Comités de Dirección, de la Comisión Ejecutiva o del Consejo es cada vez más común” (Comunicación \& RRPP; Burson-Marsteller).

"Hoy, la comunicación es la inteligencia y la gestión estratégica de los activos intangibles. Ellos son la clave de la producción de Valor, de la Fidelización y de la Sostenibilidad del negocio... Organizar y controlar su funcionamiento, sus relaciones internas y con los actores sociales; velar por su imagen pública y su reputación y coordinar eficazmente sus recursos son exigencias que ninguna empresa puede despreciar en una era como la nuestra en donde la calidad de la conducta empresarial, de sus relaciones e interacciones y la buena consideración pública llegan a ser más importantes incluso que los productos y los servicios... En la nueva Economía, el éxito será para quien sepa gestionar mejor las relaciones" (Costa, 2009: 9).

Los datos obtenidos en las encuestas reflejan que los factores que consolidarán la posición futura del Dircom se relaciona con el apoyo en la toma de decisiones de la alta gerencia; manejo de la microcomunicación sobre la comunicación y la incorporación al modelo de gestión de la responsabilidad social y el desarrollo sostenible. 
Figura No 13. Factores que consolidarán la posición del Dircom en la organización en tres años

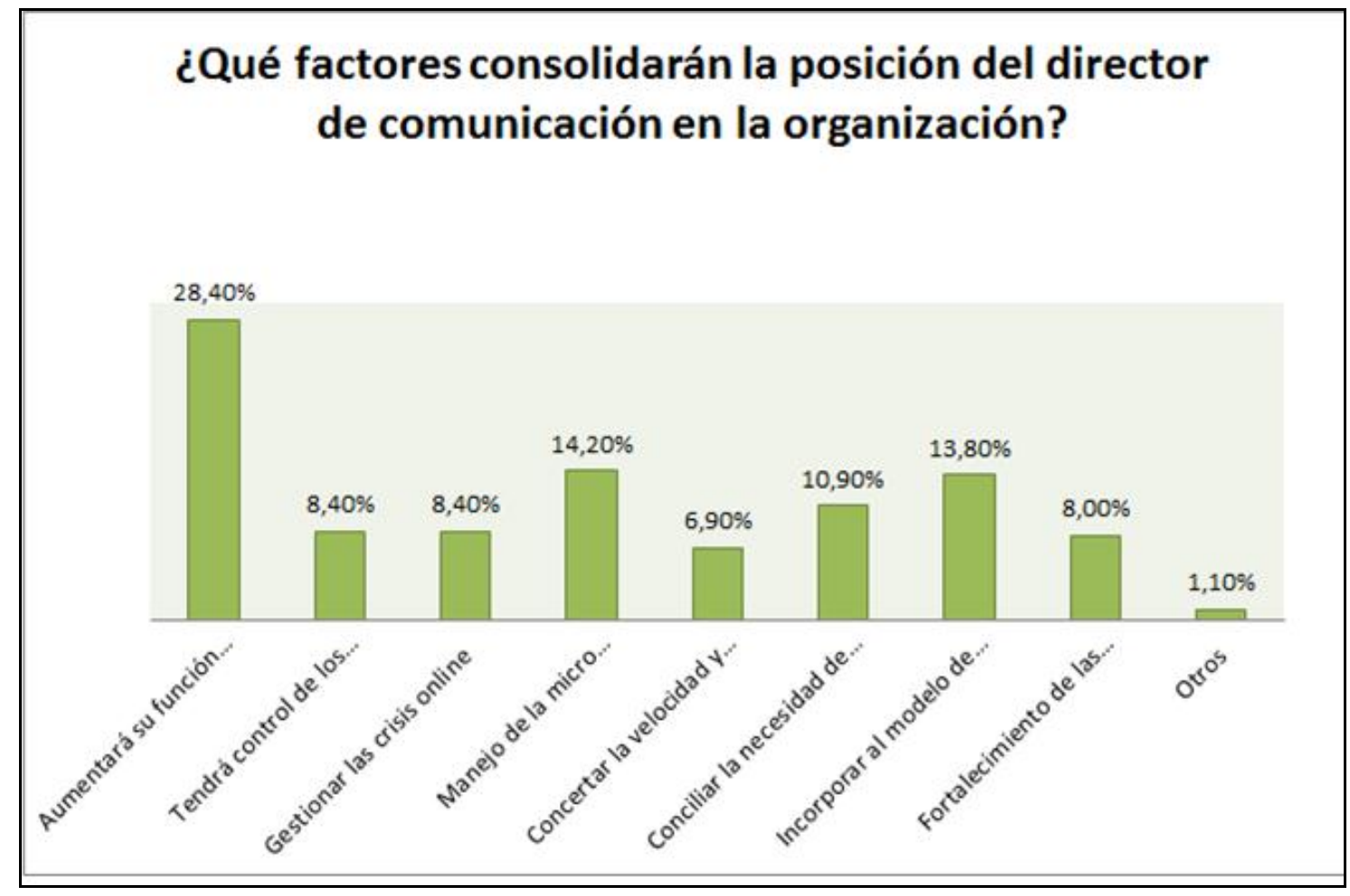

Fuente: Encuesta. Investigación realizada por el Observatorio de la Comunicación Estratégica en Ecuador

\subsection{Aumentará su función estratégica}

La interacción entre organización y comunicación es indiscutible puesto que están comprometidas y son indivisibles; es imposible pensar en organización sin que en ella esté subyacente una política y estrategia general de comunicación basada en un cambio fundamental de visión que pone énfasis en la gestión de los recursos organizacionales intangibles: reputación, imagen, credibilidad, confíanza y que gira en torno a una gestión relacional honesta, transparente y sencilla con el entorno interno y externo.

Hoy en día se espera que el Dircom, a más de crear estrategias de comunicación, canales y mensajes, proponga y aporte a las organizaciones elementos que le faciliten la toma de decisiones oportuna y que incidan de forma directa en la consecución de los objetivos organizacionales. 


\subsection{Manejo de la microcomunicación sobre la comunicación}

La necesidad de hacer microcomunicación o comunicación pensada para públicos muy específicos, surge de la aparición de comunidades con intereses muy particulares fruto de su interrelación en redes sociales o profesionales que demandan el establecimiento de relaciones y esperan obtener valor de ellas.

"Los individuos han pasado de ser considerados receptores a asumir el papel de gestores de la comunicación que reciben y de la que emiten. El cambio ha hecho variar el modo de comunicar de los medios de masas (de discursivos a dialogantes) y los hábitos de sus audiencias; ha movido a reajustar estrategias comerciales de mercado de transacciones a relaciones; ha conducido a incorporar nuevos escenarios de comunicación personal y masiva...." (Túñez, 2011: 15).

Hoy, trabajar en comunicación supone no sólo la identificación prolija y adecuada de los públicos a los que se quiere llegar con estrategias y tácticas bien diseñadas, sino que ellas estén también pensadas para hacer uso pertinente y coherente de las plataformas y redes cada vez más especializadas.

Esto no quiere decir por ningún motivo que se deba trasladar el boletín de prensa o el anuncio publicitario a las plataformas o redes donde están los públicos, sino que se deben construir con creatividad nuevas formas de contacto, comunicación y sobre todo, relación.

\subsection{Incorporar al modelo de gestión la responsabilidad social y el desarrollo sostenible}

Los públicos buscan establecer sus relaciones de credibilidad y confianza con el productor (la organización) y ya no sólo con el producto. "Se observa así un desplazamiento de la atención comunicativa del mensaje al emisor; de lo anunciado al anunciante (Pibernat i Doménech, 1986: 81); de lo hablado (la marca) al sujeto 
hablante (la organización) (Capriotti P., 1992 [versión online, 2006: 16).

Las condiciones comentadas son percibidas por las organizaciones y, ante los cambios profundos que se demandan de ellas, ven como alternativa la adopción de un modelo de gestión socialmente responsable que pueda apoyar el desarrollo integral de la sociedad.

La Responsabilidad Social es un modelo de gestión que tiene como fin la sostenibilidad. Está integrada en la razón de ser misma de la organización y las decisiones organizacionales se adoptan tomando en cuenta los valores, políticas y criterios éticos y morales ligados a la transparencia y rendición de cuentas a la sociedad que rebasan las obligaciones legales existentes.

La RS debe ser compartida por todos los niveles que integran la organización o se relacionan con ella a nivel interno y externo (públicos y stakeholders) en función de constituir un proceso favorable para todos ("ganar y ganar") es decir, que la organización obtenga una mayor productividad y rentabilidad sin pasar por encima del bienestar social y económico de sus colaboradores, ni tampoco de las expectativas de la comunidad en la que opera tras la perspectiva de lograr desarrollo económico, social y el cuidado del medio ambiente como premisas de su gestión responsable (triple botton line).

En el proceso de diagnóstico, implementación, seguimiento y socialización de la gestión socialmente responsable, la comunicación como función estratégica cumple un papel indispensable" (Valarezo, 2009: 40).

La gestión socialmente responsable entra dentro de la política de comunicación general de las organizaciones y debe ser abordada desde los principios de la ética y la verdad; ocultar información o emitir verdades a medias son prácticas insostenibles en el tiempo y se pueden constituir en motivos de peso para desgastar o destruir la imagen y reputación de la organización. 
Figura No 14. Modelo de gestión socialmente responsable

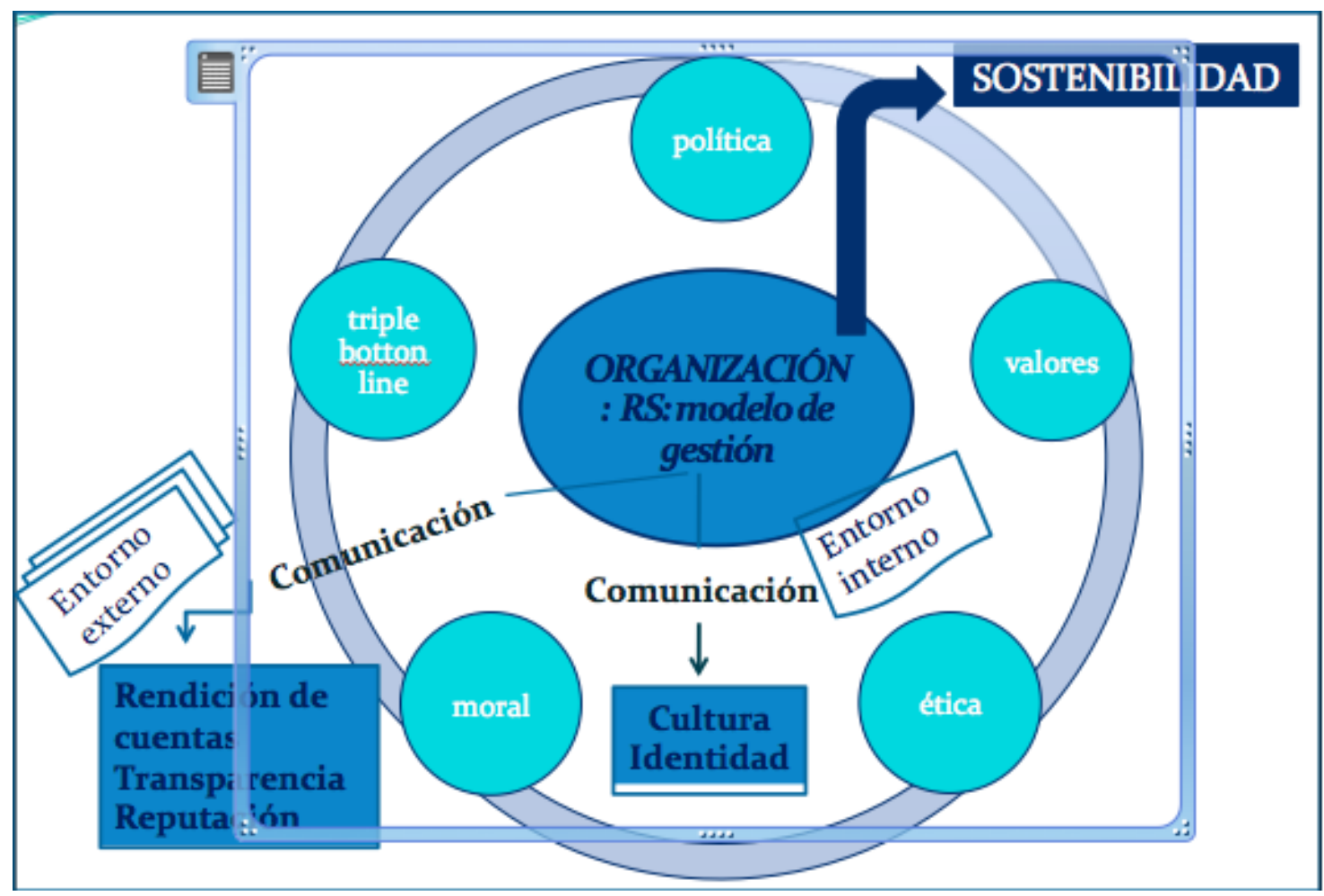

Elaboración: Valarezo, Karina (2009). Trabajo de Investigación Tutelado. Responsabilidad Social Universitaria y su vinculación con la comunicación

Abordar más audiencias y canales con recursos limitados, el control de nuevos medios, gestionar crisis online y el fortalecimiento de las redes profesionales son otros de los factores que, en menor medida, pero también los encuestados consideran importantes al referirse al posicionamiento que tendrá la figura del Dircom en los próximos años.

\subsection{Abordar más audiencias y canales con recursos limitados}

Sin duda, entre las actividades importantes que debe desempeñar un Director de Comunicación es el cuidar que los recursos económicos y humanos, cada día más reducidos, se puedan optimizar de la mejor manera en función de los objetivos estratégicos planteados y de lo que espera la organización y específicamente la dirección de comunicación. 
De los objetivos se desprenden las estrategias de comunicación, las mismas que se diseñarán teniendo en cuenta no solo el soporte, canal o medio que se empleará, sino sobre todo, el mensaje que se quiere transmitir y las expectativas del público al que se quiere llegar. Los públicos al ser cada vez más específicos requieren de mensajes segmentados y concretos que le generen valor.

Lograr lo mencionado pasa por la creatividad de los equipos de comunicación para conseguir implementar un plan de comunicación efectivo que abarque las audiencias y públicos de interés con la menor cantidad de recursos. La inversión tiene que estar orientada a las acciones que le produzcan mayor valor en sus públicos también un mayor control sobre los resultados.

\subsection{Control de nuevos medios}

El control o en sentido más amplio la gestión de nuevos medios permite crear reputación online y afianzar la offline. La construcción de la reputación es parte fundamental de la gestión y construcción de los recursos intangibles tan apreciados en los públicos actualmente.

En los nuevos medios, el diálogo, el respeto y la creación de valor es determinante para que las acciones cotidianas puedan ir día a día germinando en legitimidad y confianza hacia la organización.

El cambio fundamental está en dejar de comunicar a grandes audiencias para buscar la manera de establecer un diálogo con los individuos. De esta forma el público se coloca en el centro de la relación con sus marcas (Interactiva, 2007).

\section{Gestionar la crisis online}

Gestionar una crisis online equivale a que la organización a través de la Dirección de Comunicación tenga planteada un esquema de estrategias y acciones que permitan anticiparse, reparar o minimizar una crisis en entornos virtuales.

Toda organización tiene presencia en la red independientemente de que gestione o no sitios web o redes propias. Los usuarios, públicos, 
consumidores se encargan de llevar sus experiencias del mundo offline al online con mucha facilidad e inmediatez.

Las crisis que pueden presentarse en cualquier momento, y que tienen una viralidad increíble en red, afectan la imagen y reputación de la organización. En este punto se debe hacer un puntualización importante en el hecho de que la gestión de la imagen y reputación y por tanto la gestión de una crisis online, no constituyen un problema únicamente de la Dirección de Comunicación sino que es un tema de incumbencia de la organización en su conjunto.

Las crisis demandan una respuesta de la organización estratégica e inmediata. Contar con un manual de gestión de crisis equivalente a la adopción de protocolos de actuación, es muy útil por la premura y condiciones específicas de nerviosismo o expectativa que ellas generan dentro de las organizaciones, en los públicos y en el entorno.

\subsection{Fortalecimiento de las redes profesionales}

Finalmente los Directores de Comunicación sin duda tienen el desafío de propiciar vínculos que permitan clarificar sus responsabilidades y papel dentro de las organizaciones.

Discutir propuestas que permitan innovar dentro del campo de la gestión de intangibles favorecerá a la valoración de la comunicación como un recurso fundamental del quehacer estratégico de las organizaciones.

Además, y sin lugar a duda, las redes relacionadas con la gestión de la comunicación cada vez se incrementarán y se harán más específicas de acuerdo a las temáticas de interés así: interna, externa, online, comercial, institucional, etc.; o también al giro de negocio o de especialización de las organizaciones así: farmacéutica, universitaria, hospitalaria, minera, ambiental, etc. 


\section{Referencias bibliográficas}

Capriotti, P. (1992 [versión online, 2006). La imagen de empresa. Estrategia para una comunicación integrada. El Ateneo, Barcelona: http://www.bidireccional.net].

Comunicación \& RRPP; Burson-Marsteller. (s.f.). "El Dircom del futuro y el futuro del Dircom". Recuperado el 30 de Marzo de 2015, de http://burson-marsteller.es/:

http:/ www.google.com.ec/url?sa $=t \& r c t=j \& q=\& e s r c=s \& s o u r$ $\underline{c e}=$ web\&cd $=1 \&$ ved $=0$ CB0QFjAA\&url $=$ http $\% 3 \mathrm{~A} \% 2 \mathrm{~F} \% 2 \mathrm{Fbur}$ son-marsteller.es $\% 2$ Fwpcontent $\% 2$ Fuploads $\% 2 F 2013 \% 2 F 03 \% 2 F I n f o r m e-F u t u r o-$ Dircom.pdf\&ei=X8JbVeWkHPWNsQSKkIG4BA\&usg=AFQj CNF3cEf4FZ2HM7GkdHyUx6U hnTHg\&sig2=OP9fWEKWHI2H $\underline{\text { bBIBmSTEwg\&bvm }=\text { bv. } 93756505, \text { d.cWc }}$

Costa, J. (2009). DirCom hoy. Dirección y Gestión de la Comunicación en la nueva economía. Barcelona: Cesta Punto Com.

Casado Molina, A., Méndiz Noguero, A. y Peláez Sánchez, J. (2013). "The evolution of dircom: From communication manager to reputation strategist". Comunicación y Sociedad, 26 (1), 47-66.

Interactiva. (2007). "Dossier Planificación Online. Planificación 2.0." Revista de la comunicación interactiva y el marketing digital (77), 42-50.

Mora, J. M. (2009). 10 ensayos de comunicación institucional. Pamplona: Eunsa.

Túñez, M. (2011). La gestión de las organizaciones. Zamora, España: Comunicación Social.

Valarezo, K. (2009). Responsabilidad Social y su Vinculación con la Comunicación. Santiago de Compostela: USC. 


\section{IIII}

\section{E1 futuro de la comunicación digital como soporte a la gestión estratégica de las organizaciones}

Rosario Puertas. Universidad Técnica Particular de Loja, Ecuador

Elizabeth Cadme. Universidad Técnica Particular de Loja, Ecuador Alejandro Álvarez Nobell. Universidad Nacional de Córdoba - CONICET Universidad Católica de Córdoba, Argentina

T A comunicación en las organizaciones es todo lo que la empresa 1 dice de sí misma. Si todo comunica, desde la publicidad hasta la actividad cotidiana de la empresa (Capriotti, 1999: 30-31), también se incluye Internet como el soporte que facilita establecer diálogos individuales y grupales (Túñez, 2012: 147).

Según los estudios realizados por el Banco Mundial, ${ }^{12}$ desde al año 2005 el uso de Internet (por cada 100 personas) ha ido creciendo, y según se puede observar en el gráfico (1), la tasa de crecimiento de acceso a Internet de Ecuador es del 40.4\% (según el Instituto

\footnotetext{
${ }^{12} \mathrm{El}$ Banco Mundial es una organización integrada por 188 países. Brinda asistencia financiera y técnica para países en desarrollo. Presenta datos estadísticos sobre varios indicadores entre ellos los Usuarios de Internet por cada 100 personas. Disponible en: http://bit.ly/1DBoG8f [consultado
} $1 / 12 / 2014]$ 
Nacional de Estadísticas y Censos, INEC, ${ }^{13}$ (2014) de Ecuador en el informe publicado el 14 de mayo de 2014), porcentaje que supera la tasa promedio mundial que corresponde al 31.8\% en el año 2013.

Figura No 15. Estadísticas del uso de Internet. Comparativa desde 2005 a 2013

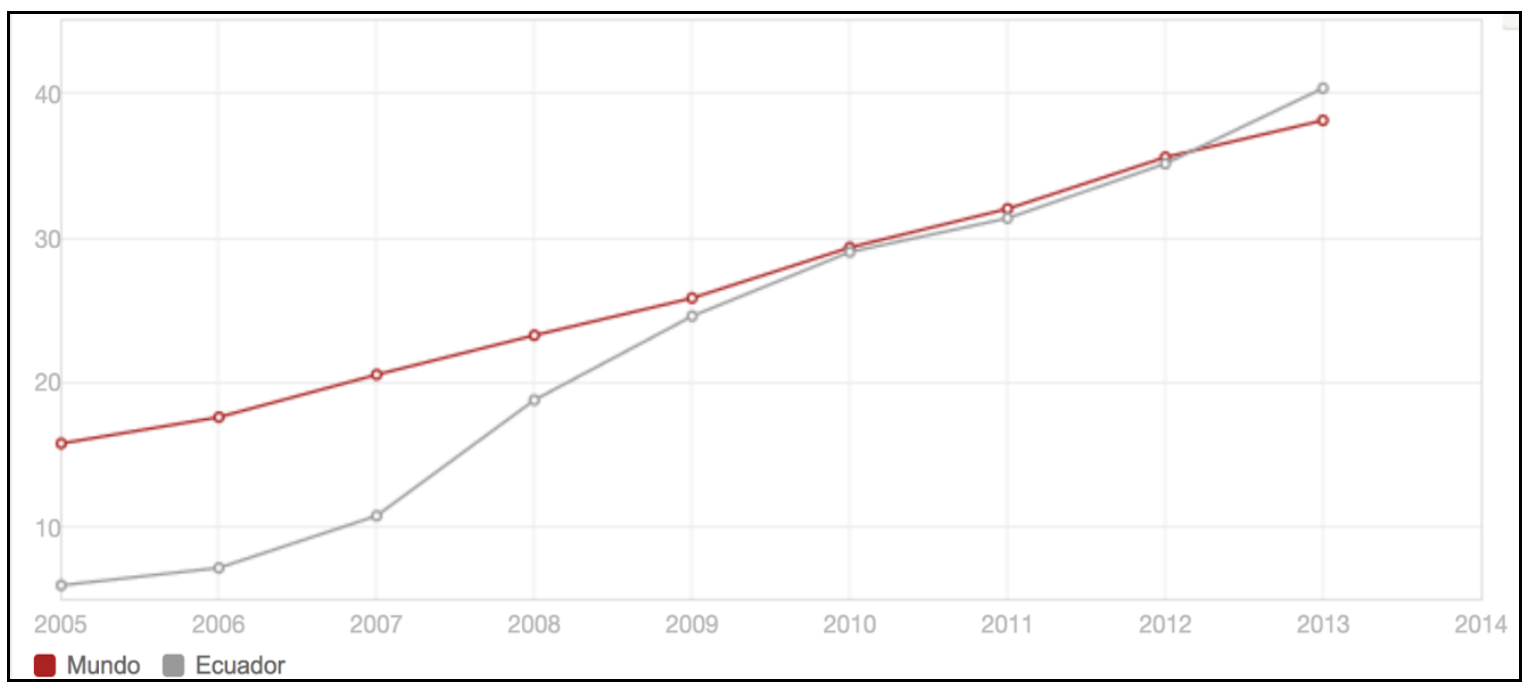

Fuente: Banco Mundial (2013) comparativa de uso de Internet a nivel mundial versus el uso de Internet en Ecuador 2005 - 2013. Disponible en: http://goo.gl/ck0FYH [consultado 1/12/2014].

El estudio Observatorio de comunicación estratégica en Ecuador realizado en 2014 mostró que el 13\% de comunicadores en Ecuador y el 54\% de académicos internacionales estiman que la comunicación digital es un área esencial dentro de la estructura del Dircom. Incluso, entre los considerados canales efectivos de comunicación organizacional, se ubican en primer lugar las redes sociales $(39 \%)$ y en segundo la página web (18\%). Así mismo, para los académicos internacionales, el impacto en redes sociales (54\%) y la audiencia en la web institucional (53\%) son los métodos de medición y evaluación de estrategias de comunicación más utilizadas.

\footnotetext{
${ }^{13}$ El Instituto Nacional de Estadística y Censos es el órgano rector de la estadística nacional y el encargado de generar las estadísticas oficiales de Ecuador para la toma de decisiones en la política pública. Disponible en: http://www.ecuadorencifras.gob.ec/la-institucion/ [consultado el 01/05/2015]
} 
La exigencia es alta para los profesionales que están al frente de la comunicación, tanto organizacional como periodística, destacando que el nivel de conocimiento sobre comunicación digital debe estar acorde a las exigencias actuales. La adaptación y la constante capacitación sobre las novedades y las herramientas tecnológicas son básicas para cualquier área de comunicación.

\section{La web 2.0 se consolida como herramienta de absoluta influencia en la gestión comunicacional}

La web 2.0, según explica Tim O’Reilly (2007), es una herramienta de gestión de la comunicación externa de las organizaciones. Es un soporte que se basa en interactividad, hipertexto y multimedia para proyectarse socialmente y entablar relación con todo tipo de públicos y con otras organizaciones.

Los Directores de Comunicación-Dircom de Ecuador consideran que Internet marcará tendencia en la comunicación organizacional al ser un canal efectivo, simultáneo, inmediato, de bajo costo y con mínimo impacto al medio ambiente. Aunque no se dejarán de lado los medios tradicionales como herramientas útiles y efectivas para difundir contenidos.

La comunicación digital y los medios sociales son valoradas por los gestores o responsables de la comunicación en un 22,4\% como una de las tres líneas prioritarias de acción en comunicación de las empresas, por sobre las relaciones públicas (20,3\%) y la comunicación interna (19,2\%). Según el criterio emitido por los Directores de Comunicación entrevistados, el Dircom debe poseer una visión integral que va desde la publicidad, relaciones públicas, marketing, mass media, manejo de formatos y herramientas online, branding e imagen corporativa, además de tener conocimiento del entorno económico, político, social, entre otros. Sin embargo, en la actualidad, la comunicación digital es considerada una parte de la estrategia, pero no prioritaria.

Al consultar a los Dircom en la entrevista sobre: “¿Cómo influirá en su trabajo la revolución 2.0 y las revoluciones tecnológicas que están 
por venir?", su percepción es que la influencia tecnológica es absoluta (40\%), sobre todo en el campo de la comunicación, e incluso las herramientas tecnológicas aportan de forma significativa a las funciones que cumplen los comunicadores en las organizaciones. En cambio, el 32\% de los entrevistados señalan que es una herramienta que apoya la gestión de la comunicación organizacional y, en porcentajes iguales $(13 \%)$, consideran que permitirá la personalización de la comunicación y determinará la inmediatez de la misma.

Cuando se trata de definir la revolución tecnológica, sobre todo en el campo de la comunicación, varios son los puntos de vista. Sin embargo, todos están de acuerdo en que los pasos dados hasta el momento aportarán de forma significativa e histórica en el quehacer del Dircom.

\section{E1 mayor beneficio de la web 2.0 y 3.0 en la interacción con los seguidores}

La web 2.0 se centra en el usuario y en la colaboración-cooperación y destaca la interacción desde aplicaciones que le permite navegar por espacios virtuales y encontrar lo que está buscando (Dreier, 2005; cit en Santiago \& Navaridas, 2012: 19-30).

En cambio, la web 3.0 son entornos presentes en páginas web semánticas con contenidos etiquetados con mayores detalles descriptivos (Aced, 2010). Se colocan los datos para que las máquinas puedan entenderlos de manera natural o que los conviertan a esa forma para poder leerlos; se busca hacer una web más colaborativa, más entendible (Interactive and Cooperative Technologies). A dichos entornos refieren la apertura-compatibilidad, interoperabilidad, web 3D, control de información y web semántica (Santiago \& Navaridas, 2012: 19-30).

El $92 \%$ de los académicos internacionales y nacionales a través del Delphi afirman que se debe buscar interacción con los seguidores aprovechando las tecnologías de la web 2.0 y la 3.0; el 38\%, que la información de la empresa sea fácilmente encontrada por los 
buscadores, no como palabras claves sino según la estructuración interna de la página web (taxonomías ${ }^{14}$ ).

La integración de la web 2.0 y 3.0 revela una sociedad más abierta y conectada que demanda el diálogo y la transparencia de las organizaciones, lo que compromete a las empresas a alinear la estrategia de comunicación con los objetivos organizacionales, claramente coordinados desde la Dirección de Comunicación.

Figura No 16. ¿Cómo aprovechar la web 2.0 y 3.0 para la gestión de la comunicación?

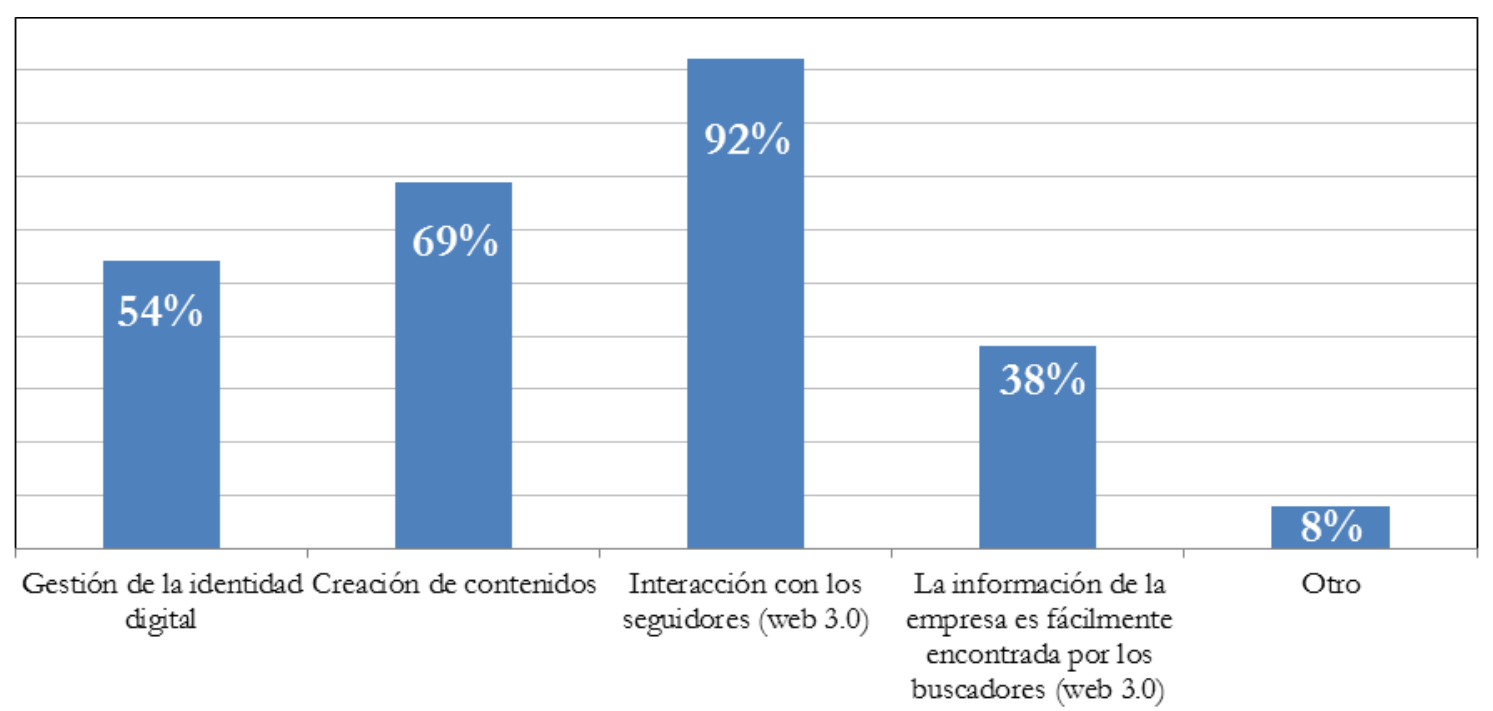

Fuente: Delphi (primera fase). Investigación realizada por el Observatorio de la Comunicación Estratégica en Ecuador

Así lo menciona Ana María Suárez, docente de la Universidad de Medellín, Colombia: "el Dircom orienta al cuerpo directivo sobre las relaciones equilibradas con sus públicos, decisión estratégica que permitirá lograr una reputación favorable y consolidada" (segunda fase del Delphi).

\footnotetext{
Taxonomía es una jerarquía semántica en la cual entidades de información son relacionadas ya sea por subclasificaciones o subclases. Tomado de http://ict.udlap.mx/people/carlos/is346/admon11.html [22/04/2015]
} 
El Dircom define los canales y los mensajes adecuados para cada público objetivo. Las herramientas utilizadas, en orden de prioridad, para los Directores de Comunicación -según los resultados de las entrevistas- son: redes sociales, gestión de medios de comunicación, boletines de prensa, página web institucional, sala de prensa digital, establecer aliados estratégicos, videos de producción institucional, mailings, reuniones, planificación organizada.

\section{3. ¿Las redes sociales se constituyen en canales efectivos?}

Las redes sociales se convirtieron en un espacio de encuentro, de negocio y de debate al integrarse con la filosofía 2.0 de las organizaciones -con o sin ánimo de lucro, públicas y privadas-; marcando un nuevo entorno y un nuevo soporte comunicativo entre los ciudadanos y las organizaciones, en un modelo multidireccional (Túñez, 2012: 161).

En función del tipo de contenido a difundir, como estrategia efectiva, es necesario segmentar los mensajes enfocándose en el público al que se desea llegar y de acuerdo a la red social, ya que cada una tiene sus propias pautas y normas de comportamiento según explica Miguel Túñez (2012: 162). El público es un grupo de personas u organizaciones que se ven afectados o que influyen en el comportamiento y en la toma de decisiones de la empresa convirtiéndose en el grupo objetivo o estratégico al que la empresa quiere que lleguen los mensajes o al que quiere entender.

Del primer estudio realizado por este proyecto, se llegó a la conclusión de que los canales más efectivos convergen hacia la comunicación digital, cuyo protagonismo recae en las redes sociales como herramientas para difundir contenido institucional de organizaciones en Ecuador, por su simultaneidad, inmediatez, bajo costo y el mínimo impacto ambiental que generan.

Al consultar en una segunda fase del Delphi a los académicos que contribuyeron al estudio, destacaron que los mensajes dependen del propósito y del grupo objetivo hacia el cual va dirigido, además de las particularidades de cada red social; todo ello alineado con la estrategia 
de comunicación corporativa. Complementando esto, Miguel Túñez (2012: 161) explica que la institución debe decidir las redes o comunidades que más se ajustan a su perfil de actividad asumiendo el compromiso de contribuir activamente para con los usuarios (Túñez \& Sixto, 2010: 5).

Los avances tecnológicos son la principal causa de cambio en los procesos de comunicación. Siguiendo la tendencia mundial, en Ecuador, según las estadísticas del INEC (2014), el 65\% de la población tiene acceso a Internet y el 32,6\% de ese sector la emplea como una herramienta de comunicación. Gracias a ello, las personas cuentan con medios y formas de manifestar su agrado o disgusto frente a una actividad, organización o marca; facilidades que los medios digitales brindan y que ha dado lugar a los ciudadanos-periodistas.

La comunicación en la actualidad ha adquirido otro matiz, en el cual la tecnología se convierte en una herramienta imprescindible para cumplir con una de las principales premisas: comunicar. Es por esto que los Directores de Comunicación, a través de la entrevista, reconocen los beneficios de la web como apoyo a las organizaciones:

$\checkmark$ Ofrece un sinnúmero de posibilidades aprovechadas para la comunicación organizacional.

$\checkmark$ Es un aliado para mejorar y facilitar la comunicación con los stakeholders.

$\checkmark$ Es una alternativa económica e inmediata de comunicación; se utiliza principalmente para marketing digital.

$\checkmark$ Difunde información con inmediatez y con un alcance inimaginable por los medios tradicionales.

$\checkmark$ Permite particularizar mensajes para públicos determinados; para que la información llegue a quién debe llegar sin que sea considerada como spam.

$\checkmark$ Utiliza lenguaje directo, dinámico.

Es una comunicación más personal, de respuesta inmediata, como exigencia del usuario.

La utilización de las redes sociales es actualmente un camino obligatorio en la comunicación organizacional de varios sectores 
como el educativo, el religioso, político, ONGs, así como también de empresas públicas y privadas, entre otras.

Ana María Suárez, docente en Colombia, menciona que "establecer la gestión comunicacional, relacional y planificada ayuda a prevenir crisis y atender situaciones emergentes, de manera clara, oportuna y responsable con los públicos en todos los canales que la organización utilice".

Es evidente que una comunicación interactiva con los públicos otorga una ventaja competitiva necesaria para mantenerse en el mercado. Por tanto, debe considerarse a la comunicación digital como una estrategia fundamental en las empresas. En Ecuador, la tendencia es que cada vez más empresas utilicen las redes sociales y otros medios digitales en la comunicación organizacional.

\section{Las redes sociales evolucionarán considerablemente en la gestión de la comunicación}

La tecnología hoy en día ha permitido introducir una nueva forma de comunicación en red: asincrónica, rápida, efectiva y desligada de un lugar físico. Lo que nos lleva a referirnos a las redes sociales como "servicios basados en la web que permiten a sus usuarios relacionarse, compartir, coordinar acciones y en general, mantenerse en contacto (Orihuela, 2008: 2).

Las redes sociales son un modelo de comunicación multidireccional en el que todos tienen la oportunidad de comunicarse con todos de manera que las redes se han convertido en espacio de encuentro, negocio y debate. Sin embargo, la participación en los entornos 2.0 debe ser activa con los públicos objetivos, permitiendo el intercambio de opiniones y contenidos de manera que ambos obtengan beneficios en plena sintonía con el concepto de marketing de relaciones (Túñez y Sixto, 2011: 5)

Los académicos, expertos en comunicación organizacional, consideran que los procedimientos $\mathrm{y} / \mathrm{o}$ herramientas para gestionar y monitorear los medios digitales que deben ser dominados por los 
comunicadores organizacionales, para controlar los mismos y evitar las crisis online, son:

Tabla No 3. Procedimientos y/o herramientas que se deben dominar para controlar los medios digitales y gestionar las crisis online.

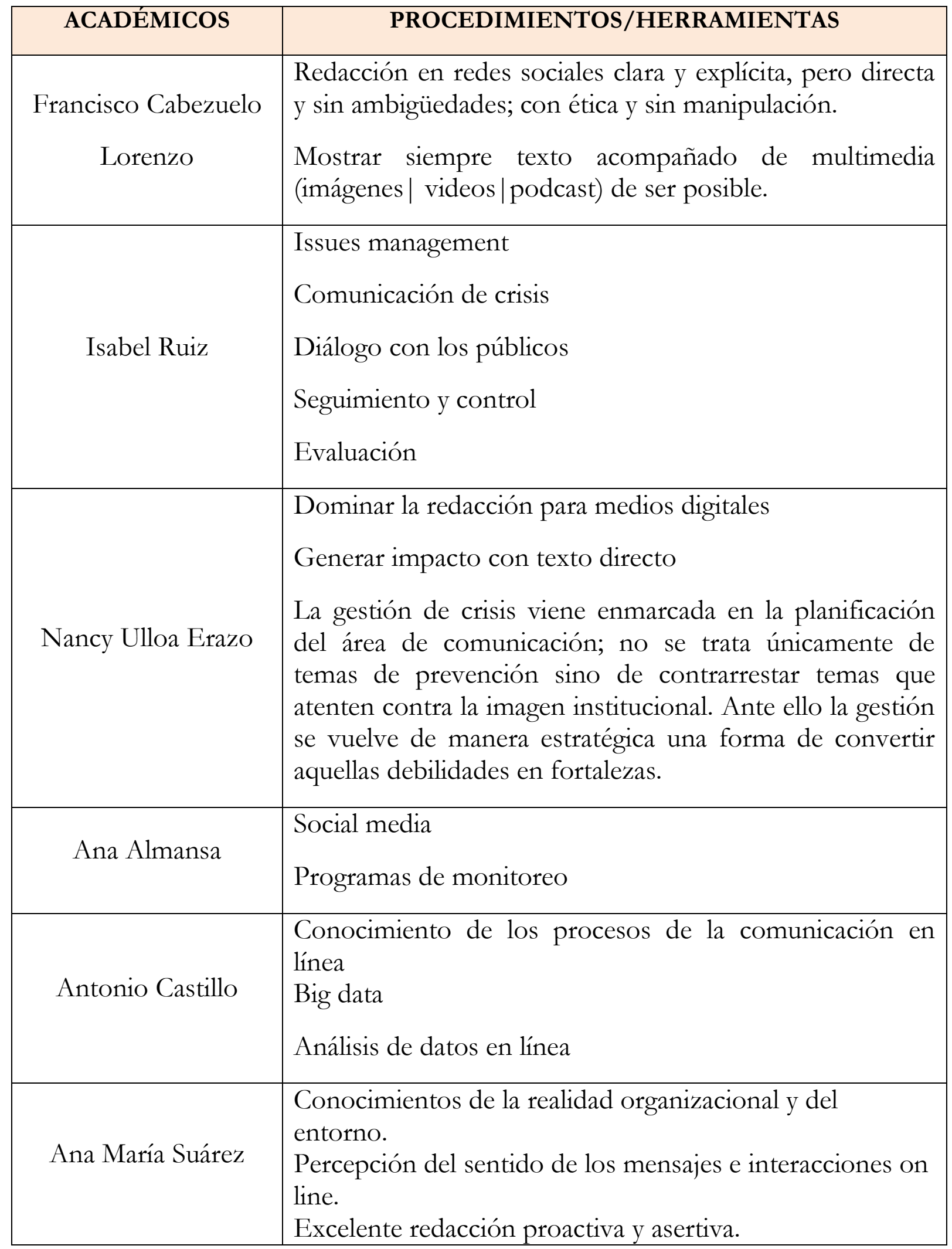




\begin{tabular}{|c|l|}
\hline & $\begin{array}{l}\text { Soporte técnico adecuado, programas de diseño, } \\
\text { fotografía original y con derechos al día. }\end{array}$ \\
\hline Ángeles Moreno & $\begin{array}{l}\text { Investigación de la conversación digital } \\
\text { Generación de contenidos Engagement. }\end{array}$ \\
\hline
\end{tabular}

Fuente: Delphi (primera fase). Investigación realizada por el Observatorio de la Comunicación Estratégica en Ecuador

\section{Evolución de las redes sociales como apoyo en la gestión de la comunicación}

Rojas (2006) detalla 4 elementos importantes en la evolución de la comunicación: información, conocimiento, comunicación y tecnologías que son fundamentales dentro de la sociedad moderna; son perfectamente compatibles, combinables y complementarias; funcionan como un gran engranaje que permite a la sociedad tomar decisiones: creer o no creer, votar o no votar, participar o no participar, comprar o no comprar, son sólo algunos ejemplos. Por lo tanto, las empresas, que en su mayoría persiguen fines lucrativos, deberán tener presente el resultado de emplear estos cuatro elementos para el logro de sus objetivos.

Sin embargo, Ana Almansa, de la Universidad de Málaga (España), comenta "por un lado se debe incluir la comunicación digital y, por otro, la llamada gestión de intangibles que debe estar relacionada con la gestión de la comunicación organizacional... ¿ ¿o acaso no estamos creando imagen con lo que enviamos a los medios de comunicación, por ejemplo?" (Segunda fase del Delphi).

Como se mencionó anteriormente, al momento de trazar las estrategias digitales se debe tomar en cuenta la imagen institucional que se transmite a través de elementos multimedia (texto, imágenes, videos, podcast), el mensaje que se comunica, las consecuencias o el impacto que tendrá la red sobre el grupo al cual va dirigida la información. Por tanto es importante, dentro de la gestión de comunicación estratégica, al considerar a las redes sociales como herramientas, evaluar su funcionamiento, su estructura, el servicio 
que proporciona, cuál es la red más utilizada por una determinada comunidad.

Dentro de los sistemas de medición, el valorar las acciones de comunicación también es importante para los Dircom porque organizacionalmente esto se traduce en cifras y estas cifras en costos. Entre los entrevistados, la aplicación a la medición de compromiso y fidelidad en redes sociales se aplica en un 33\% como porcentaje mayor en los sistemas de medición que a su consideración se impondrán para valorar las acciones e inversiones de la comunicación estratégica; por sobre la aplicación de indicadores de calidad en un $20 \%$, y la utilización del Balanced Scorcard y KPI en un porcentaje menor del $7 \%$.

\section{Las redes generalistas cederán espacio a las redes especializadas}

Para conocer sobre el futuro de las redes fue necesario consultar a los Dircom en la entrevista sobre: “¿Cómo cree que evolucionará el uso de las redes sociales en la gestión de la comunicación estratégica y si prevalecerán las redes generalistas o se incrementarán las de carácter especializado?”

El 50\% de los entrevistados señala que las redes generalistas tienen mayor oportunidad de llegar a más usuarios, por el simple hecho de que no se dirigen a un público específico; de igual manera, muchas empresas prefieren hacer uso de las redes generalistas porque tienen mayor impacto en las publicaciones. Por tales razones, a pesar de la evolución de las redes sociales, este tipo de redes no desaparecerán pero irán cediendo espacio a las redes especializadas. Sólo un mínimo porcentaje opina que éstas desaparecen completamente.

Las redes generalistas cederán espacio considerando que la segmentación será una constante pues es parte de un proceso, y el usuario tendrá la necesidad de racionalizar su tiempo solamente en lo que es de su interés, priorizando así dentro de las redes lo que considera su prioridad para conocer e interactuar. 
Es comprensible que se tenga una opinión dividida en cuanto a la utilización de redes generalistas pues debemos tomar en cuenta que seguimos en proceso de penetración de Internet en la comunidad ecuatoriana y aún no tenemos una cultura bien definida respecto a la utilización de redes sociales.

Por otra parte, es posible que tengamos un crecimiento paralelo entre redes generalistas y redes especializadas, dependiendo de la experiencia que vayan adquiriendo los usuarios. Como en otros países, la evolución se evidencia en la madurez con la cual los usuarios manejan una red social, por tanto es un factor que influirá en los próximos años. Según la opinión de los entrevistados, las redes generalistas se van a mantener pues el público es amplio y siempre querrá conocer sus vastas posibilidades e irá desde lo más general para luego poco a poco escoger, según sus intereses y prioridades, a una red especialista. Aseguran también que las redes especialistas son utilizadas por pequeños segmentos de público especializado y toda empresa por lo general siempre tendrá el interés de estar en contacto con la colectividad a través de redes sociales no especializadas tales como Facebook, Twitter, etc.

El análisis de los resultados del estudio permite concluir que a pesar de no tener una penetración de tecnología e Internet de un 90 ó $100 \%$, podemos ya considerar que la utilización de redes sociales de carácter general o específico constituye una alternativa al alcance de las organizaciones de nuestro país y que puede consistir en una poderosa herramienta para la comunicación de las organizaciones.

\section{La comunicación digital y las herramientas que brindarán mayor efectividad para la comunicación estratégica}

A pesar de que el acceso a Internet aún no es generalizado en Ecuador, se ha convertido en el medio de comunicación de todos los centros urbanos en general. Los resultados del primer año del Observatorio (2014) permitieron comprobar que las herramientas de la Web 2.0 ocupan un lugar importante dentro de las estrategias 
utilizadas por los Dircom y expertos involucrados en procesos de comunicación estratégica.

Bianchi (2013) realiza una análisis de varias herramientas de la Web 2.0 que se consideran de alto impacto para la comunicación digital, pues se ha generado una extensa comunidad de personas conectadas en el mundo que constituye una innovadora plataforma con potencial para el cambio social y que, además de ser de bajo coste es de fácil manejo.

En este contexto, podemos observar que muchas organizaciones exitosas dentro de sus estrategias de comunicación han sido acompañadas de algunas herramientas de la Web Social, que seguirán innovándose e incorporándose al ecosistema de la comunicación digital.

Figura No 17. ¿Qué herramientas serán más efectivas para comunicar en los próximos tres años?

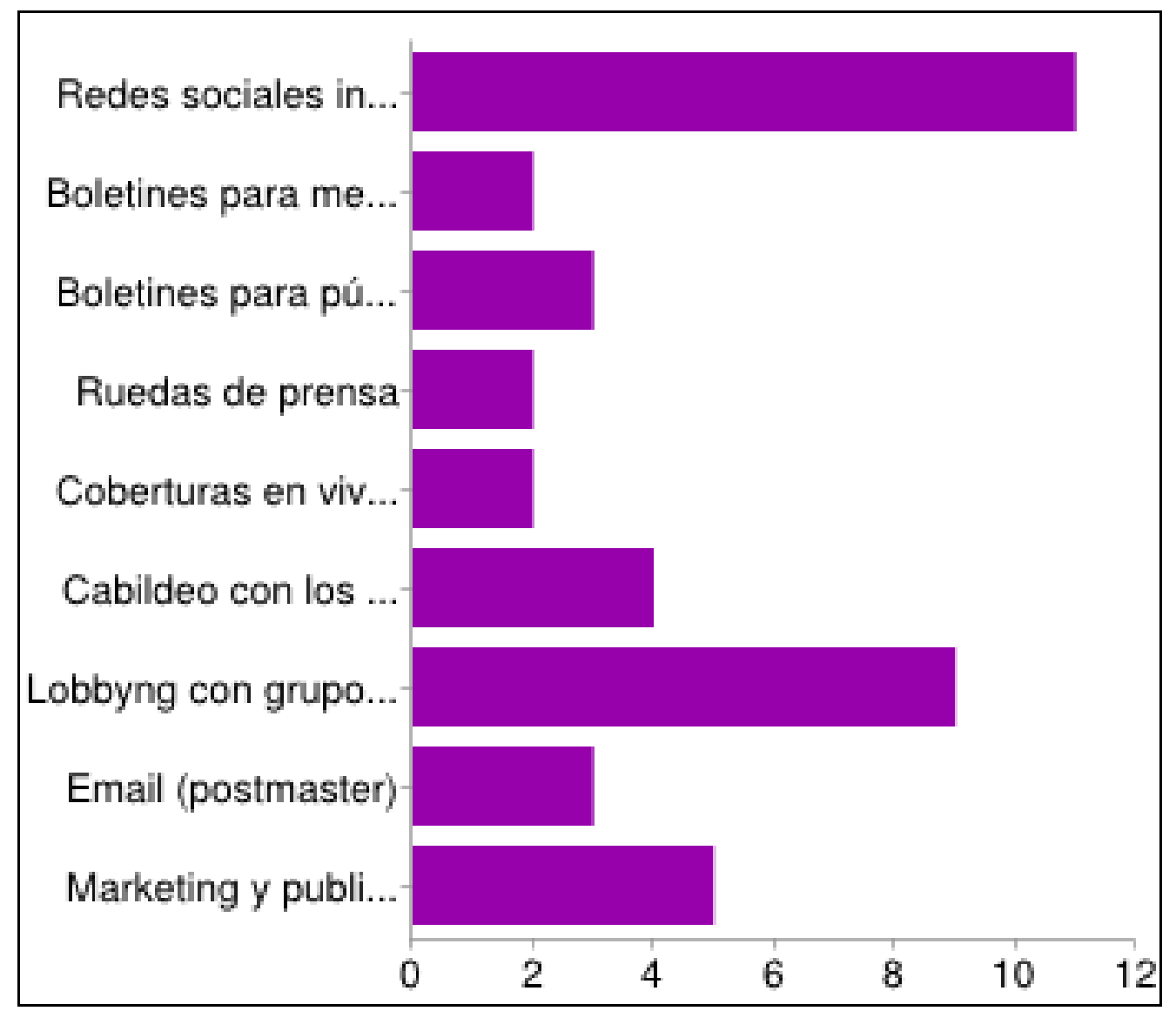

Fuente: Delphi (primera fase). Investigación realizada por el Observatorio de la Comunicación Estratégica en Ecuador 
Según la experiencia de los académicos internacionales y nacionales en la primera fase del Delphi, exponen que las herramientas más efectivas que se utilizarán serán en primer lugar las redes sociales institucionales con el 85\% y correo electrónico a través mailing con el $23 \%$. Esto implica que los medios digitales se irán convirtiendo en una potente herramienta de comunicación y, aunque no se especifica el medio de comunicación para boletines tanto para medios de comunicación como para público interno $(38 \%)$ y coberturas en vivo $(15 \%)$, bien podrían realizarse mediante la utilización de medios digitales para brindar mayor cobertura hacia grupos de usuarios determinados dentro y fuera de la misma organización.

Las herramientas de la web 2.0 para la gestión de la comunicación que serán más efectivas de aquí a tres años para los Dircom Ecuador, alcanzaron: un 31\% utilizarán las redes sociales considerándolas como un canal efectivo; $8 \%$ la página web institucional y $4 \%$ la sala de prensa digital.

\section{Figura No 18. Herramientas utilizadas por los Dircom Ecuador}

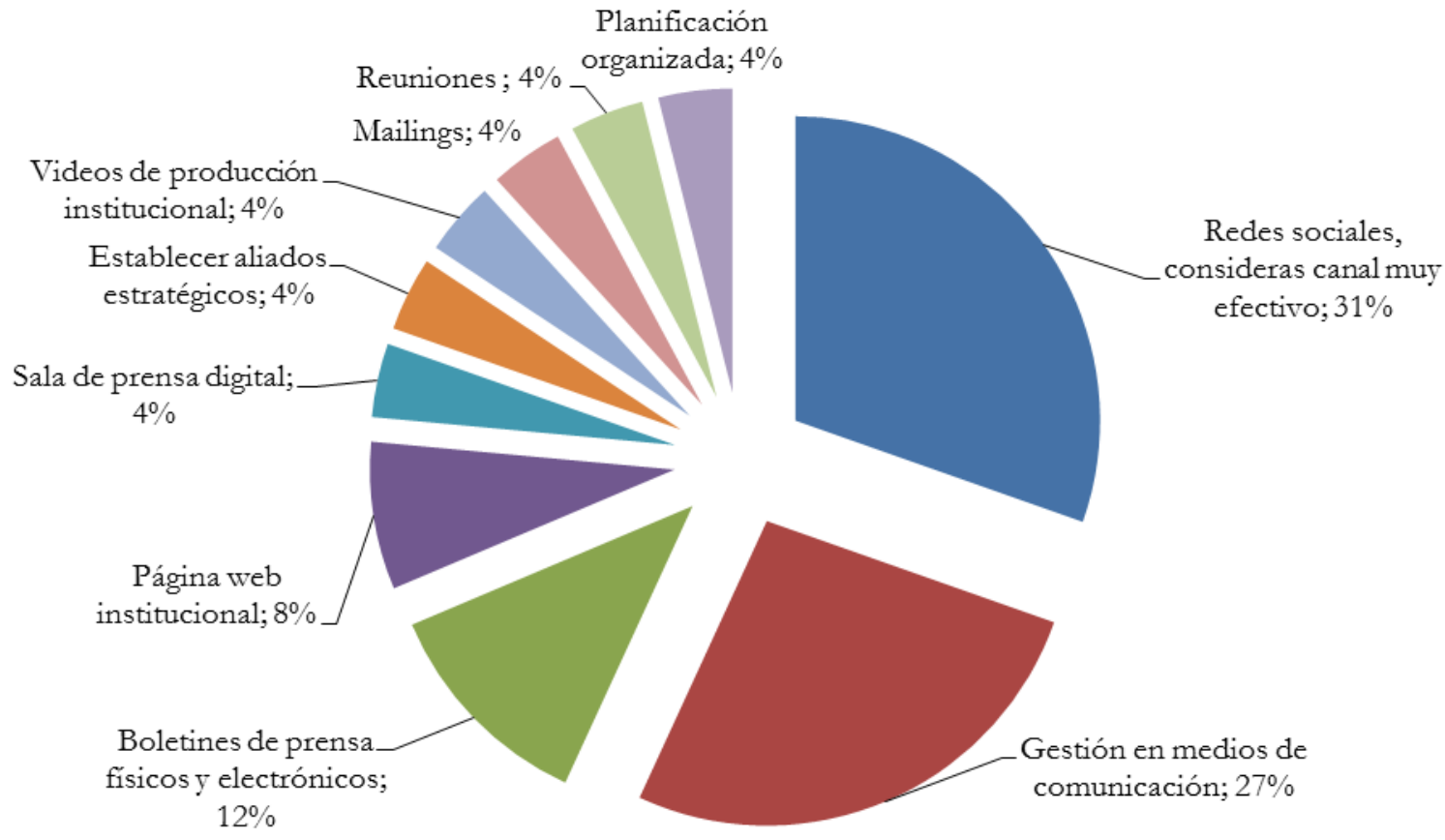

Fuente: Entrevista. Investigación realizada por el Observatorio de la Comunicación Estratégica en Ecuador 
Dentro del ecosistema digital, las formas de consumir han evolucionado como lo señala Ideas Digitales Aplicadas (2014). Por ello se debe tener en cuenta el ciclo de vida de los lectores en el ámbito digital para poder segmentar las audiencias hacia quienes se han de preparar las diferentes tácticas de comunicación. Así mismo, se hace referencia a las métricas utilizadas para medir el rendimiento como la tasa de rebote, porcentaje de lectura, tiempo en página, total shares, entre otros, que permitirán avanzar hacia nuevos modelos de comunicación, cambios en la cultura de datos y la búsqueda de indicadores más ajustados.

Las tendencias para el año 2015, según las predicciones realizadas por E.life ${ }^{15}$, se centran en la utilización de algunas tecnologías que se han desarrollado en los últimos años. Así tenemos:

$\checkmark$ Big Data, técnica que se basa en el análisis de grandes cantidades de datos, podría utilizarse para conocer mejor a los usuarios y relacionarse con ellos en los momentos clave. Una de las principales aplicaciones de la metodología se observa dentro de Consumer-Centered Monitoring dedicada a la expansión de los focos de relación con el cliente.

$\checkmark$ Uso de tecnología IBeacon, que utiliza transmisores de bajo consumo para notificar proximidad a ciertos dispositivos y que podría medir la proximidad de consumidores hacia determinados puntos. Y que integrada con CRM (Customer Relationship Management) mejoraría su potencial.

$\checkmark$ Las Apps, que cada vez se adentrarán en nuestro entorno, podrían segmentarse y, como en otros países, hacer Spin-Offs llegando de diferentes maneras a distintos perfiles de usuarios.

$\checkmark$ Innovaciones y crecimiento de la utilización de sites, email y otras herramientas también se han considerado como tendencia para el 2015.

\footnotetext{
${ }^{15}$ E.life Group especialistas en inteligencia y gestión de relación con el consumidor usando las nuevas tecnologías. Nuestras especialidades comprenden las siguientes áreas de conocimiento. Tomado de: http://www.elife.com.br/
} 
Es evidente que se tiene un vasto conjunto de herramientas que poco a poco se irán adentrando en el contexto ecuatoriano el cual deberá adaptarse y estar al igual nivel de otros países. Ahora mismo lidera la utilización de las redes sociales pero en poco tiempo se asegurará la utilización de técnicas - caso BigData- como parte de las estrategias de la comunicación en las organizaciones de Ecuador.

\section{Referencias bibliográficas}

Aced, C. (2010). Perfiles profesionales 2.0. Barcelona: UOC.

Bianchi, M. (2013). "Comunicación digital y nuevos medios. Herramientas de alto impacto a bajo costo". Asuntos del Sur (ADS). Disponible en:

http://www.muchoconpoco.org/content/mcp/images/foros /comunicacion_digital.pdf [consultado 25/04/2015].

Capriotti, P. (1999). "Comunicación Corporativa. Una estrategia de éxito a corto plazo". Reporte C\&D - Capacitación y Desarrollo $N^{\circ} 13$ (pp. 30-33). Argentina. Disponible en: http://www.bidireccional.net/Blog/Comunicacion Corporat iva 1.pdf [consultado el 20/04/2015]

Ideas Digitales Aplicadas (15/10/2014). "Métricas en medios de comunicación digital". [Diapositivas de Slideshare].

Disponible en: http://www.ida.cl/blog/analiticaweb/resumen-webinar-metricas-en-medios-de-comunicaciondigital/ [consultado 06/05/2015].

Instituto Nacional de Estadísticas y Censos - INEC (2013).

“Tecnologías de la Información y Comunicaciones (TIC'S) 201". Disponible en:

http://www.ecuadorencifras.gob.ec/documentos/webinec/Estadisticas Sociales/TIC/Resultados principales 1405 15.Tic.pdf [consultado 17/02/2015].

Iab Interactive Advertising Bareau (11/02/2015). "Los medios de comunicación online son los soportes digitales que mayor credibilidad tienen". Disponible en: http://www.iabspain.net/noticias/los-medios-de- 
comunicacion-online-son-los-soportes-digitales-que-mayorcredibilidad-tienen/ [consultado 5/05/2015]

Interactive and Cooperative Technologies (s/f) "Web semántico.

Definición”. Universidad de las Américas-Puebla, México.

Department of Computer Systems Engineering. Disponible en: http://ict.udlap.mx/people/carlos/is346/admon11.html [consultado 22/04/2015].

Mosquera Villegas, M. (2008). "De la Etnografía antropológica a la Etnografía virtual. Estudio de las relaciones sociales mediadas por Internet". Revista Fermentum - Mérida, Venezuela.

O'reilly, T. (2007) "What is Web 2.0: Design patterns and business models for the next generation of software" (pp. 1-17). Communications \& strategies

Santiago Campión, R. \& Navaridas Nalda, F. (2012). "La web 2.0 en escena". Pixel-Bit: Revista de medios y educación $\mathrm{N}^{\circ} 41$ (pp. 1930).

Túñez, M. (2012). La gestión de la comunicación en las organizaciones. Zamora, España. Comunicación Social Ediciones y Publicaciones. 



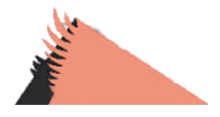 \\ Epílogo
}

\section{Una lectura de la realidad desde la Comunicación estratégica en el Ecuador}

\author{
Jenny Yaguache Q. Ph. D. \\ Sección Departamental Comunicación Organizacional \\ Directora del Departamento de \\ Ciencias de la Comunicación \\ Universidad Técnica Particular de Loja \\ Loja-Ecuador
}

— CUADOR al igual que otros países de Latinoamérica presenta cambios turbulentos en la gestión de la comunicación estratégica, muchos de ellos son parte de las excelentes iniciativas que se desarrollan en el mundo. Estos cambios, en conjunto con la realidad del país, permiten que desde la academia se proponga proyectos de investigación que ofrezcan una radiografía de las diversas formas de gestión de la comunicación.

Las empresas ecuatorianas apuestan cada día a cambios que les permita enlazar las estrategias de la organización con las de la comunicación, como uno de los retos principales para lograr posicionamiento y por ende ganar valor y confianza. La creación de 
departamentos de comunicación en el sector privado y en el público, es un punto a favor para que la comunicación, como eje trasversal a todo proceso de decisión empresarial y/o organizacional, tenga su válido reconocimiento.

La comunicación digital es sin duda uno de los principales retos que enfrentan los gestores de la comunicación, un desafío enmarcado sobre todo en la diversidad de públicos que se crean a través de las plataformas online. Es por esta razón justamente que los autores de la presente obra -en los cuales se incluye su servidora- se proponen, desde el año 2014 realizar una serie de investigaciones sobre los modelos y nuevas formas de gestionar la comunicación en el Ecuador, dada la realidad del país, incluso por la puesta en marcha de una ley de comunicación y por diversos factores externos que se imponen como políticas públicas.

Estas políticas exigen, por ejemplo, la profesionalización de los responsables de comunicación, condicionante que marca cambios en la administración y visión de los procesos de comunicación con dinámicas nuevas pero también con importantes combinaciones que da la experiencia de los gestores responsables de las unidades de difusión en años anteriores.

Los artículos que se presentan en esta obra recogen de manera fiable las opiniones que los líderes de la gestión estratégica de la comunicación del Ecuador tienen sobre la trabajo y los retos que enfrentan a la hora de armar su plan estratégico de comunicación. Como se dice en líneas anteriores, el futuro de los directores de comunicación y de sus equipos, está en desafiar efectiva y eficientemente la comunicación digital, tema profundamente analizado por Puertas, Cadme y Álvarez-Nobell.

Los resultados muestran un balance en el uso de las estrategias online frente a las tradicionales. Se reconoce que uno de los canales efectivos para la comunicación son las redes sociales y en segundo lugar el uso de la página web. Por lo tanto, la exigencia para los gestores de la comunicación es cada día más retadora, tanto organizacional como periodística, destacando que el nivel de conocimiento sobre comunicación digital debe estar acorde a las exigencias actuales. 
Ecuador por lo tanto, se une a las tendencias de Latinoamérica. Según el último informe presentado por Moreno y Molleda (2015), denominado Latin American Communication Monitor, la comunicación digital es una de las principales herramientas que permite llegar a la multiplicidad de canales y es justamente esta tendencia la que se identifica en los profesionales ecuatorianos. Para dichos autores "la implementación de los social media, no se considera exitosa en parcelas relativas a las relaciones internacionales o a la mejora o innovación de productos o servicios" (2015: 144). Puertas, Cadme y Álvarez-Nobell, indican, que los profesionales ecuatorianos asignan como línea prioritaria a la comunicación digital y a los medios sociales pero también están de acuerdo en que hace falta una formación especializada al respecto.

La formación integral es otro de los elementos que aparece cuando se analiza el futuro del Dircom en las organizaciones ecuatorianas. Una formación que exige una visión holística (Costa, 2009) que permita armonizar las relaciones de la organización con sus públicos internos y externos. Las empresas requieren profesionales responsables de la planificación estratégica y táctica, de la gestión de los valores intangibles, de la imagen pública y de la reputación institucional ¿Pero cómo se logra esto? ¿Cuáles son las posibilidades del Dircom para ascender en sus empresas?

Ecuador cuenta con 10 universidades que ofertan las carreras de Relaciones Públicas o Comunicación Organizacional. Desde el año 1998 inició la profesionalización en esta importante técnica de gestión empresarial. Los estudios de postgrado, son cada vez más frecuentes, a esto se suma una diversidad de capacitaciones que despiertan el interés en los involucrados en la profesión.

Valdiviezo, Valarezo y Córdova desarrollan la última interrogante posibilidades del Dircom-, pues analizan a profundidad la actuación del Dircom en las instituciones ecuatorianas. Según los resultados obtenidos, el $92 \%$ de los responsables de la gestión de la comunicación se encuentran junto a la alta dirección y el $8 \%$ está en un nivel medio. 
Sin embargo, hay que reconocer que queda mucho camino que recorrer. Existen empresas que apuestan por la comunicación y comprenden que ésta cumple un papel importante para su crecimiento y que por supuesto la presencia del Dircom es primordial; pero también hay empresas que han dejado a la comunicación a un segundo plano, direccionada con un agente externo para el diseño o elaboración de piezas publicitarias y de estudios de mercadeo.

Según los resultados del Observatorio, una de las principales líneas de trabajo que cumple el Dircom ecuatoriano, es la gestión de la comunicación interna, un área que por muchos años fue tema exclusivo de la oficina de Recursos Humanos, pero que hoy es compartida en decisión y ejecución por el equipo de comunicación. La segunda, es la referente al control de los nuevos medios y a todas las relaciones que nacen de este tema.

Entre las habilidades y conocimientos que debe tener el Dircom para su desempeño profesional, de acuerdo a criterios de académicos nacionales, es la destreza para aumentar su función estratégica como apoyo en la toma de decisiones. Esto es, sin lugar a dudas, la función clave del gestor de la comunicación, porque es aquella que le permitirá, posteriormente, hacer un balance del cumplimiento de objetivos que se señalan en la planificación estratégica.

Y cuando nos referimos al balance, nos acercamos a un elemento de alta importancia para la gestión de la comunicación, es como la fresa del pastel que cerrará el buen sabor o el desagrado por un plato que se saborea; este elemento es la evaluación, que supone dos variables claves independientes pero absolutamente relacionadas: organización y comunicación (Castillo y Álvarez Nobell, 2014).

Para llegar a la medición, los investigadores hacen un sondeo sobre el logro de los objetivos que las empresas se plantearon para el último año. Los resultados revelan que de 107 empresas estudiadas, entre el $70 \%$ y $90 \%$ cumplieron con sus objetivos comunicacionales. Las agencias de publicidad se han convertido en aliadas trascendentales del director de comunicación, ya que desde ahí se canalizan las 
estrategias creativas en función de la experiencia de equipos especializados en diferentes áreas de la comunicación comercial, que en muchos de los casos, no es posible tener dentro de una misma organización (Paladines, Yaguache, Granda y Altamirano).

El Observatorio de la Comunicación Estratégica de Ecuador presenta por lo tanto, un panorama claro del trabajo actual y de la perspectiva que tiene la gestión de la comunicación en el país. Quedan aún diversos temas por investigar. Los cambios sustanciales en la forma de concebir, producir y ejecutar campañas de comunicación corporativa, abren varios campos de actuación para la investigación.

\section{Referencias bibliográficas}

Castillo y Álvarez Nobell, A. (2014). Evaluación en comunicación estratégica. España: McGraw Hill Education.

Costa, J. (2009). El DirCom hoy: Dirección y gestión de la Comunicación en la nueva economía. Barcelona: Gràfic. Granollers.

Moreno, A., Molleda, J.C., Athaydes, A. \& Suárez, A.M. (2015). LatinAmerican Communication Monitor 2015. Excelencia en comunicación estratégica, trabajo en la era digital, social media y profesionalización. Resultados de una encuesta en 18 países. Bruselas: EUPRERA 



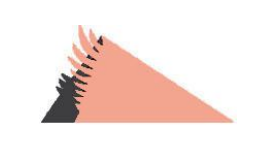

\section{Los autores}

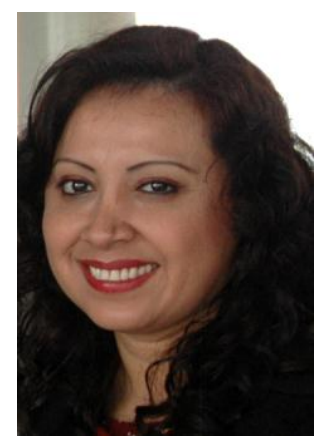

Fanny Yolanda Paladines Galarza Licenciada en Publicidad en la Universidad Tecnológica Equinoccial (Quito-Ecuador). Máster Executive en Dirección y Gestión de Marketing Estratégico en la Escuela de Negocios (EOI) Madrid-España. Ph.D en Comunicación y Periodismo por la Universidad Santiago de Compostela de España.

Profesora titular de las materias Publicidad y Comunicación Organizacional en las titulaciones en Relaciones Públicas y Comunicación; y en Maestría de Gestión Empresarial de la Universidad Técnica Particular de Loja-Ecuador. Publicación de artículos en Revistas como Palabra Clave, Materia Prima, Latina, Razón y Palabra, Redmarka, CISCI, Signo y Pensamiento. Capítulos de libros como: Investigar la comunicación en Loja-Ecuador e Investigar la comunicación en Loja-Ecuador: el valor de la formación, producción y consumo. Publicación en el Anuario de las Empresas de Comunicación de Ecuador.

Ex Directora del Área de Marketing de la UTPL, miembro del equipo de calidad de las titulaciones de Relaciones Públicas y Comunicación Social de la UTPL. Actualmente Coordinadora de la Titulación de Relaciones Públicas y Directora del Proyecto interno "Observatorio de la Comunicación Estratégica en Ecuador" en la UTPL.

$\mathrm{Al}$ momento investiga temas relacionados con la marca/branding, marca digital, gestión en redes sociales, comunicación corporativa/estratégica tradicional y digital, etc. 


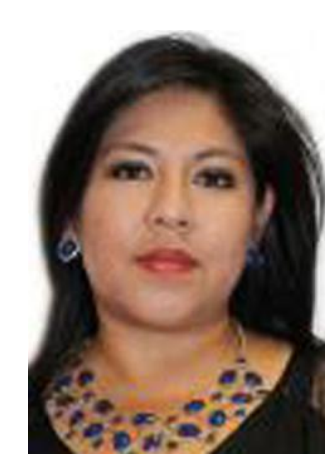

Jenny Jovita Yaguache Quichimbo $\mathrm{PhD}$ en Comunicación y Periodismo por la Universidad Santiago de Compostela. Profesora titular de las materias Comunicación Organizacional y Administración de Medios en las titulaciones de Relaciones Públicas y Comunicación.

Publicaciones en Revistas como Palabra Clave, Materia Prima, Latina, Razón y Palabra, Dircom, Signo y Pensamiento.

Capítulos de libros en: Investigar la comunicación en Loja-Ecuador e Investigar la comunicación en Loja-Ecuador: el valor de la formación, producción y consumo. Publicación en el Anuario de las Empresas de Comunicación de Ecuador. Estudios sobre la prensa digital iberoamericana, "Colección Mundo Digital" de Revista Mediterránea. Al momento es Directora del Departamento de Ciencias de la Educación y Responsable de la Sección Departamental de Comunicación Organizacional del mismo Departamento. Investiga temas sobre Comunicación Organizacional y Gestión de la Empresa de Organización.

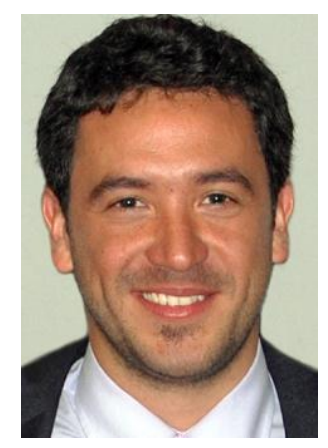

Alejandro Álvarez Nobell PhD. en Dirección Estratégica de la Comunicación y Máster en Gestión Estratégica e Innovación en Comunicación (Univ. de Málaga, España). Lic. en Comunicación Social (Univ. Nacional de Córdoba, Argentina) y Licenciado en Periodismo (Univ. de La Laguna, España).

Investigador interno (posdoctoral) CONICET en la Universidad Católica del Córdoba (Argentina). Profesor Adjunto (a cargo) por concurso en la Escuela de Ciencias de la Información de la Universidad Nacional de Córdoba (Argentina).

Integrante del Proyecto I+D+I "Infoparticip@: Comunicación y Periodismo para la participación ciudadana en el seguimiento y la evaluación de la gestión de los Gobiernos Locales" (Univ. Autónoma de Barcelona) e Advisory Board Member del Latin American Communication Monitor, una investigación transnacional organizada por la European Public Relations Education and Research 
Association (EUPRERA). Profesor grado y posgrado en Universidades de Argentina, España, Ecuador, Brasil, México.

Coordinador Observatorio Universitario de Medios (OUM Córdoba en Argentina). Autor de "Evaluación estratégica en Comunicación" (McGrawHill, 2014); "BrandPR Relaciones Públicas de Marca" (2013) entre otros libros; y más de 60 capítulos, artículos científicos, ponencias, artículos de divulgación.

Fue Secretario de Ciencia y Tecnología (ECI - UNC, Argentina) y Director Alterno de la Especialización en Comunicación Pública de la Ciencia y Periodismo Científico (UNC, Argentina). Anteriormente Director del Brand PR Máster en Marketing y Comunicación Corporativa (2011 - 2013 - USJ, España).

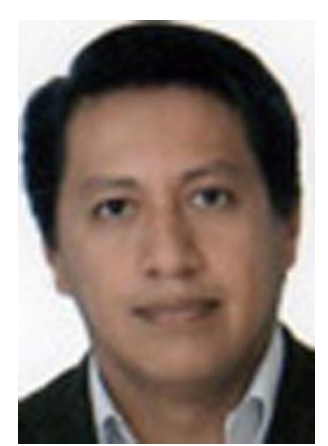

Carlos Vladimir Granda Tandazo Licenciado en Marketing en la Universidad Tecnológica Equinoccial (Quito). Candidato a Doctor en Comunicación y Periodismo por la Universidad Santiago de Compostela de España. Máster Executive en Dirección y Gestión de Marketing Estratégico en la Escuela de Negocios (EOI) Madrid-España.

Profesor titular de Marketing de las titulaciones de Relaciones Públicas, Comunicación y Administración de Empresas. Publicaciones en Revistas como Redmarka, Materia Prima y Razón y Palabra.

Coautor del libro: Investigar la comunicación en Loja-Ecuador. Actual Director de Proyectos Institucionales de la UTPL. Desarrolla la línea de investigación marca ciudad. Investiga temas relacionados con la marca/branding, marca digital, gestión en redes sociales, comunicación corporativa/estratégica tradicional y digital, etc. 


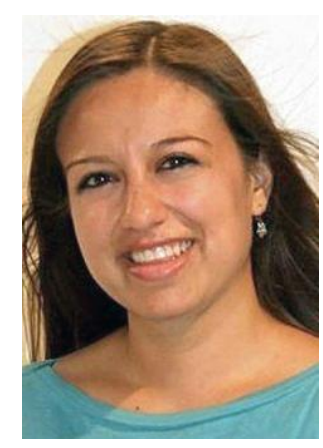

Rosario Johanna Puertas Hidalgo Ingeniera en Marketing por la Universidad Internacional del Ecuador. Doctoranda y máster en Comunicación e Industrias Creativas por la Universidad Santiago de Compostela (España). En la tesis del máster investigó sobre la publicidad en la prensa de Loja - Ecuador.

En la tesis doctoral se encuentra investigando la gestión de la comunicación en redes sociales en universidades de Latinoamérica para obtener como resultado final un manual del buen uso de las redes sociales.

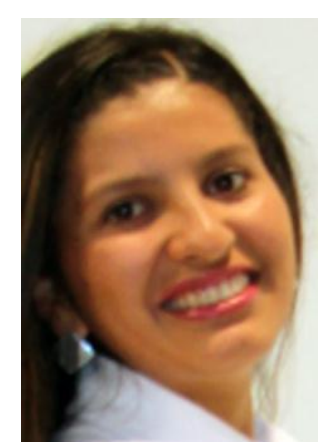

Karen Cesibel Valdiviezo Abad Licenciada en Comunicación Social por la Universidad Técnica Particular de Loja-Ecuador. Doctoranda de la Universidad Santiago de Compostela-España. Máster en Investigación en Comunicación por la Universidad de Navarra-España. Docente-titular en las titulaciones de Relaciones Públicas y Comunicación de la Universidad Técnica Particular de Loja.

Actualmente es Coordinadora de Filosofía Corporativa y Responsabilidad Social Universitaria en la UTPL. Investigadora, ha participado como expositora en eventos académicos y de investigación a nivel nacional e internacional. Su línea de investigación es Comunicación Organizacional.

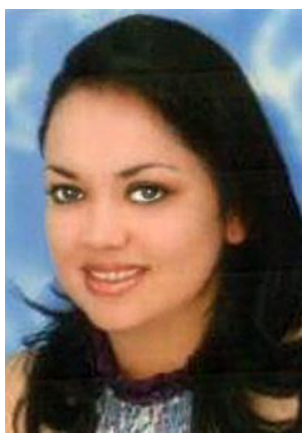

Jhoana Raquel Córdova Licenciada en Comunicación Social por la Universidad Técnica Particular de Loja y Magister en Ingeniería y Gestión del Conocimiento por la Universidad Federal de Santa Catarina (Brasil). Posee además Diplomado en Edición de Medios Impresos por la Universidad Técnica Particular de Loja (Ecuador). Es autora de varios artículos científicos. 
Docente en las titulaciones de Relaciones Públicas y Comunicación en la Universidad Técnica Particular. Docente invitada por la Universidad Santo Thomas de Talca, Chile. Responsable de Comunicación en la Organización Universitaria Interamericana y Coordinadora de Comunicación en la Cátedra Unesco de Cultura y Educación para la Paz.

Su tesis de Maestría se enfocó en el estudio de la Identidad Organizacional dentro de las Instituciones de Educación Superior dirigida por el Dr. Francisco Fialho, reconocido investigador brasilero.

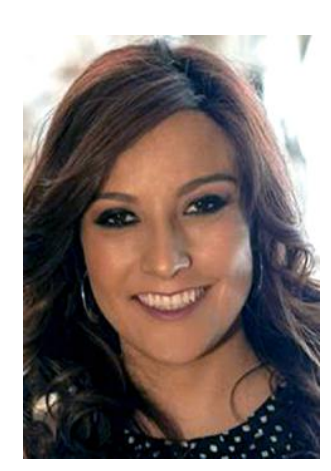

Verónica Paulina Altamirano Benítez Licenciada en Comunicación Social por la Universidad Técnica Particular de Loja (Ecuador).

Máster en Comunicación e Industrias Creativas por la Universidad Santiago de Compostela (España); Doctoranda de la USC; Diplomada en Comunicación Organizacional; Diplomada en Comunicación para el Docente principal en las titulaciones de Relaciones Públicas y Comunicación de la Universidad Técnica Particular de Loja. Coautora de libros internacionales y artículos en revistas científicas y divulgativas.

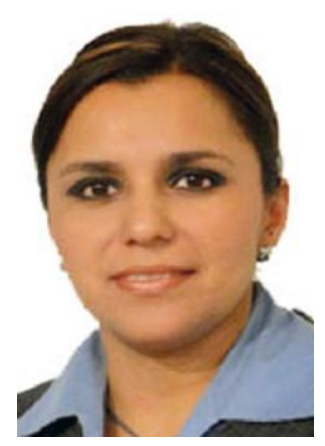

Karina Paola Valarezo González Licenciada en Relaciones Públicas por la Universidad Tecnológica Equinoccial (Quito-Ecuador). Doctora-PhD en Comunicación y Periodismo por la Universidad Santiago de Compostela, España. Profesora Titular de grado y postgrado de las asignaturas Relaciones Públicas, Gestión y Planificación de las Relaciones Públicas y Responsabilidad Social Empresarial. Investigadora, ha publicado artículos en revistas pertenecientes a índices como Latindex, Scopus e Isi web of knowledge. 
Autora de capítulos de libros revisados por pares académicos; directora de proyectos de investigación; ponente en diferentes eventos académicos y de investigación. Ex asesora del Congreso de Diputados de la República del Ecuador en temas de comunicación.

Ex Coordinadora de la Titulación de Relaciones Públicas de la Universidad Técnica Particular de Loja, Modalidad Presencial. Ex Coordinadora de la Titulación de Asistencia Gerencial y Relaciones Públicas de la UTPL, Modalidad Abierta y a Distancia. Actualmente es Directora de Comunicación, Dircom, de la UTPL.

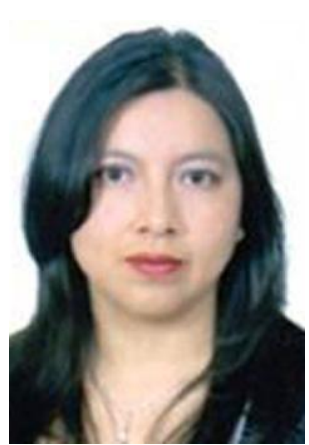

Irma Elizabeth Cadme Samaniego Ingeniera en Sistemas Informáticos y Computación. Estudiante de Maestría de Inteligencia Artificial en la Facultad de Informática, Grupo de Ingeniería. Investigadora del Grupo de Tecnologías Avanzadas de la Web y Sistemas Basados en el Conocimiento. Docente Universitaria en la titulación de Ingeniería en Sistemas Informáticos y Computación y de Ingeniería en Informática.

Participa de varios proyectos relacionados con Web Semántica, Linked Data Accesibilidad para la Educación, E-Learning, entre los cuales se destacan SmartLand (Territorios Inteligentes), Oportunidad, Observatorio de Comunicación Estratégica del Ecuador, entre otros. 
Los textos contenidos en este libro han sido sometidos previamente a un proceso de revisión de doble ciego por pares. 